\title{
V.A. A.
}

\section{El fin de un modelo de política}

Javier Herrero, Milena Trenta (Coords.)

Editores: Vanessa Rodríguez Breijo, Samuel Toledano Buendía, Ciro Hernández, Alberto Ardèvol Abreu

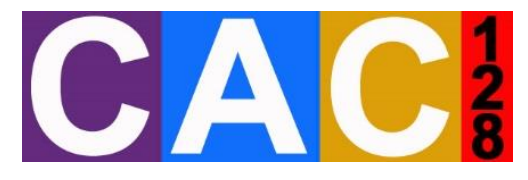

Cuadernos Artesanos de Comunicación / 128

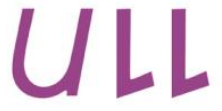

Universidad de La Laguna

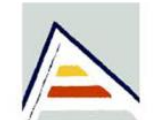

Universitat d'Alacant Universidad de Alicante

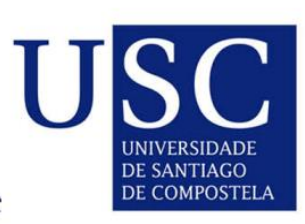

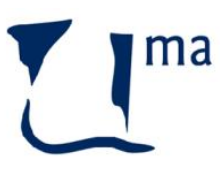

UNIVERSIDAD DEMALAGA

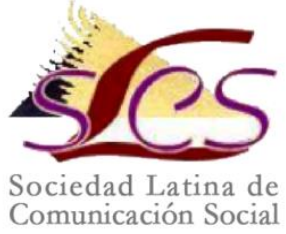




\section{CAC 128 - El fin de un modelo de política}

Javier Herrero, Milena Trenta (Coords.)

VV.AA.

Editores: Vanessa Rodríguez Breijo, Samuel Toledano Buendía, Ciro Hernández, Alberto Ardèvol Abreu

Diseño: F. Drago

Imprime y distribuye: F. Drago. Andocopias S.L.

c/ La Hornera, 41. La Laguna. Tenerife.

Teléfono: 922250554 | fotocopiasdrago@telefonica.net

Edita: Sociedad Latina de Comunicación Social - edición no venal -

La Laguna (Tenerife), 2017 - Creative Commons *

(http://www.revistalatinacs.org/09/Sociedad/estatutos.html)

Catálogo $=\underline{\text { http: } / / \text { www.cuadernosartesanos.org }}$

Protocolo de envío de manuscritos con destino a CAC:

http://www.cuadernosartesanos/protocolo.html

Descargar el $p d f$ :

http://www.cuadernosartesanos.org/\#128

ISBN: 978-84-16458-83-7

D.L.: TF-934-2017

DOI: $\underline{10.4185 / \mathrm{CAC} 128}$ 


\section{VV. AA. \\ Cuadernos Artesanos de Comunicación \\ Coordinador editorial: José Manuel de Pablos \\ Comité Científico \\ Presidencia: José Luis Piñuel Raigada (UCM) \\ Secretaría: Milena Trenta}

- José Luis Terrón (Universidad Autónoma de Barcelona, UAB)

- José Miguel Túñez (Universidad de Santiago, USC)

- Victoria Tur (Universidad de Alicante, UA)

- Nerea Vadillo Bengoa (Universidad San Jorge, Zaragoza)

- Miguel Vicente (Universidad de Valladolid, UVA)

- Ramón Zallo (Universidad del País Vasco, UPV-EHU)

- Núria Almiron (Universidad Pompeu Fabra, UPF)

- Francisco Campos Freire (Universidad de Santiago de Compostela)

- José Cisneros (Benemérita Universidad Autónoma de Puebla, BUAP)

- Bernardo Díaz Nosty (Universidad de Málaga, UMA)

- Carlos Elías (Universidad Carlos III de Madrid, UC3M)

- Paulina B. Emanuelli (Universidad Nacional de Córdoba, UNC)

- José Luis González Esteban (Universitas Miguel Hernández de Elche, UMH)

- Marisa Humanes (Universidad Rey Juan Carlos, URJC)

- Juan José Igartua (Universidad de Salamanca, USAL)

- Xosé López (Universisidad de Santiago de Compostela)

- Maricela López-Ornelas (Universidad Autónoma de Baja California, AUBC)

- Javier Marzal (Universidad Jaume I, UJI)

- José Antonio Meyer (Benemérita Universidad Autónoma de Puebla, BUAP)

- Ramón Reig (Universidad de Sevilla, US)

- Miquel Rodrigo Alsina (Universidad Pompeu Fabra, UPF)

- Xosé Soengas (Universidad de Santiago de Compostela)

* Queda expresamente autorizada la reproducción total o parcial de los textos publicados en este libro, en cualquier formato o soporte imaginables, salvo por explícita voluntad en contra del autor o autora o en caso de ediciones con ánimo de lucro. Las publicaciones donde se incluyan textos de esta publicación serán ediciones no comerciales y han de estar igualmente acogidas a Creative Commons. Harán constar esta licencia y el carácter no venal de la publicación.

Este libro y cada uno de los capítulos que contiene, así como las imágenes incluidas, si no se

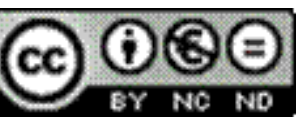
indica lo contrario, se encuentran bajo una Licencia Creative Commons Atribución-No Comercial-Sin Derivadas 3.0 Unported. Puede ver una copia de esta licencia en http://creativecommons.org/licenses/by-ncnd/3.0/ Esto significa que Ud. es libre de reproducir y distribuir esta obra, siempre que cite la autoría, que no se use con fines comerciales o lucrativos y que no haga ninguna obra derivada. Si quiere hacer alguna de las cosas que aparecen como no permitidas, contacte con los coordinadores del libro o con el autor del capítulo correspondiente.

* La responsabilidad de cada texto es de su autor o autora. 


\title{
El fin de un modelo de política
}

\begin{abstract}
Los acontecimientos políticos y electorales acontecidos durante los meses que preceden a este IX Congreso Internacional Latina de Comunicación Social nos permiten reflexionar sobre las transformaciones surgidas en las formas de hacer política y los discursos que la acompañan.

El desplazamiento, las apropiaciones de los presupuestos y de los valores tradicionales presentes en el discurso del "otro político", y las diferentes maneras de construir el propio sobre ese postulado, son objeto de esta intervención.

Los enunciados y acciones derivados son tomados en consideración con la pretensión de evidenciar los medios utilizados, las estrategias presentes en dichas apropiaciones, así como, los valores usurpados para mostrar las fortalezas y debilidades presentes en el contemporáneo arte de hacer política y sus mediatizaciones, la cuales posibilitan una respuesta inmediata gracias, entre otros elementos, a las redes sociales en las que los políticos han asentado su vinculación y enlace con sus seguidores, o sus oponentes, en ese nuevo espacio público que es la Sociedad del Conocimiento o Sociedad Red y los instrumentos de comunicación que ésta provee para la difusión y la circulación de las ideas que desemboquen en construcciones simbólicas que se quieren compartir o imponer para, en definitiva, persuadir, convencer o conquistar.
\end{abstract}

\section{Keywords}

periodismo, comunicación audiovisual, política, elecciones, discursos, valores, medio, estrategias, mediatizaciones, redes sociales, sociedad del conocimiento, sociedad red, construcciones simbólicas.

\section{Forma de citar este libro}

Nombre del autor o autora del apartado (2017): El fin de un modelo de política. Cuadernos Artesanos de Comunicación, 128. La Laguna (Tenerife): Latina. 
El fin de un modelo de política

\section{El fin de un modelo de política}

001 - La conciencia mediática - Juan Ignacio Hernáiz Blázquez Profesor emérito de la Universidad Complutense de Madrid ignaciohernaiz@hotmail.com

La conciencia mediática es la conciencia de los medios de comunicación de masas. La alienación en el sentido de Hegel, como desgarramiento de la conciencia, el amo y el esclavo, la dialéctica o fenomenología del espíritu, donde una parte de la sensibilidad está dominada por la otra, el inconsciente sobre el consciente Marx trasladó ese concepto a la economía, con la lucha de clases sociales y Freud a la sicología. La conciencia mediática es una cuestión estética, aunque también ética y técnica. Umberto Eco en su último libro, publicado después de su muerte en 2016, hacer un análisis de la sociedad líquida.

Bloom escribe que la enseñanza es una forma de espectáculo, por lo tanto, es óbice que el mayor espectáculo de todos los tiempos, es la televisión, lo cual nos lleva lógicamente a que, la educación de los niños, en, la actualidad, es para la mayoría, la pequeña pantalla. Paglia dice que, la televisión, es como el rosario católico, inventado por Sto. Domingo de Guzmán, nacido en Caleruega (Burgos), convence a fuerza de repetir las veinticuatro horas del día, en todas las cadenas, insistiendo con los espots publicitarios, pese a que los anuncios comerciales cambien estéticamente, mantienen sicologicamente el sistema económico de la sociedad del consumo o del bienestar o neocapitalista o postmoderna.

Althusser que analiza la escuela, como soporte ideológico del estado, siempre se había pensado que, la mayor influencia en los niños, era el colegio, por encima de la pandilla de amigos y de la familia, los tres grupos primarios de referencia, ahora es la televisión. Es decir, lo que los padres enseñen a los hijos, los maestros a los alumnos y los amigos, juntas las tres influencias, son menores que la pequeña pantalla. 
La estética de la televisión es muy importante, como arte undécimo, junto con el vídeo, la radio, el disco, el cassette, el magnetofón y el Dvd independiéntemente de la técnica y de la ética, el arte icónico es decisivo, aparte de la tecnología y de la publicidad, la creatividad audiovisual es enorme, además de la aplicación de la ciencia y de la propaganda comercial, ideológica, económica, política, moral y religiosa. La imagen de la pequeña pantalla atrae a la mayoría de la gente, aunque haya una minoría que no sufra tal efecto, de ello se aprovechan los políticos y los negociantes.

Ahora, en la tercera fase de la historia de la comunicación, en la sociedad digital, como explica Terceiro, en la era de la información, como expone Manuel Castells, en la tercera ola que propone Toffler, la pérdida de la memoria, por influencia de la televisión, puede ser mayor si cabe. El individuo del futuro, a diferencia del ser humano del pasado con una memoria total, sin llegar al absoluto divino, y del sujeto actual, con una memoria parcial, no recordará nada. Por si fuera poco, encima de la televisión Internet, la mayor base de datos de la historia de la humanidad.

\section{2 - La comunicación entre Cervantes y otros autores del siglo dorado} español - Juan Ignacio Hernáiz Blázquez - Profesor emérito de la Universidad Complutense de Madrid ignaciohernaiz@hotmail.com

Quevedo hizo un verso a Ambrosio de Spinola, igual que Calderón y que el cuadro de Diego Rodríguez de Silva y Velázquez. Lope de Vega hizo un poema del monarca Felipe II el Prudente y era enemigo de Cervantes y que había sido soldado de Juan de Austria en Lepanto, el hermanastro del rey e hijo del emperador Carlos I de España y V de Alemania. El cual era renacentista y los Felipes barrocos, igual que el Greco, aunque en su juventud fuera renacentista, lo mismo que el monarca Felipe II el Martillo de los herejes. Para complicar más el lío y para aclararlo hago un esquema, es mi teoría de la amistad y enemistad que unía a todos los artistas del siglo de Oro español, mejor dicho, las dos centurias XVI y XVII pues Calderón también es de ella, asimismo dejando la Celestina o tragicomedia de Calixto y Melibea de Fernando de Rojas publicada en el año 1.499. 
El fin de un modelo de política

Doménico Theotocopoulos el Greco pinta para el rey Felipe II el diablo del Mediodía y retrata a Cervantes, es amigo del escritor y escultor Benito Arias Montano y del pintor Pacheco, Juan Montano el inquisidor es amigo de Juan de Herrera el constructor de la octava maravilla del mundo el monasterio de S.Lorenzo de el Escorial que tiene su capítulo específico, Herrera es protegido de Felipe II, Velázquez es yerno de Francisco Pacheco y amigo de los pintores Alonso Cano, Francisco de Zurbarán y el escultor Martínez Montañés. Quevedo, Lope y Cervantes fueron miembros de la cofradía de esclavos del Santísimo sacramento que está en la calle de Atocha, al lado de la imprenta del primer Quijote. Velázquez le retrató reflejando su grandeza de alma humana.

003 - Redes sociales como herramienta de apoyo a la enseñanza universitaria. Casos México y Ecuador - Diana Rivera Rogel Universidad Técnica Particular de Loja - derivera@utpl.edu.ec y Claudia Rodríguez-Hidalgo - Universidad Técnica Particular de Loja - cvrodriguezx@utpl.edu.ec

Las redes sociales han incrementado las habilidades de comunicación de los universitarios, dándoles la posibilidad, no solo de informarse y socializar a través de ellas, sino también de crear sus propios contenidos y difundirlos a gran escala. La vinculación de las redes sociales a la educación constituye una ventaja diferencial de cara a innovar las herramientas, los procesos y los contenidos.

En ese contexto, el objetivo de esta investigación es medir el uso de las redes sociales como herramienta académica por parte de universitarios de México y Ecuador. Como técnica de investigación se utilizó la encuesta orientada a obtener datos sobre la relación académica estudiante-profesor a través de las redes sociales, la apreciación de los estudiantes sobre el uso de estas como recurso en la docencia, entre otros datos.

Entre los resultados se evidenció que el 90\% de universitarios considera necesario incluir a las redes sociales como herramientas auxiliares en su formación; más de la mitad de ellos ha sacado provecho 
de las actividades académicas que las incluyen, aunque reconocen que su uso mayoritario sigue siendo para socializar y distraerse.

004 - El protagonismo de los medios de comunicación y las redes sociales en los debates sobre conflictos armados de 5 parlamentos europeos (España, Reino Unido, Francia, Alemania y la Unión Europea) - María Rosa Berganza Conde-rosa.berganza@urjc.es; Beatriz Herrero Jiménez - beatriz.herrero@urjc.es; Jorge Toirac jg.toirac@gmail.com; Rubén Tamboleo García ruben.tamboleo@urjc.es; Eva Gómez Monteroevaluisa.gomez@,urjc.es - Universidad Rey Juan Carlos

El presente trabajo forma parte del proyecto nacional CSO2016-78187$\mathrm{R}$ del MINECO. Tiene como objetivo profundizar en un fenómeno de gran relevancia para la resolución de conflictos armados, como es la influencia de los medios de comunicación y las redes sociales en los debates parlamentarios y en el desarrollo de políticas encaminadas a establecer la paz en zonas con un alto índice de violencia. La importancia de estudiar los debates parlamentarios radica en el reciente fenómeno de la 'parlamentarización de los asuntos internacionales', mediante el cual el control sobre la política exterior de los Estados se ejerce en el ámbito parlamentario (Stavridis \& Pace 2011). Además, como muestran distintos estudios, los actores políticos se ven cada vez más influidos por la lógica de los medios (media logic) en sus actuaciones, es decir, por criterios más mediáticos que políticos (political logic) a la hora de ejercer su trabajo (Davis, 2007; Strömback, 2011; Strömback \& Esser, 2014). Esto significa que sus acciones y decisiones están guiadas en muchas ocasiones pensando en los medios y por la consideración previa de si sus actos generarán o no un buen titular (Davis, 2007).

Para esta investigación se ha elegido la guerra de Siria como caso de estudio. Para ello se han analizado más de tres mil debates procedentes del Parlamento Europeo, el Parlamento alemán, francés, británico y español desde enero de 2011 (inicio del conflicto) a junio de 2015. Se ha realizado un análisis de contenido cuantitativo automatizado mediante el programa AmCAT, indicado para el análisis de Big Data. 
El fin de un modelo de política

Los resultados, aunque muestran variaciones significativas entre países, dan cuenta de una importante presencia de los medios de comunicación y las redes sociales como fuente informativa dentro de los discursos parlamentarios; y también de la preocupación de los parlamentarios por la influencia que los nuevos medios sociales puedan tener en la radicalización de sus usuarios.

005 - La dimensión politica de la protesta social televisada. Un abordaje integral - Dra. Silvina Beatriz Berti - Departamento de Ciencias de la Comunicación, Universidad Nacional de Río Cuarto, Argentina - silvina.berti@gmail.com

Desde hace ya décadas, la conflictividad social ha tomado las arterias argentina. La protesta se ha instalado en las calles, en los espacios públicos y ha devenido parte del paisaje cotidiano de los ciudadanos y no tan solo de las grandes ciudades. En términos generales identificamos ciertos componentes que facilitan el estudio de la protesta; a saber: los distintos actores que se ven involucrados, los motivos que desencadenan las expresiones de disconformidad en el espacio público y los métodos que eligen para manifestarse. Cada uno de ellos admite clasificaciones ulteriores; por ejemplo, al referirnos a los actores diferenciamos entre quienes se movilizan (e identificamos como los demandantes), aquellos hacia quienes van dirigidas las demandas (los demandados) y otros que podemos que de una manera $\mathrm{u}$ otra se ven involucrados en el conflicto entre demandantes y demandados (a los que denominamos "terceros involucrados"). Los motivos también pueden ser discriminados y reagrupados de maneras diversas, por ejemplo, podemos pensar en cuestiones referidas al ámbito laboral, de la salud, de la justicia, condiciones de vida, etc. Y en cuanto a los métodos, son variados y dependen de los grupos que demandan (y su nivel de organización), a repertorios disponibles de visibilización de la problemática, etc. Ahora bien, leídas en clave política, podemos entender a la protesta también como un tipo de acción en la que los ciudadanos pretenden incidir de alguna manera en el proceso político. En otras palabras, podemos analizarlas como el ejercicio del derecho ciudadano a intervenir en el espacio público (campo de la política) en tanto búsqueda de modificación de las decisiones que se toman desde las instancias de poder y que recaen 
sobre ellos. En el momento en que los sujetos sociales se instauran como sujetos activos y se organizan alrededor de un derecho vulnerado, se convierten en sujetos políticos. Sus acciones, que pueden ser clasificadas de diversas maneras (desde el constituirse como elector a participar activamente en estructuras del estado) incluyen la demanda social. Así, este sujeto político puede ejercer su competencia reclamando la solución de problemas, defendiéndose o reaccionando ante injusticias, etc.

Entendiendo a la protesta desde una perspectiva comunicacional, no podemos ignorar un factor crucial que refiere a la construcción discursiva a la que los medios (la televisión en nuestro caso) someten a la protesta. En ese sentido, esta ponencia presenta una perspectiva de análisis integral de la protesta social televisada haciendo foco en su dimensión política y su conjugación con los componentes mencionados. Es una perspectiva integral del proceso de comunicación que lleva a la indagación de la instancia de producción, al análisis de las noticias y al estudio de su recepción.

006 - Troma y Japón: una contrarréplica al orientalismo en la serie B norteamericana - Lucas Morales Domínguez - Escuela Universitaria de Turismo de Santa Cruz de Tenerife lucas.morales@eutur.es

Edward Said definió en 1978 el término orientalismo, un constructo intelectual nacido en Occidente mediante el cual se establecieron una serie de estereotipos e ideas irreales que garantizaban su dominio cultural sobre el resto del mundo. A pesar de que muchos de los conceptos que orbitan alrededor de Japón parecen más positivos que los aplicados a otros países, ayudan a alimentar un retrato incierto de su sociedad, simplificándola hasta el punto de incluir a todos los ciudadanos en un solo perfil, desvirtuando la diversidad que posee.

Las vías de distribución de este sesgo identitario son muchas, entre ellas el cine. Teniendo como base estudios anteriores que analizan la propagación del orientalismo a través del cine occidental donde aparecen turistas que visitan el país del Sol Naciente, esta comunicación analiza el caso de dos películas de serie B norteamericana que son una 
El fin de un modelo de política

excepción de la regla: 'El Vengador Tóxico 2' (Herz y Kauffman, 1989) y 'El sargento Kabukiman' (Herz y Kauffman, 1991). Ambas filmadas por los mismos realizadores y distribuidas bajo el sello de Troma, las dos obras presentan la confluencia entre lo oriental y lo occidental desde un punto de vista diferente al del cine contemporáneo, lo que supone un paréntesis en el orientalismo convencional y en la construcción de significados generales sobre sociedades complejas.

007 - Fact-checking en la prensa y los medios digitales españoles: análisis del caso de la tercera moción de censura de la democracia española - Javier de Sola - Universidad de Zaragoza - jdesola@unizar.es

El Diccionario Oxford ha elegido el término "posverdad" como palabra del año en 2016, un concepto que viene a reflejar la menor influencia de los hechos objetivos en la formación de la opinión pública que de otros elementos como lo emocional o las creencias personales. En un contexto marcado, además, por la falta de credibilidad de la clase política y de los medios de comunicación -una reciente encuesta de Reuters refleja que solo el 34\% de los españoles confían en los medios, se ha consolidado una verificación de la información que apuesta por todo lo contrario y que ha dejado de ser novedosa en países como Estados Unidos, aunque todavía es relativamente incipiente en el caso de España: el fact-checking. En este contexto, los días 13 y 14 de junio se debatió y votó una moción de censura -la tercera de la democracia española- planteada por Unidos Podemos contra el presidente del Gobierno, Mariano Rajoy, y el Partido Popular. Durante estos dos días los partidos políticos con representación en el Congreso de los Diputados realizaron una serie de afirmaciones para defender la labor propia y criticar la ajena, afirmaciones, en algunos casos, contradictorias. Así, esta investigación es un análisis de contenido de la cobertura de los principales periódicos y medios digitales españoles en relación con estos hechos $y$, en ese sentido, el artículo refleja que los medios han llevado a cabo coberturas muy diferentes y que el factchecking todavía no es una práctica común a todas -ni siquiera a una mayoría- de las redacciones españolas.

008 - Acercamiento a los usos sociales del sitio web periodistico Juventudrebelde.cu - Lic. Claudia Alemañy Castilla - Revista 
Juventud Técnica de la Casa Editora Abril - email: calemanycastilla@gmail.com

La presente investigación realiza un análisis sobre los usos sociales del sitio web periodístico Juventudrebelde.cu que realiza un grupo de usuarios residentes en La Habana. Desde la perspectiva cualitativa, y un marcado carácter empírico-descriptivo de análisis, el estudio ofrece una descripción del sistema de prácticas socioculturales desarrolladas por usuarios de Juventudrebelde.cu, a partir de las diferentes condicionantes, el aprovechamiento de los códigos tecnocomunicativos, los contenidos generados por los usuarios y las potenciales transformaciones en la práctica social cotidiana. El estudio aplicó diferentes métodos y técnicas de investigaciones como la entrevista semi-estandarizada, el grupo de discusión y el test de usuario. Los resultados de ese estudio señalan que existen condicionantes tecnológicas, individuales y situacionales en torno a los usos sociales, y que la revisión de los sitios motiva cambios en el día a día de sus usuarios.

009 - Aplicación de la teoría microeconómica al rumor en las organizaciones - Lito García Abad - CESUGA, Universidad San Jorge-jlgarcia@usj.es

La comunicación es una ciencia interdisciplinaria que, desde el viejo modelo de Lasswell y el funcionalismo de la primera mitad del siglo $\mathrm{XX}$, ha estado bebiendo de las disciplinas más variadas, como la matemática, la psicología, la sociología, la lingüística, la semiótica, la antropología o las ciencias económicas. En este último campo destacan las aportaciones de los economistas y la economía de la información, que analizan el papel de la información en el funcionamiento de los mercados.

En esta comunicación se aplica la teoría microeconómica de formación del precio de equilibrio en los mercados de competencia perfecta al ciclo de vida del rumor en las organizaciones: su nacimiento, desarrollo y extinción. Asimismo se analiza cómo se desplazan las curvas de oferta y demanda de información en función de la transparencia organizativa y de la estrategia informativa organizacional. Por último, se presentan 
El fin de un modelo de política

las puertas que abre esta propuesta de línea de investigación para trabajos futuros sobre casos de crisis organizacional y el management de la función comunicativa organizacional.

010 - Decir las verdades: Jiménez Lozano, en El País (1976-1986) José Bernardo San Juan - Departamento de Ciencias de la Educación, Lenguaje, Cultura y Artes, Ciencias HistóricaJurídicas y Humanísticas y Lenguas Modernas. Universidad Rey Juan Carlos - jose.bernardo@urjc.es

Buena parte de la obra de José Jiménez Lozano (premio Cervantes de 2002) se encuentra en la frontera entre periodismo y literatura, entre filosofía, política e incluso teología. La crítica ha centrado su atención, más fundamentalmente, en su obra literaria y ensayística pero sus textos en la prensa son también reflejo de un pensamiento poliédrico. En este trabajo se realiza -a través de un análisis de contenidos- la exposición de las líneas de fuerza y los temas comunes en los artículos que, entre 1976 y 1986, publicó este autor en el diario El País.

011 - Contaminación ambiental en Hidalgo. Desfasamiento entre las agendas política, pública y mediática - Rosa María Valles Ruiz mvalles@uaeh.edu.mxy Sandra Flores Guevara sandra_flores@uaeh.edu.mx Universidad Autónoma del Estado de Hidalgo (México)

La problemática ambiental en México alcanza ya niveles alarmantes, debido en parte a la concentración de vehículos automotores en la ciudad de México y a la emisión de residuos tóxicos de industrias establecidas en el territorio nacional. En el estado de Hidalgo (ubicado al centro del país) existen zonas como la Tula-Tepeji considerada por la Organización de las Naciones Unidas (ONU) como la más contaminada del mundo, debido a la emisión de residuos tóxicos de las refinerías de petróleo y cementeras que operan ahí. La magnitud del problema implica un abordaje prioritario de los medios de comunicación. Empero, no es así de manera general.

El objetivo de esta ponencia es conocer el tratamiento informativo y de opinión que sobre la contaminación en la región Tula-Tepeji otorgó 
la prensa escrita durante 2015. Se reflexiona teóricamente en los conceptos de agenda política, agenda pública y agenda mediática.

A través de la metodología del análisis del discurso se analizan 112 textos periodísticos en nueve diarios de la capital del estado de Hidalgo. La metodología es mixta: cuantitativa y cualitativa. En la primera se asientan los siguientes aspectos: ubicación en las secciones de los diarios, clasificación por géneros periodísticos, etcétera. En el análisis cualitativo se analiza la orientación que en los medios se dio a los mensajes emitidos, su incidencia en las agenda política y pública y la construcción que realizan en la agenda mediática.

El análisis registró un desfasamiento entre las agendas políticas, pública y mediática. El sector público da prioridad a otras informaciones; los organizaciones sociales a otras y la agenda mediática construye su propia oferta informativa y de opinión.

012 - El conflicto por los Bienes de la Franja: la importancia del léxico en la cobertura de la prensa aragonesa y catalana - Javier de Sola Universidad de Zaragoza - jdesola@unizar.es y Ricardo Zugasti - Universidad de Zaragoza - rzugasti@unizar.es

La disputa del patrimonio de las parroquias de la diócesis de BarbastroMonzón se ha convertido, desde mediados de los años noventa, en uno de los grandes focos de enfrentamiento entre la Iglesia aragonesa y catalana; y, no solo eso, también entre los representantes políticos y los agentes sociales de una y otra comunidad. En este contexto, el presente estudio muestra, a través de un análisis de contenido y en el marco de la teoría del framing, las diferencias significativas que se producen en la cobertura periodística de este proceso de seis diarios (Heraldo de Aragón, La Vanguardia, El Periódico de Aragón, El Periódico de Catalunya, Diario del Altoaragón y Segre) durante más de veinte años. Decisiones como referirse al patrimonio en litigio como "Bienes de las parroquias" u "Obras del Diocesá" revelan la posición adoptada por cada cabecera y su mayor o menor en el conflicto. El estudio se complementa, además, con una serie de entrevistas en profundidad con los directores de cada periódico para analizar los resultados obtenidos y con el fin de lograr la triangulación metodológica. 
El fin de un modelo de política

013 - La enseñanza de la Ética y la Deontología Profesional en Periodismo y Comunicación Audiovisual. Una experiencia con el apoyo de la ficción en el Cine y la Televisión - Dra. María del Mar López Talavera - mmlopezt@ucm.es y Dra. Elena Real-Rodríguez ereal@ucm.es - Dpto. Periodismo III, Facultad de Ciencias de la Información, Universidad Complutense de Madrid.

¿Contribuye la ficción de la Televisión y el Cine de alguna forma a transmitir, reforzar, asimilar o alterar valores morales?, ¿podemos llevarlo al terreno práctico y aprender algo del modo en que la ética ha de estar presente en nuestras vidas personales y profesionales, a partir de los ejemplos interiorizados de algunas películas?

Esta comunicación quiere presentar los resultados que sus autoras obtuvieron en un proyecto de innovación docente, apoyado en el análisis de películas, a estudiantes de la asignatura de Ética y Deontología Profesional para los Grados en Periodismo y Comunicación Audiovisual, de la Facultad de Ciencias de la Información de la Universidad Complutense de Madrid. El proyecto se planteó como una dinámica didáctica novedosa, complementaria a la explicación teórico y al resto de la práctica, en relación a los contenidos programáticos de la asignatura, y claramente enfocada a la mejor asimilación y aplicación de los conceptos estudiados.

En este sentido, se seleccionaron películas que encajasen adecuadamente con los diferentes apartados de la materia impartida en clase. Los alumnos se repartieron en grupos de trabajo a los que se fue asignando una película. Previamente se había elaborado una ficha para guiar y facilitar el análisis, que luego cada grupo debería exponer oralmente en el aula.

Los objetivos de partida del proyecto fueron los siguientes:

- Comprobar la relación directa y permanente que existe entre teoría y práctica en los contenidos de la asignatura.

- Capacitar al alumno para el discernimiento de los medios y los fines de toda acción humana. Resolución de problemas y toma de decisiones. 
- Integrar los nuevos lenguajes audiovisuales en la docencia universitaria. Contemplar la ficción en la televisión y el cine con espíritu crítico y no meramente como un producto técnico, estético o lúdico.

- Hacer la necesaria correspondencia de los contenidos académicos de la asignatura con la experiencia cotidiana en los medios, la práctica periodística y audiovisual.

* Los resultados de esta Comunicación forman parte del Proyecto de innovación docente "Series televisivas y películas para periodistas y comunicadores audiovisuales. Una propuesta de integración en el marco de la Ética y Deontología Profesional". Universidad de La Laguna. Convocatoria 2016. Proyecto núm. 64. Directoras: María Dolores Meneses Fernández y María del Mar López Talavera.

014 - La imagen fotográfica de niños y niñas y su configuración simbólica en la narrativa mediática de las tragedias humanas - Claudia Pilar García Corredor - Pontificia Universidad Javeriana pigarcia@javeriana.edu.co

Esta ponencia se origina en la investigación "lo invisible de los relatos mediáticos del dolor" realizada entre los años 2015 y 2016," que aborda el fenómeno de las narrativas mediádicas configuradoras de acontecimientos dolorosos. Los medios de comunicación informan y, en ese proceso de difundir concurren fenómenos comunicativos con el tratamiento de las imágenes fotográficas, que es necesario detenerse a revisar en el presente texto.

Preguntarse por el tratamiento que se hace de las imágenes que documentan desastres, guerras y barbaries, preguntarse por la fotografía como representación pero también como configuradora de contenidos nuevos es el propósito de este trabajo que aquí se resume. Específicamente el uso de las imágenes de niños en medio de calamidades en las que sufren personas de muchas condiciones sociales, políticas, ideológicas y culturales, como también personas de diferentes edades, abuelos, madres, niños y adultos, en fín la diversidad es tan inmensa como la existente en la especie humana. 
El fin de un modelo de política

Son tres los acontecimientos que se revisan en este texto, la niña Omayra Sánchez, fallecida tras el deshielo en noviembre de 1985, del volcán-nevado del RuÍz que arrazó por completo la población de Armero, Colombia, el niño sirio Aylan Kurdi, de tres años de edad que se ahogó en las playas de Grecia en el año 2016 huyendo de la guerra en su país hacia un futuro prometedor y, la tercera imagen de Kim Phuc, la niña de la bomba de napalm durante la guerra en Vietnam que huye del horror de la explosión, con su cuerpo quemado, Kim es sobreviviente de la bomba incendiaria, y la imagen que hace ya 40 años el fotógrafo vietnamita Nick Ut, captó y, según su propio testimonio, después acudió a auxiliar a la pequeña, movido por un impulso protector que le impedía abandonarla.

Todos estos niños convertidos en símbolo de una tragedia hacen pensar en el sentido que tiene la fotografía como objeto visual y mediático. El abordaje desde la fotografía se apoya en la fundamentación desde Susan Sontag, que reflexiona sobre la fotografía como imágenes que van más allá de la instantánea, sobre la comunicación y los medios los aportes de Jesús Martín Barbero y Germán Rey. Sobre el concepto de narrativas, desde Aristóteles hasta Paul Ricoeur para entender como las narrativas configuran los acontecimientos y escriben la historia de la humanidad.

015 - La exbibición cinematográfica en las redes sociales: análisis de los perfiles de Cinesa y Yelmo en Facebook, Twitter, Instagram, YouTube y Google+ David Vicente Torrico - Universidad de Valladolid david.vicente.torrico@uva.es

La combinación de banda ancha, dispositivos móviles y redes sociales ha propiciado la aparición de un nuevo escenario conectado, convergente y fragmentado, en el que la exhibición cinematográfica debe intentar cautivar a sus clientes potenciales para combatir la constante pérdida de espectadores. En la presente investigación proponemos un acercamiento descriptivo-comparativo, mediante la aplicación de la técnica del estudio de caso, sobre los perfiles en las redes sociales más populares de las empresas que dominan el sector de la exhibición cinematográfica en España, Cinesa y Yelmo, con el objetivo de analizar su popularidad, la comunicación con sus 
seguidores y la aportación de un valor añadido a su relación comercial. Los resultados demuestran que ambas compañías llevan a cabo una estrategia similar en las redes sociales, donde aportan contenidos de valor añadido a sus seguidores, pero, por el contrario, no explotan completamente su capacidad de interacción, dejando desatendidos sus perfiles y, con ello, a sus potenciales clientes.

\section{6 - Branding interno e identidad en la Benemérita Universidad} Autónoma de Puebla: estudio de caso - Kathia Elena Salinas Ponce Benemérita Universidad Autónoma de Puebla - Correo electrónico: kathia.salinas5@gmail.com

La imagen institucional es uno de los elementos más importantes para el desarrollo de la lealtad, así como para el prestigio e identidad hacia el interior de las organizaciones. En ese sentido, la Benemérita Universidad Autónoma de Puebla (BUAP), renovó su imagen visual para garantizar su innovación y posicionamiento académico. Por ello, en esta investigación se realiza un análisis del branding al interior de esta institución pública de educación superior, tomando como caso de estudio el Complejo Regional Sur, uno de los campus más grandes. La metodología de análisis se construyó a partir de la elaboración de un instrumento de consulta sobre la opinión de los integrantes de la organización, a través de la aplicación de un cuestionario formado por 30 reactivos que fue contestado por 268 integrantes de la comunidad universitaria de la BUAP. El objetivo fundamental fue identificar los elementos que constituyen un mecanismo de identidad a partir de un análisis de brandig con la finalidad de encontrar una relación entre esta y los stakeholders, es decir, la influencia de le exposición de la marca en los públicos internos y la generación de identidad entre la comunidad universitaria. Al final con los resultados se destacan las áreas de oportunidad y una medición del impacto de marca en la reputación.

017 - La cultura de la violación y el cine. Estudio de caso: la película Teeth - Beatriz Aparicio Vinacua - Universidad San Jorge beatriz6av@hotmail.com y Víctor Manuel Pérez Martínez vmperez@usj.es - Universidad San Jorge 
El fin de un modelo de política

En el marco de la línea de investigación sobre «las representaciones de la mujer en el contexto audiovisual y de las nuevas narrativas», en esta comunicación, se presenta un estudio sobre la representación de la cultura de la violación en el cine a partir de teorías y metodologías vinculadas a la «perspectiva de género», entendiéndola, como una metodología de acercamiento para el estudio de la dimensión cultural y social en el cual se desenvuelven las personas. La investigación se concreta en un estudio de caso y tiene como objetivo de la película Teeth (2007). Se trata por tanto de un estudio que pretende combinar tres aspectos: el de la comunicación audiovisual, el del carácter social del tema estudiado y el ámbito científico. Las fases metodológicas de este proyecto han sido: a) la revisión sistemática, para identificar documentación actualizada sobre la temática de la investigación y los conceptos a los cuales hacía referencia; b) el estudio de caso, para delimitar el objeto de estudio; c) el análisis del film como método para abordar el acercamiento a un film como objeto de estudio. Este filme critica la cultura de la violación y lleva a Dawn (protagonista del film) desde el extremo de la chica recatada y religiosa hasta el de la femme fatale empoderada.

018 - El uso de Twitter como espacio de comunicación política del Partido Republicano y del Partido Demócrata en la campaña electoral de 2016 Víctor Manuel Pérez Martínez - vmperez@usj.es, Cristina Federío González - alu.40545@usj.es y María Lasheras Laborda - alu.54980@usj.es - Universidad San Jorge

Las elecciones de los Estados Unidos son importantes desde la perspectiva de la vida política de los estadounidenses, desde la geopolítica internacional $\mathrm{y}$, en definitiva, desde cualquiera de los ámbitos vinculados a la comunicación política. Particularmente tiene interés en esta comunicación la estrategia que los partidos políticos desarrollan en la campaña electoral en el contexto de los social media. En esta comunicación planteamos un avance del estudio que tiene por objetivo el análisis del uso de Twitter por el Partido Demócrata y el Partido Republicano en la campaña electoral de 2016 a la Casa Blanca. El estudio incluyó las particularidades de los tweets publicados y su impacto en Twitter. Las conclusiones dejan abierta la posibilidad de 
valorar que la comunicación política en las redes sociales trasciende más allá de la dinámica propia de los partidos políticos.

019 - Influencia, reputación y gestión de la comunicación 2.0 de los prescriptores Casey Neistat, Banksy y Vimema - Sergio Mena Muñoz - Universidad Complutense de Madrid - smenamun@ucm.es Universidad Europea Miguel de Cervantes - smena@uemc.es y Francisco de Andrés Huertas - Universidad Complutense de Madrid - frdeandres@gmail.com

La amalgama aparentemente anárquica de mensajes que circulan por internet está dominada por una multitud heterogénea de emisores, receptores, productores, consumidores, audiencias, particulares, marcas, empresas, instituciones, organismos y demás interactuantes. De entre todas las presiones que ejercen todos estos actores, destaca la figura de aquellos usuarios que, por afinidad, rigurosidad, imitación o ascendencia aglutinan a un número muy importante de seguidores fieles sobre los que ejercen una influencia directa que se expande sobre el resto de internautas por mención de terceros. Estos prescriptores, que en muchos casos gestionan la comunicación de marcas y empresas, también se han convertido en líderes de opinión a través de sus mensajes. En esta comunicación se muestra el seguimiento analítico que se ha realizado sobre las campañas más conocidas de tres prescriptores, Casey Neistat, Banksy y la agencia Vimema, entre los años 2000 y 2017. Se pretende conocer qué herramientas han utilizado los mencionados sujetos de investigación en qué campañas, con qué intenciones, con qué objetivos y siguiendo qué estrategias o directrices. Por medio de la descripción de todos estos elementos se demostrará a través de estos tres casos que el peso de los prescriptores es clave dentro del ecosistema de comunicación 2.0.

020 - Principios básicos para el diseño de la guía docente de la materia Dirección de Arte en el marco del EEES - Blanca Miguélez Juan Universidad del País Vasco/Euskal Herriko Unibertsitatea (UPV/EHU) - blancamiguelezjuan@gmail.com

En el EEES la guía docente es un instrumento vital de planificación y orientación en el proceso de enseñanza-aprendizaje tanto para dentro 
El fin de un modelo de política

como para fuera del aula. En su creación, revisión y actualización toman parte conjuntamente el profesor o profesores que se responsabilizaran de la docencia de dicha asignatura, el coordinador de la misma y el departamento al que está adscrita. Este documento con información básica e imprescindible coherente al plan de estudios del título de grado al que pertenece la materia y acorde al proceso que va a desarrollar el alumno durante el curso recoge, además, el compromiso y la garantía de que se cumplirá lo que en él se explicita.

Esta guía, única por cada asignatura, que orienta a los estudiantes y permite hacer un seguimiento de cómo se va a desarrollar el proceso de enseñanza-aprendizaje tiene que fijar objetivos, competencias, contenidos, sistema de evaluación, bibliografía, actividades, etc. Pero al concluir el curso académico o el cuatrimestre, los alumnos de Dirección de Arte no solo deben ser capaces de dominar unos contenidos que les permitan superar un procedimiento de evaluación tradicional como una prueba final establecida, sino que deben acreditar la consolidación de ciertos aprendizajes que relacionen actitudes, destrezas y habilidades profesionales que evidencien una asimilación de la realidad profesional del Director de Arte.

Desde una perspectiva cualitativa se describe cómo están detalladas actualmente las guías docentes de la materia Dirección de Arte de una preselección de ocho universidades españolas en las que se imparte Dirección de Arte dentro de los estudios de Comunicación Publicitaria. La presente comunicación tratará de dar respuesta a la pregunta: ¿qué cambios se deben incluir en las guías docentes de la materia Dirección de Arte?

021 - Enrique Peña Nieto: su figura presidencial en medios de comunicación mexicanos - Sergio Manuel de la Fuente Valdez sermanfuen@yahoo.com - Universidad Autónoma de Nuevo León y Yolanda López Lara yolandalopezlara_uanl@hotmail.com - Universidad Autónoma de Nuevo León

Se está efectuando una investigación en red, donde participan 3 cuerpos académicos. Es de carácter descriptivo, exploratorio, no 
experimental, cualitativo, con rasgos cuantitativos y correlacional, relacionada con la imagen del presidente mexicano Enrique Peña Nieto, que publican los medios masivos y alternativos de comunicación en este país. El objetivo general: analizar los discursos publicados en los medios de comunicación a través de los géneros periodísticos y en redes sociales. Objetivos Específicos: establecer los espacios informativos dedicados en las publicaciones de las actividades presidenciales, determinar el lenguaje, estilo, tono y recursos lingüísticos utilizados en la redacción de los discursos. Identificar los valores universales y generales plasmados en los discursos informativos y valorar las opiniones y juicios, motivo de controversia suscitada por los actores de la esfera pública, como consecuencia de las acciones gubernamentales y su entorno, en publicaciones realizadas entre febrero y abril de 2017.

El universo son los diarios capitalinos de circulación nacional, los canales de televisión nacionales y las redes sociales. La muestra: periódicos La Jornada, El Financiero, Excélsior, Milenio Nacional, algunos canales de Televisa y Twiter. Selección de la muestra: noticias, columnas, artículos editoriales, caricaturas políticas difundidas en los medios objeto de estudio El instrumento de medición fue el análisis de contenido, mediante la elaboración de un manual con categorías y subcategorías que miden las variables consideradas.

Principales hallazgos: los espacios dedicados a la publicación de información sobre las actividades presidenciales en prensa, canales de televisión abierta y cerrada y twiter son amplios, con una aproximación del 25\%, en relación con el espacio total, acompañados de una a dos fotografías representativas y elocuentes. El lenguaje utilizado es coloquial, en pocas ocasiones culto y escasamente, vulgar. El estilo predominante es el periodístico; el tono: persuasivo, festivo, irónico y sarcástico. Varía, según el género periodístico.

Los valores universales empleados en la redacción de los discursos son: democracia, la paz, la justicia, la igualdad, la solidaridad y los valores generales: respeto, honestidad, compromiso y responsabilidad. Las tendencias de los redactores de noticias, a pesar de la supuesta objetividad de éstas fue comentar negativamente en la mayoría de los 
El fin de un modelo de política

casos las decisiones y participaciones del presidente Pena Nieto. En los comentarios por televisión comercial y de paga, la mayoría reprobó las acciones; lo mismo hicieron quienes redactaron artículos editoriales y caricaturas políticas o cartones editoriales, donde hay una gama de opiniones y juicios de los cuales se intuyen argumentos y tesis que descalifican fehacientemente, las tareas presidenciales, en un porcentaje significativo, alrededor del 70\%. Los artículos publicados en redes sociales no fueron la excepción, al reprobar en considerable mayoría los quehaceres del jefe del Estado Mexicano. Pocos redactores minimizaron los problemas nacionales existentes. La mayoría los maximizó, circunstancias que dañan su imagen en la esfera pública y crean controversias.

022 - Comunicación politica y esfera pública: aproximaciones a los usos de redes sociales de jóvenes en Quito-Ecuador - Gabriela Cabascango maria.cabascango@udla.edu.ec-Universidad de Las Américas

- Ecuador; Diego Apolo - diego.apolo@unae.edu.ec Universidad Nacional de Educación (UNAE) - Ecuador y Saudia Levoyer - saudia.levoyer@uasb.edu.ec-Universidad Andina Simón Bolívar, Sede Ecuador

En la actualidad dentro de la comunicación política, internet juega un papel fundamental en la participación de ciudadanos en lo referente a temas económicos, políticos y sociales. En este caso, los usos de redes sociales que realizan los jóvenes al consumir y compartir contenidos (Toffler, 1980) marcan las pautas e influyen en la configuración de sus percepciones en cuanto a la esfera pública (Raimondo, Reviglio y Diviani, 2016). En tal sentido, De la Garza, Barredo y Calderón (2017), plantean que el consumo de redes sociales de jóvenes ecuatorianos sobrepasa ampliamente a otro tipo de medios; pero que pese a ello, la participación política en redes es escasa. Bajo estas perspectivas, se desarrolló un estudio de enfoque mixto aplicado a varones y mujeres de entre 17 y 26 años de la ciudad de Quito que mediante el uso de encuestas y entrevistas a expertos, permitió conocer las percepciones que tienen los jóvenes sobre las redes sociales y su influencia en torno a su participación desde la red (Apolo, Guerrero y Jiménez, 2015). 
023 - Caracterización de libro de texto gratuito digitalizado en educación primaria en México - Sandra Delia Faustino Cruz, Instituto de Investigación y Desarrollo Educativo, Universidad Autónoma de Baja California, México- delia.faustino@uabc.edu.mx; Maricela López Ornelas, Instituto de Investigación y Desarrollo Educativo, Universidad Autónoma de Baja California, Méxicoornelas@uabc.edu.mx y Javier Organista Sandoval, Instituto de Investigación y Desarrollo Educativo, Universidad Autónoma de Baja California, México- javor@uabc.edu.mx

La presente investigación, tiene como propósito exponer algunas definiciones del libro de texto digitalizado (LTD) — registradas en la última década - para categorizarlos en base a sus atribuciones tecnológicas. El proceso metodológico de corte cuantitativodescriptivo, se fundamentó en cinco fases: a) revisión de la literatura iberoamericana; b) identificación de los conceptos, incidencias y propiedades del libro de texto digitalizado; c) descripción de sus ventajas y desventajas; y d) tipificación de sus características tecnológicas; y d) clasificación de los libros de texto gratuitos digitalizados producidos por la SEP. La muestra comprendió el estudio y análisis de 42 libros de texto gratuitos digitalizados, producidos por la Secretaría de Educación Pública para educación primaria en México - los cuales están disponibles en formato de documento portátil (PDF, por sus siglas en inglés) —. Entre los resultados se advierte, que algunos libros — según el grado y la asignatura-, proveen propiedades de multimedia e interactividad que requieren acceso a Internet. Mientras que otros, solo están digitalizados sin ofrecer ninguna otra propiedad tecnológica excepto el propio formato en PDF.

024 - Alfabetización mediática y su contribución al aprendizaje en la escuela - Wilson Gárate Andrade - Universidad de CuencaEcuador (wilson.garate@ucuenca.edu.ec) y Marco Vinicio Padilla Pineda- Universidad de Cuenca- Ecuador (marcopp@uets.edu.ec)

Los procesos de alfabetización mediática y realización transmedia resultan indispensables para el aprendizaje en la escuela. La abundancia de trabajos colaborativos y la cada vez mayor producción de 
El fin de un modelo de política

contenidos digitales transmedia nos lleva a pensar que la educación formal ignora uno de las mayores potencialidades de aprendizaje, emergidas en aplicaciones de internet y redes sociales. El trabajo propuesto es el resultado del proyecto Transmedia literacy, grupo de investigación interdisciplinario constituido por la Universidad Nacional de Educación, UNAE, y la Universidad de Cuenca, en Ecuador, como parte de un trabajo de investigación mayor dirigido por Carlos A. Scolari, en nueve países de tres continentes. Con el cual se ha alcanzado una mayor comprensión de cómo los adolescentes consumen, producen, comparten, crean y aprenden en entornos digitales. Es evidente que estudiantes jóvenes son realizadores de contenidos en los entornos digitales.

La incorporación de esas habilidades y destrezas a la formación académica formal, seduce a quienes se preguntan cómo es que aprenden los jóvenes los usos de la comunicación digital; en qué medida significa un aporte al proceso de construcción de los aprendizajes colaborativos; $y$, cuáles serían las posibilidades de asimilación de estos nuevos hábitos por parte de profesores y padres de familia en la complementariedad informal de los aprendizajes. El objetivo del proyecto es el aprovechar el conocimiento de las estrategias mediante las cuales los jóvenes aprenden la utilización de las aplicaciones de herramientas digitales $y$, cómo, mediante estas estrategias, se podrán incorporar a las técnicas didácticas en los centros de educación. Para conseguirlo se aplicó una serie de estrategias metodológicas de etnografía digital, talleres participativos, entrevistas en profundidad, con sus correspondientes categorizaciones y jerarquizaciones de contenidos para la interpretación y posterior tratamiento $y$ usos de los datos en materiales de trabajo complementarios en guías didácticas.

025 - Análisis de la comunicación para la sustentabilidad de los procesos de cambio social: Caso cobertura periodística sobre el calentamiento global - Lilia Maricela Mendoza Longoria - Universidad Autónoma de Nuevo León - lmmlongoria@hotmail.com - Janet García González - Universidad Autónoma de Nuevo León janetgarcia71@yahoo.com.mx - Esteban Picazzo Palencia - 
Universidad Autónoma de Nuevo León epicazzo@yahoo.com

Uno de los principales desafíos de la comunicación para el cambio social, es poder entender su relación con la cultura, y por ende, con el proceso de desarrollo. En este contexto, el papel de los medios de comunicación, es apoyar las iniciativas de desarrollo a través de la difusión de mensajes. En el caso específico de la prensa, aunque las estrategias entre países diverjan ampliamente, su modelo predominante sigue siendo el mismo: informar a la población sobre los proyectos de desarrollo, sus ventajas y recomendar su apoyo. Sin embargo, en lo que respecta a temas ambientales y climáticos, se ha demostrado que éstos no son relevantes para la agenda de los medios y su proceso de jerarquización de información. Es por ello, que el objetivo principal de esta investigación, es analizar el tratamiento informativo que transmite la prensa escrita y digital en México hacia el calentamiento global, desde la perspectiva teórica del establecimiento de la Agenda. A través de la metodología cuantitativa se llevó a cabo el análisis del discuro, de un total de 92 notas de la prensa escrita (dos periódicos locales y dos nacionales) y digital (5 cuentas de la red social twitter de reconocidos periodistas mexicanos). Los resultados obtenidos exponen que la agenda de los medios, en términos generales, habla del calentamiento global cuando está relacionado con temas de contaminación, y para informar sobre desastres provocados por el hombre y sus consecuencias. En cuanto a la prensa escrita, el tema de mayor preponderancia encontrado fue el de ambiente; y en la prensa digital, se detectó una tendencia hacia lo relacionado con los desastres hechos por el hombre. En conlcusión, el cambio social sustentable desde la perspectiva de la comunicación masiva, requiere que la comunicación cumpla funciones primordiales: generar cambios de actitudes a nivel individual, interpersonal y/o comunitario o social, y recomendaciones focalizadas desde los marcos legales; a través de la difusión de información estratégica dirigida principalmente a los tomadores de decisiones en todos los niveles y sectores de la sociedad.

026 - El plagio académico en la era informacional. Una reflexión sobre la postura de algunas instituciones de educación superior en MéxicoMaricela López Ornelas, Instituto de Investigación y Desarrollo 
El fin de un modelo de política

Educativo, Universidad Autónoma de Baja California, Méxicoornelas@uabc.edu.mx; Javier Organista Sandoval, Instituto de Investigación y Desarrollo Educativo, Universidad Autónoma de Baja California, México- javor@uabc.edu.mx y Katiuska Fernández Morales, Instituto de Investigación y Desarrollo Educativo, Universidad Autónoma de Baja California, Méxicokatiuska.fernandez@gmail.com

Vivimos en la era tecnológica o sociedad de la información, cuya característica primordial, es el uso de las tecnologías de la información y la comunicación (TIC) en diversos contextos, con relación al ámbito educativo, el acompañamiento de las TIC se ha percibido como la posibilidad del acceso abierto al conocimiento, es decir, asequible para todos. No obstante, estos beneficios derivados la apertura al conocimiento a través de Internet, han acrecentado y diversificado una práctica antigua, el plagio académico. Bajo esta situación, el presente documento presenta a manera de reflexión, la complejidad que actualmente permea en algunas universidades públicas y privadas respecto al uso deshonesto de la información electrónica en la producción de trabajos académicos. Se exponen conjuntamente, distintos casos, que involucran a mandatarios de estado, rectores, políticos e investigadores reconocidos. Asimismo, se registran las posturas de diversas instituciones educación superior (IES) mexicanas que proveen políticas explícitas ante estos temas. Si bien, el documento no pretende profundizar en la diversidad de conceptos, sus alcances o limitaciones, sí espera generar una reflexión positiva sobre la postura que algunas IES nacionales están adquiriendo ante este incremento, aparentemente imparable y en ocasiones difícil de sancionar.

027 - Las pintadas, demandas ciudadanas frente a la política - J.

Ignacio "Iñaki" Chaves G. - Uniminuto (Bogotá, Colombia) ichaves61@gmail.com / jose.chaves@uniimnuto.edu

Las expresiones de la ciudadanía para hacer públicas sus demandas frente al accionar de los poderes pueden darse de múltiples formas, más aún en tiempos de nuevas tecnologías, de una mayor penetración de internet y de un elevado uso de las redes virtuales por la población. 
A pesar de ello, las "tradicionales" formas de expresión siguen siendo vigentes y utilizadas por una parte importante de la ciudadanía que, o no tiene opción de usar lo tecnológico o cree que es más directo y efectivo el expresionismo callejero. Las pintadas son una de esas maneras de significarse de quienes no se sienten representados o le apuestan a hacer públicas sus inquietudes de manera gráfica en las calles.

Analizar las pintadas, en este caso de un sector de la ciudad de Bogotá, nos permite establecer esa otra manera de hacer política, o de intentar incidir en la misma. En las pintadas se juntan la imaginación y la crítica para soñar, aúnan las demandas ciudadanas con el arte y el ingenio para expresarse. Con ellas, las paredes hablan, expresan lo que un sector de la ciudadanía desea comunicar. Sin ataduras, ocupando el espacio público, dando muestras de esa libertad de la que hablaba Sen como parte del desarrollo del ser humano. Pintar las paredes como medio y como fin de la libertad soñada y en parte alcanzada.

028 - Resignificaciones y resistencias en tiempos del net art - Sergio

Alvarado Vivas - Uniminuto (Bogotá, Colombia) seralowen@gmail.com / salvarado@uniminuto.edu

Las transformaciones acaecidas por la paulatina expansión de las TIC ha llevado a diversas resignificaciones en cómo el ciudadano representa sus entornos inmediatos y otros tantos con los que se encuentra hiperconectado. Es allí, donde el arte como una manifestación de la subjetividad humana ha sufrido cambios sustanciales. Pese a ser portadora tradicionalmente de una serie de rótulos que aluden a lo exclusivo, los entornos digitales ahora trazan dinámicas que ponen en crisis el acto clásico de contemplación de cualquier derivación artística.

Los primeros pasos dados por el surrealismo del siglo XX, la explosión del pop art encabezada por Andy Warhol y los numerosos movimientos de street art que se han proliferado en todo el mundo, sin duda constituyeron la antesala de la transformación que tendría el arte en su faceta digital en términos de creación, difusión e interacción. Como una de las corrientes más representativas aparece el net art, la cual agrupa expresiones acuñadas en el hipertexto con discursos 
El fin de un modelo de política

diversos, muchos de ellos resistentes, reflexivos cuando menos. Obras que dan espacio a otras voces, donde el rapto de las imágenes que deambulan en el ciberespacio es una práctica habitual.

Se pretende analizar itinerarios que la cibercultura está propiciando para que el ciudadano, en su rol de prosumer, tenga la posibilidad de aproximarse e incluso de ser parte activa de las narrativas del net art. Órbitas artísticas donde el aura que las habita, tal como lo predijo Walter Benjamin, desaparecería casi por completo. Dando así predominio al valor comunicativo y experiencial del individuo sobre las cualidades estéticas y las circunstancias históricas de su realización. De tal forma, valdría preguntarse si el arte digital se puede estar transformando en una ruta emancipadora y en un punto de fuga para viralizar otros discursos que no suelen tener resonancia en agenda mediática.

029 - El soft power de México en Cataluña - José Ramón Santillán Buelna - Universidad Rey Juan Carlos joseramon.santillan@urjc.es

Esta ponencia investiga el soft power de México en Cataluña a través de los periódicos La Vanguardia y El Periódico de Catalunya durante los años de 2013 al 2016. A partir de una muestra representativa de 110 noticias, se presenta un análisis cuantitativo donde los resultados muestran que estos diarios construyen una imagen de potencia cultural y vigor económico. Las temáticas culturales que reciben mayor cobertura son: la literatura y el cine, la música y el teatro, la inmigración, la educación, el turismo, la gastronomía y el patrimonio histórico. En cuanto a las económicas destacan la oportunidad de invertir en el país que es considerado estable financieramente y se reconoce la calidad de las empresas y productos. Estas grandes fortalezas se enmarcan también en el contexto más amplio de las relaciones con España. Otra de las conclusiones es que escritores, cineastas, artistas, cantantes, cocineros, académicos, estudiantes y la población mexicana residente en Cataluña son los principales promotores del poder suave.

030 - Eduprosumidores: estrategias para el fortalecimiento de competencias docentes en la formación inicial de educadores mediante el uso de recursos 
digitales. Perspectivas desde la Universidad Nacional de Educación (UNAE) Ecuador - Diego Apolo - diego.apolo@unae.edu.ec Docente Investigador Universidad Nacional de Educación (UNAE) - Ecuador; María Nelsy Rodríguez Lozano maría.rodriguez@unae.edu.ec - Docente Investigadora Universidad Nacional de Educación (UNAE) - Ecuador. y Alejandra Bueno de Santiago - Alejandra.bueno@unae.edu.ec Docente Investigadora Universidad Nacional de Educación (UNAE) - Ecuador y Johe Solano Saldaña - Estudiante Universidad Nacional de Educación

Introducción. Toffler (1980) plantea el concepto de prosumidor para identificar a aquel usuario que en algún momento producirá y consumirá contenidos, con frecuencia este abordaje ha sido desarrollado desde comunicación, marketing y publicidad con el fin de establecer estrategias que permitan acercar diferentes temas a stakeholders. En este caso, la sociedad red ha planteado un paradigma comunicativo que obliga a las instituciones educativas a proponer estrategias desde la comunicación digital que acompañen y faciliten la vinculación entre los aprendizajes informales y formales. En tal sentido, surge la necesidad de reconocer a los estudiantes como prosumidores; es decir, actores del proceso educativo capaces de aprender, investigar y producir contenidos empleando distintas plataformas. En diálogo con estas propuestas, uno de los principios del Modelo Pedagógico de la UNAE se centra en promover la didáctica invertida, las redes sociales virtuales y las plataformas digitales como estrategias que fortalezcan las cualidades humanas o competencias que requieren los futuros maestros y su compromiso con la educación en el siglo XXI. Método. Con base en lo anterior, se planteó un estudio de enfoque mixto mediante el uso de encuestas y grupos focales a estudiantes, además de entrevistas al director de innovación educativa y al coordinador del constructo de convergencia de medios educativos de esta universidad con el fin de sistematizar una experiencia en aula y proponer estrategias que contribuyan al aprovechamiento de la tecnología en temas educativos. Resultados. De esta manera, se pudo identificar que el proponer actividades que permitan el diálogo entre el uso de recursos digitales y los aprendizajes desde el aula, fortalece las capacidades creativas, discursivas, actitudinales y axiológicas de los 
El fin de un modelo de política

docentes en formación, empoderándolos de forma significativa de sus aprendizajes. Conclusión. Para finalizar se resalta la importancia que toma el reconocer a los estudiantes como prosumidores y el compromiso que deben asumir las instituciones educativas en la era digital.

031 - Eje de formación en competencias mediáticas digitales en las carreras de comunicación y periodismo al sur del Ecuador - Wilson Gárate Andrade - Universidad de Cuenca- Ecuador wilson.garate@ucuenca.edu.ec

La alfabetización digital resulta necesaria para la construcción de una ciudadanía responsable, informada y participativa. La red de internet contribuye con las herramientas y aplicaciones que han modificado las rutinas de los profesionales de la comunicación y el periodismo. Los nuevos escenarios, emergentes en internet, exigen modificaciones en la formación académica de estas profesiones. La tradicional oferta de estudios centrada, de manera básica, en cuatro ejes: redacción y lenguaje, investigación y teorías de la comunicación; géneros, formatos y estilos de la información y comunicación; incluida la redacción persuasiva y publicitaria; $y$, los aspectos deontológicos y de formación humana y social de las profesiones de la comunicación, el periodismo y afines; en la actualidad, exige una mayor preocupación por la emergencia de las comunicaciones digitales, para diversos desempeños, que exigen dominios de las herramientas y aplicaciones de internet y redes sociales.

El trabajo de investigación que se comparte es el resultado de indagar en el eje de formación en comunicación digital y mediática en seis carreras de comunicación y periodismo de universidades al sur del Ecuador, que efectúa el autor como parte de estudios de doctorado en la Facultad de Ciencias de la Información de la Universidad Complutense de Madrid. La visión de indagación se enmarca en relación a las propuestas de rediseños curriculares propuestos para las titulaciones de Comunicación y Periodismo; la nomenclatura exigida por los organismos de control, regulación y acompañamiento de las Instituciones de Educación Superior, IES, en la república del Ecuador. Se incluyen diagnósticos de conectividad, accesos y utilización de 
aplicaciones digitales sugeridas para el desempeño profesional en comunicación e información periodística. Y, un acercamiento a las actuales aplicaciones disponibles en internet y redes sociales; que especialistas proponen como indicadas y apropiadas como base de formación complementaria.

032 - Periodismo transmedia y posconflicto colombiano - Ángela Rodríguez Verge - Profesora de la Universidad Central de Colombia y de la Universidad EAN de Colombia. Periodista arodriguezv@ucentral.edu.co

Colombia vive uno de los períodos más importantes de toda su historia reciente. Después de la firma de las negociaciones con las Fuerzas Armadas Revolucionaras Colombianas (FARC), la guerrilla más antigua de América Latina, las narraciones periodísticas se empiezan a ver modificadas porque las historias que ahora se deben contar son diferentes. Aunque los cambios políticos en las sociedades contemporáneas no necesariamente llevan consigo cambios en las narraciones históricas de los mismos, la sociedad la sociedad colombiana está dispuesta a concebir la información de otra forma que no sea monomediática. ¿Cómo contar entonces un país con alrededor de 7.000 excombatientes y 10.000 milicianos que van a buscar la manera de integrarse en una sociedad infoxicada por las noticias del conflicto?

Cada historia necesita una forma de ser narrada. Y el periodismo transmedia puede ser uno de los caminos más adecuados para visibilizar los cambios. Ya no es momento de contar muertos y heridos, sino de dibujar un presente y un futuro en constante cambio que va a sufrir mutaciones sustanciales en esta etapa de posverdad y posterior posconflicto. Se deben buscar las voces de la política nacional, pero no de forma exclusiva. Los agentes sociales, las víctimas, los victimarios y la sociedad en general deben tener un lugar clave en las historias de posconflicto. Scolari (2013) afirma que el objetivo de un relato periodístico transmedia es informar de la mejor manera posible a los usuarios. Los ciudadanos pueden expandir los contenidos periodísticos generados por los medios tradicionales o directamente crear nuevos relatos informativos. Con el transmedia se aspira, como ya apuntaba 
El fin de un modelo de política

Gillmor (2004) a que el periodismo deje de ser una exposición a ser una conversación. $Y$ nunca se ha necesitado una conversación tanto como en estos momentos en Colombia.

033 - Miradas propias y ajenas de territorios urbanos en un escenario de post acuerdo - Una cartografía de las experiencias de comunicación popular en Ciudad Bolivar (Bogotá) y la Comuna 13 (Medellín) - Marisabel García Acelas - Corporación Universitaria Minuto de Dios marigarcia@uniminuto.edu

Las ciudades al ser receptáculo de población desplazada fruto de la violencia del entorno rural, se vienen constituyendo en territorios aptos para la expresión de significativas desigualdades sociales. Ello conduce a que, sobre las periferias urbanas, se traslade paulatinamente parte de la violencia estructural del país, convirtiéndolas en teatro del conflicto.

Durante las últimas décadas, los actores armados han dejado una profunda huella en barrios marginales de ciudades como Medellín y Bogotá, a lo que se suma la discriminación social, la estigmatización, el abandono estatal y la segregación socioeconómica. Estos territorios, condensan un sin número de situaciones críticas, cuya intensidad y profundidad es generalmente desconocida en su real dimensión por el resto de la sociedad. Es aquí cuando aparecen en escena los medios masivos de comunicación, quienes posibilitan la difusión de una percepción distorsionada del problema social, donde la violencia urbana termina siendo magnificada y/o simplificada por la carencia de análisis profundos.

Por su parte, las comunidades desarrollan procesos autónomos en donde las dinámicas comunicativas se convierten en una opción de participación activa y de apropiación territorial dentro de barrios segregados socialmente. Aunque son muy poco reconocidas por el sistema mediático imperante, estas iniciativas comunicativas develan propuestas políticas, organizativas y culturales. En materia comunicativa, cumplen un rol como cohesionadoras y movilizadoras de las comunidades, visibilizando la dimensión de las problemáticas, construyendo expresiones alternativas, y re significando las prácticas de resistencia en el territorio que activan la voz de los protagonistas, frente 
a las aristas complejas de la realidad en contextos de exclusión y violencia aún predominantes.

La presente ponencia condensará las discusiones centrales en relación al análisis de las experiencias de comunicación popular vigentes en el periodo 2015 - 2016, en dos zonas marginales urbanas en Colombia, Ciudad Bolívar en Bogotá y la Comuna 13 en Medellín.

034 - Caracterización y retos de la programación y audiencia de las televisiones generalistas españolas en la etapa previa al "apagón analógico" - Marta Roel - Universidad de Murcia - mroel@um.es

Esta comunicación se enmarca en el proyecto "Historia de la programación y de los programas de televisión en España: de la desregulación al apagón analógico. 1990-2010" (CSO 2015-66260-C41-P), coordinado por la profesora María Antonia Paz Rebollo, Catedrática de la Universidad Complutense de Madrid.

Se pretende aportar resultados parciales de la investigación llevada a cabo en torno al estudio de la audiencia entre 1990 y 2010, dos décadas de Neotelevisión en España que concluyen con el "apagón analógico". Se trata de una etapa histórica caracterizada, básicamente, por la aparición de las primeras televisiones privadas, la explosión progresiva de la oferta, la coexistencia de los modelos de programación públicos y privados, la ruptura con las formas "de hacer" clásicas, la relevancia de la producción autóctona o la evolución de los contenidos hegemónicos y de las tendencias de consumo audiovisual por parte de la audiencia.

Tomando como base los datos de audiencia y programación proporcionados por Sofres AM/Kantar Media, junto con otras fuentes relevantes, se analizan 20 años de actividad de las cadenas generalistas de cobertura estatal, con objeto de delimitar su caracterización y los retos que han tenido que afrontar en el escenario previo a la digitalización del sector de la televisión en España. Asimismo, se dará cuenta de como los retos que aún deben afrontar esas cadenas en la actualidad. 
El fin de un modelo de política

035 - Análisis del bumor en la publicidad televisiva colombianaJanneth Arley Palacios Chavarro - Fundación Universitaria Los Libertadores, Bogotá, Colombia japalaciosc@libertadores.edu.co y Andrés López Giraldo Chavarro - Fundación Universitaria Los Libertadores, Bogotá, Colombia - alopezg01@libertadores.edu.co

El humor en la publicidad busca satisfacer el propósito de no pasar inadvertido, generar diferenciación y sobre todo, busca quedarse en la memoria, en el recuerdo de las personas. El lenguaje, en este caso, el humorístico es parte de la estrategia o táctica comunicativa que emplea la publicidad para destacarse, posicionarse e incluso, inmemoriablizarse. Esta investigación parte de comprender que el humor además de cumplir una función en la publicidad, también reafirma imaginarios sociales, por ello, se busca analizar el discurso publicitario humorístico como representación social y, en este sentido, cómo la publicidad -en este caso la televisiva- penetra en la vida cotidiana y cobra otros significados.

El humor, por su naturaleza es un fenómeno social y, como tal, permite representar ritos, creencias, ideales de un grupo social y representan su cultura; el humor permite formas de interacción social, generar ideas, encontrar el sentido de pertenencia en un grupo (Martin \& Sullivan, 2013); también es una forma de hacer evidente nuestra capacidad creativa; por ello, analizar el humor publicitario durante la década de los ochentas y noventas, desde una visión socio - cultural, nos permitirá conocer cómo las audiencias se apropiaron de esos contenidos, cómo los transformaron a sus prácticas cotidianas y qué sentido pudo tener para ellos esos relatos, más allá de la actitud hacia la compra. En este punto, resulta interesante destacar que de acuerdo con Cifuentes y Sánchez (2005), las investigaciones sobre el humor publicitario muestran que el empleo de éste depende de la cultura en la que se encuentre y esto marca también diferencias culturales en los tipos de humor publicitarios y en los niveles de humor percibidos.

De esta manera, las preguntas orientadoras de la presente investigación giran en torno a: ¿Qué diferencias en los estilos de humor se hacen evidentes en las décadas de los ochenta y noventa en la publicidad 
televisiva colombiana y a qué imaginarios sociales aludía el humor publicitario? ¿Cómo la audiencia apropió, resignificó e interpretó el humor publicitario de las décadas analizadas, en su vida y en su cotidianidad?

036 - El cristal con que se mira: framing sobre migrantes en la era Trump - Dra. Melva G. Navarro Sequeira - Benemérita Universidad Autónoma de Puebla - melva.navarro@correo.buap.mx, Dr. José Antonio Cisneros Tirado- Benemérita Universidad Autónoma de Puebla- joseantonio.cisneros@correo.buap.mx y Dr. Jorge David Cortés Moreno- - Benemérita Universidad Autónoma de Puebla- jdcortesm@yahoo.com.mx

El Presidente de los Estados Unidos, Donald Trump, ha demostrado no promover políticas de inclusión hacia las comunidades migrantes, especialmente aquellas de origen latino y musulmán. Incluso, se debe considerar que la candidatura y actual presidencia de Trump ha sido apoyada por grupos extremistas y supremacistas. Actualmente, los temas relacionados con las comunidades inmigrantes que radican en Estados Unidos, se han convertido en asuntos recurrentes en las noticias de los medios de comunicación de dicho país, sin embargo, la postura con la que se editorializan los hechos dependen del medio que los emite, lo que incide en la esfera pública y por ende, en las dinámicas sociales que dichas comunidades confrontan de forma cotidiana. Con estos antecedentes y con el objetivo de comparar las posturas entre diversos medios tanto de corte liberal como conservardor (MSNBC, New York Times, Fox News y Breitbart), la presente investigación se centra en el análisis de tres hechos periodísticos relacionados a estos grupos de migrantes: el primer DREAMer deportado, el caso de inmigrantes ilegales encontrados muertos al interior de un autotransporte y las órdenes ejectuvias emitidas sobre el cierre de fronteras. El análisis planteado, se realiza usando la teoría de framing (Aruguete, 2011), la cual ofrece herramientas específicas para el análisis de transmisiciones de información. Ésta técnica permite ampliar la perspectiva y revelar entendimientos particulares sobre los eventos, mismos que son capacaces de transformar la opinión pública sobre el tema. 
El fin de un modelo de política

037 - Discurso mediático y cultura politica en Colombia: representaciones sociales sobre el proceso de paz-Fernando Aranguren Díaz y Borys Bustamante Bohórquez - borysbb@gmail.com - Universidad Distrital Francisco José de Caldas, Bogotá, Colombia

El artículo analiza desde la relación comunicación y cultura política aspectos pertinentes para abordar desde una perspectiva crítica y comprensiva el discurso mediático y su papel en torno del proceso de paz en Colombia. Parte de una óptica general en cuanto al fenómeno de la massmediatización en las sociedades contemporáneas, así como en las implicaciones del fenómeno en la naturaleza y funcionamiento de las democracias actuales. Dada la centralidad del tema de la paz en el país, de la implementación de los diálogos entre gobierno y guerrilla - FARC - y de los avances y retrocesos del proceso de paz, los medios masivos movilizan $\mathrm{y} / \mathrm{o}$ neutralizan imaginarios y representaciones sociales que se tornan relevantes en el ámbito de la opinión pública y la cultura política.

038 - "Feedback" cultural y nuevo rock. El caso de Muse en la Publicidad - David Fuentefría Rodríguez - Universidad de La Laguna - dfuentef@ull.es

Algunas de las principales manifestaciones audiovisuales "mainstream" del nuevo siglo suelen trabajar en una órbita de eclecticismo cultural prácticamente ilimitada, en la que la mixtura de figuras retóricas del presente y del pasado no dejan de configurar lenguajes conciliadores, a caballo entre la nostalgia, el perfeccionamiento técnico y la complicidad con el público avezado. Este texto pretende sondear, dentro de la ineludible relación entre música y Publicidad, el caso de la interacción entre las marcas Dior, Guerlain y Nestlé, y uno de los grupos de rock más exitosos de la actualidad, los británicos Muse, cuyos temas se incluyeron en tres de sus spots más celebrados. Para ello, se analizarán sus principales "insights", tomando como referencia tanto el "feedback" estilístico que ha marcado la trayectoria de la banda como el que manejaron los creativos a la hora de vender sus productos en imagen. 
039 - Llamando desde el vaso rojo - Jorge Ortiz Ascencio A01700290@itesm.mx; Carlos Vera - hello@versoca.com; Fernanda Espínola Gutiérrez y Zyanya Gallegos Gutiérrez Instituto Tecnológico de Estudios Superiores de Monterrey, Campus Querétaro

Gracias a los avances tecnológicos del celular y el Internet resulta no sólo posible sino esencial para las personas estar conectadas en todo momento sin importar el tiempo y el lugar donde se encuentren. En un entorno de este tipo, fenómenos como el drunk dailing resultan esenciales para comprender el comportamiento de los jòvenes. El estudio realizado por la universidad Midwestern en Estados Unidos presentó cómo el $79 \%$ de los estudiantes han enviado o recibido mensajes drunk dial (Ling, R. Donner, J. 2009) situación en la cual bajo el efecto del alcohol se realizan llamadas a través del celular en horarios nocturnos. Este comportamiento, resultado de la suma del acceso al celular más el consumo o intoxicación por alcohol, genera consecuencias controversiales las cuales repercuten en las relaciones interpersonales, y dada la frecuencia de este fenómeno entre jóvenes universitarios se decidió realizar esta investigación, cuyo objetivo es analizar las condiciones que conllevan al drunk dialing construyendo una guía para futuras investigaciones las cuales analicen este comportamiento. Tal exploración de carácter cualitativo tomó como base las metodologías de dos Focus Group y 68 cuestionarios en línea aplicados a estudiantes universitarios de 18 a 24 años durante el semestre enero-mayo del 2017 en la ciudad de Querétaro, México. Los resultados obtenidos fueron de puntual interés y los mismos podrán ser apreciados en el texto presentado a continuación.

040 - La relación de las marcas con el consumidor: características del consumidor emocional contemporáneo - Irene Martín Soladana Universidad Complutense de Madrid - Irenem14@ucm.es y Ana Sebastián Morillas - Universidad de Valladolid. Facultad de Ciencias Sociales Jurídicas y de la Comunicación anaseb@hmca.uva.es

La comunicación que se comparte pretende extraer características comunes a los consumidores emocionales contemporáneos. 
El fin de un modelo de política

Como punto de partida, se habla del consumidor que apareció a raíz del Fordismo a principios del siglo XX, considerando este momento como el inicio del consumidor contemporáneo (Gabriel y Lang, 1995).

Los consumidores que generó el Fordismo equiparaban la felicidad y el éxito con los bienes materiales. Desde entonces, el escenario económico y social ha cambiado a un ritmo de vértigo y como consecuencia han aparecido nuevos consumidores. Son consumidores con otras aspiraciones, que no se pueden agrupar bajo un mismo sistema de valores, bajo los mismos intereses, problemas, deseos o limitaciones. Son consumidores que se mueven por la emoción.

Para realizar este estudio, se sigue una metodología cualitativa basada en una revisión bibliográfica exhaustiva y estudio de casos. Para el análisis documental se utilizan fuentes diversas como artículos de revistas especializadas y libros específicos sobre el tema que se trata. Para el estudio de casos, se revisarán creatividades o campañas relevantes de los últimos años para observar cómo la comunicación apela a dimensiones menos racionales y más emocionales con el paso del tiempo.

Se pretende llegar a unos resultados que permitan conocer lo que caracteriza a estos consumidores emocionales a los que las marcas se enfrentan hoy, determinando aspectos como las pautas de comportamiento, cómo piensan a la hora de consumir, cómo influye su relación con el entorno para tomar una decisión de compra o qué buscan en una marca. Determinar estas características puede ser de ayuda para las marcas que buscan conocer mejor a sus consumidores y acercarse a ellos de forma más eficaz.

041 - Gerenciamento de crise de imagem: estudo do caso "Barquitandinha" - Alisson Dias Gomes - Professor Doutor do Instituto Camillo Filho (ICF) e da Faculdade Santo Agostinho (FSA), em Teresina, Piauí - Brasil -alissondg@bol.com.br y Anderson Brendo Gomes Dutra - Estudante de Administração do Instituto Camillo Filho (ICF), em Teresina, Piauí - Brasil 
O ambiente organizacional é permeado por intensas e constantes transformações. Neste contexto, o papel do administrador passa a ter novas significações diante da perspectiva contemporânea de incessantes atualizações e buscas por novos conhecimentos. $\mathrm{O}$ ambiente virtual, demarcado pelo uso contínuo de tecnologias vinculadas à Internet - websites, sites de redes sociais (SRS), sistemas de tecnologia de informação, entre outros - requer novo posicionamento das organizações, dos gestores e de seus colaboradores. Por conseguinte, o presente artigo visa apresentar a influência das redes sociais digitais no âmbito corporativo, traçando paralelos entre o eixo teórico-prático, com o propósito de apresentar a significância do uso destes canaisde maneira estruturada e intencional, evitando, por sua vez, a ocorrência de crises de imagem. Para tanto, adota-se como métodos científicos, a revisão de literatura(Gil, 2010),a pesquisa eletrônica(Gerhardt\&Silveira, 2009)e o estudo de caso(Lakatos \&Marconi, 2011; Severino, 2007),elegendo o"Bar Quitandinha" como objeto de estudo, com a finalidade de analisar sistematicamente os conteúdos que foram veiculados na fanpage do estabelecimento noFacebook, decorrentes deexperiência vivida por uma cliente. Ao final, consideram-se as ações depreendidas com o caso, estabelecendo argumentações pertinentes sobre as possíveis variáveis que podem desencadearuma situação de crise, bem como formas eficientes para evitar e sanar novas ocorrências.

\section{2 - ¿Para qué utilizan la Tecnología los profesionales en activo de} Educación Social? - Marcos Cabezas González - Universidad de Salamanca - mcabezasgo@usal.es); Sonia Casillas Martín Universidad de Salamanca - scasillasma@usal.es; Francisco Javier Herrero Gutiérrez -Universidad de Salamanca javiherrero82@usal.es y Wiselis Rosanna Sena Rivas Universidad de Salamanca wiselissena@gmail.com

La formación permanente en Tecnologías de la Información y la Comunicación es necesaria para cualquier Educador Social que quiera desempeñar su trabajo de manera competente en la sociedad actual. El principal objetivo que se pretende conseguir con esta investigación es el de conocer el nivel de competencia digital que poseen los profesionales de la educación social. La metodología utilizada es 
El fin de un modelo de política

cuantitativa, no experimental y descriptiva, y se ha utilizado la encuesta electrónica como medio de recogida de información. La muestra está compuesta por 422 educadores sociales, de los cuales, 154 son hombres $(36.5 \%)$ y 268 mujeres (63.5\%), con edades comprendidas entre los 18 y los 62 años, pertenecientes a 18 Comunidades Autónomas diferentes.

Entre los principales resultados cabe destacar que estos profesionales autoevalúan su conocimiento como aceptable. También dicen conocer los principales dispositivos tecnológicos como la Tablet, Smartphone, ebook y Pizarra Digital Interactiva (PDI). Respecto a su manejo, el dispositivo que casi todos ellos saben manejar es el ordenador, otros como las Tablet o el ebook consideran que lo manejan de una forma más moderada y en el caso de la PDI dicen no saber manejarla, no la necesitan para su trabajo. Se evalúan muy positivamente acerca del manejo de herramientas de comunicación, herramientas para la búsqueda de documentación y herramientas de administración y gestión. Su actitud hacia las TIC la valoran de manera muy positiva.

Queda demostrado que los educadores sociales tienen un nivel de competencia digital adecuado a su desempeño profesional, han aprendido a manejar aquellos dispositivos y herramientas que necesitan para desempeñar se labor profesional. Definitivamente, la necesidad de saber manejar tecnología a la hora de desarrollar un trabajo junto con recibir una formación permanente adecuada, hacen que los profesionales se manejen con las Tecnologías de forma óptima.

043 - Incidencia de la comunicación en la visibilización de la mujer en las empresas del tercer sector, Colombia: Bogotá y Cundinamarca - Jannet Liliana Moncayo Barrera-Universidad Cooperativa de Colombia - Jannet.moncayo@campusucc,.edu.cojannetmoncayob@gmail.com

La Universidad Cooperativa de Colombia, misionalmente propende por la construcción y difusión del conocimiento sobre la economía solidaria que le dio origen, apoyando el desarrollo competitivo de las organizaciones del sector cooperativo; por ello ha pretendido a través de sus compromisos pedagógicos contribuir con el fortalecimiento de estas entidades. De otro lado, a pesar de la misión de solidaridad 
igualdad y equidad que promueven las entidades solidarias, no es fácil identificar en ellas la manera como se han comprometido con la equidad de género, o cómo se ha venido posicionando el papel de la mujer en el sector, debido a que usualmente es poco visibilizada o por lo menos no tan notorio ese papel.

Por lo anterior, se planteó la necesidad de investigar en primer lugar, sobre el papel de la mujer en algunas entidades del sector, su nivel de protagonismo y las limitaciones que pueda tener su desempeño en el sector; y en segundo lugar, sobre el papel de la comunicación para visibilizar la contribución de la mujer en las empresas de economía solidaria en Colombia, si los diferentes procesos y estrategias comunicativas están siendo aprovechadas para hacer más visible ese papel.

Por medio de la investigación Papel de la Comunicación en la Visibilización de la Mujer en la Economía Social y Solidaria, financiado por la Universidad Cooperativa de Colombia, desde el Programa en Comunicación Social se buscó evidenciar la participación de las mujeres en este sector y sobre todo, la forma como los procesos y estrategias comunicativas han hecho frente a este reto de reconocer el rol de la mujer, siendo consistentes con los principios solidarios y cooperativos que promulga el sector.

Partiendo de un diseño metodológico de tipo exploratorio descriptivo con enfoque fundamentalmente cualitativo, que ha pretendido enfatizar en la necesidad de describir la forma como la comunicación puede comprometerse para contribuir y resaltar el desempeño laboral de la mujer en el sector cooperativo.

044 - La presencia digital de los CEO españoles - Joaquín MarquésPascual - EAE Business School (centro adscrito a UPC) joaquin.marques@campus.eae.es y José Miguel Esteban, EAE Business School (centro adscrito a UPC) jm.esteban@campus.eae.es

La sociedad digital está impactando en las organizaciones empresariales revolucionando la forma en que estas se comunican con sus públicos. 
El fin de un modelo de política

Las empresas y sus directivos se ven obligadas a desarrollar otro tipo de actuaciones con más diálogo, así como formas más abiertas, utilizando para ello las nuevas herramientas digitales de comunicación pluridireccionales. Los CEO (chief executive officer), en tanto que líderes de sus proyectos, deben ampliar sus perfiles digitales entre los que se encuentran disponer de cuentas en las redes sociales de mayor difusión. Este trabajo analiza la presencia digital en redes de los principales CEO españoles (los representados en el IBEX 35), así como su actividad, entendiendo que ello debe ser una de las habilidades estratégicas que deben desarrollar los directivos de empresa en plena era digital. Además, esa presencia activa debe considerarse como un indicador de buena gobernanza en el contexto de la RSE (responsabilidad social empresarial).

045 - Historia de vida como método de investigación (Caso: Mujeres periodistas en San José de Cúcuta) - Eliana Caterine Mojica Acevedo, Universidad de Pamplona (Cúcuta - Colombia) elianamojica@unipamplona.edu.co

El proyecto Mujeres periodistas, lideresas de opinión en San José de Cúcuta permitió desarrollar una metodología de historias de vida con cinco (5) periodistas que se caracterizan por ser directoras de medios locales de comunicación, así como corresponsales de medios nacionales. Para la elaboración de las historias de vida, se tuvo en cuenta la entrevista en profundidad, que está organizada por momentos en donde se establecen aspectos de su vida personal y profesional, así como aspectos alrededor de su práctica en el oficio, las condiciones para poder ejercer su rol como periodistas y su postura frente al tema de género para la participación en el gremio. El instrumento en su totalidad cuenta con 120 preguntas, que fueron establecidas en seis momentos: Vocación, en formación, inicio en la vida laboral, en terreno, rol actual y perspectiva de género.

Esta ponencia busca reflexionar sobre el uso de las historias de vida como método para explorar la situación de las mujeres en zonas de frontera, sus roles y la transformación de los mismos, dados los permanentes cambios sociales, políticos, económicos y culturales que 
se originan en estos espacios, principalmente, en la frontera colombovenezolana afectada por su cierre desde el 2015.

046 - La interactividad entre usuarios y televisiones públicas. Estudio de caso: Si fueras tú de RTVE (2017) - Belén Araujo Herrero Universidad de Santiago de Compostela belen.araujo.95@gmail.com

En la sociedad de la comunicación 2.0 las redes sociales funcionan como un gran nexo de unión entre marcas, empresas, organizaciones y los seguidores y clientes de éstas. La interactividad entre ambos actores ha ido creciendo en los últimos años y se han ido produciendo experimentos en múltiples plataformas que progresivamente han otorgado más poder a los usuarios. Vemos, así como los consumidores han pasado de ser meros espectadores a tener también un papel en la acera de la producción (el conocido nacimiento de la figura del prosumidor). Esta investigación estudia las posibilidades de interacción entre usuarios y televisiones públicas y se concreta en un estudio de caso, la serie de RTVE Si fueras tú (2017). Se ha analizado la estrategia transmedia llevada a cabo por el equipo de la RTV pública española y se realizado un seguimiento de la respuesta recibida por parte de los espectadores a lo largo del transcurso de la serie para explorar las debilidades y fortalezas de su innovador formato.

047 - Empoderamiento de la palabra. Ejemplo de traspaso del sujeto pasivo al sujeto político - Nicolás Tilli, Universidad Toulouse 1 Capitole, Toulouse, Francia, nicolas.tilli@ut-capitole.fr

En nuestras sociedades modernas occidentales la problemática generada por una representación social (compuesta por informaciones, creencias, imágenes y actitudes) estigmatizadora de la enfermedad mental y de la persona que la padece (fuente de discriminación y de desigualdades) no siempre ocupa una plaza central en las políticas de publicas (favoreciendo el surgimiento de iniciativas participativas innovadoras).

Este fuerte estigma se traduce habitualmente en "factor negativo" (en el sentido de: inhibición) a la hora de solicitar ayuda y de acceder al 
El fin de un modelo de política

tratamiento y en un obstáculo (en el sentido de: barrera) para la creación de lazos sociales y el acceso al mundo profesional. Siguiendo a Jodelet (1984), si consideramos que las representaciones sociales facilitan la comunicación entre los miembros de una sociedad y establecen un orden dentro de ella; es evidente que estos valores, practicas e ideas tienen una gran influencia en los intercambios sociales y en la integración social y democrática de las personas que padecen una enfermedad mental. Esta comunicación tiene por objetivo presentar una alternativa de participación ciudadana (asociativa) que busca utilizar los medios de comunicación para ejercer una influencia en las representaciones sociales relacionadas a la salud mental y a las personas que las padecen. De esta manera el objetivo es lograr operar un cambio en el imaginario social discriminador y estigmatizador, alcanzar una sociedad mas democrática e inclusiva y fomentar la toma de poder (empoderamiento) por parte del ciudadano influyendo de esta manera en las decisiones de políticas de salud.

Este nuevo dispositivo de trabajo que utiliza al medio de comunicación como herramienta de un proceso de mediación, se focaliza en el impacto (positivo/negativo) en diferentes espacios (territorios) y niveles (inter-personal, intra-personal y extra-personal) favoreciendo el corrimiento de eje de la representación social negativa y operando un ajuste de su funcionalidad reguladora de la interacción social.

La participación ciudadana, eje central de este proceso de coconstrucción discursivo y de identidad (individual, grupal y colectiva), traduce una realidad de empoderamiento del espacio publico que busca corregir las representaciones sociales estigmatizantes y lograr un impacto en la toma de decisiones (consecuencias políticas y sociales).

048 - El uso creativo de la pseudociencia y la experimentación en las nuevas tendencias de comunicación publicitaria - Begoña Moreno López - Universidad Europea de Madrid Begona.moreno@universidadeuropea.es

La comunicación publicitaria ha buscado, a lo largo de los años, diferenciar productos y marcas a través de la creatividad. Empleando para ello todos los recursos posibles que se encontraban a su alcance y 
no dudando en absorber técnicas y métodos de distintas disciplinas para la creación simbólica de valores y percepciones.

Con los cambios y desarrollos tecnológicos de los últimos quince años, la creatividad publicitaria ha evolucionado sustancialmente para poder adaptarse a los nuevos medios que han ido naciendo en el entorno digital. De modo que no solo los medios se han transformado sino que, consustancialmente, han evolucionado los modos de comunicar, los objetivos y las formas.

En este caldo de cultivo han surgido varias tendencias publicitarias aparentemente antagónicas. Así podemos ver el gran auge que están teniendo las nuevas corrientes vintage, que recuperan lo artesanal y handmade, al mismo tiempo que se desarrollan campañas con aplicaciones cada vez más tecnológicas (entre las que se encuentra los bot y la nueva inteligencia artificial, por ejemplo). Y, entre ellas, podemos observar una gran tendencia a la justificación científica o pseudocientífica.

No se trata solo de la aplicación del neuromarketing en los entornos de venta sino de la recuperación de los antiguos demostrativos de producto a valores de marca o comprensiones de los insight aplicados a un concepto creativo. La creatividad publicitaria recupera los antiguos experimentos psicológicos de los años 60 y 70, como el experimento del malvavisco, para aplicarlos a sus nuevas propuestas creativas en acciones especiales. De este modo, los experimentos psicológicos y sociológicos publicitarios, encuentran un nuevo modo de emplear el "demostrativo" de producto, o una argumentación "científica" para la compra, la creación de imagen de marca o promover el cambio de actitud.

049 - Informaçao e entretrenimiento nas alturas: estudio de caso da "Revista Gol" - Alisson Dias Gomes - Professor Doutor do Instituto Camillo Filho (ICF) e da Faculdade Santo Agostinho (FSA), em Teresina, Piauí - BRASIL - alissondg@bol.com.br y Brunelle Valente Botêlho - Estudante de Administração do Instituto Camillo Filho (ICF), em Teresina, Piauí - BRASIL brunellevalentebotelho@gmail.com 
El fin de un modelo de política

A comunicação é um dos instrumentos mais poderosos dentro de uma organização e ao longo das últimas décadas tem sido utilizada de formas diversificadas. Deste modo, diferentes tipos de ferramentas surgiram para adequar-se às realidades circunstancialmente mutuantes, em razão das próprias práticas de interação. Desde os tempos mais remotos, a necessidade de comunicar-se envolve os indivíduos e as organizações. Neste cenário, as empresas são instigadas a promover relacionamentos com seus públicos, a fim de se tornarem presente na vida de cada um, em busca de gerar boas percepções, fazendo com que seja lembrada pela combinação de recursos e aspectos, desde os sensoriais (físicos, tangíveis, etc.) até os corporativos (simbólicos, representativos, etc.). Nesta configuração, vale enfatizar que a comunicação está inserida no conjunto de elementos que fortalecem a marca de qualquer empresa/organização. À vista disso, o estudo se propõe a refletir e discutir sobre a importância e os efeitos que uma ferramenta de comunicação pode gerar, em específico, o uso de uma revista corporativa. Faz-se necessário adotar, como métodos científicos, a revisão de literatura tendo por base os teóricos Martinuzzo (2014), Zenone (2013), Tavares e Schwaab (2013). No que tange aos aspectos metodológicos, tem-se claro que se trata de uma pesquisa eletrônica (Kotler; Keller, 2006) e de estudo de caso (Scalzo, 2008), tendo como objeto de análise a revista Gol Linhas Aéreas Inteligentes, em sua edição 180, março de 2017, momento de comemoração dos 15 anos de existência. O propósito desse estudo é analisar a maneira como a referida empresa se relaciona com os leitores-consumidores, por meio deste potente canal de comunicação, elencando as vantagens e as estratégias utilizadas para consolidação da marca.

050 - El tratamiento del postconflicto por medio de infografías y visualizaciones de datos - Beatriz Elena Marín Ochoa Universidad Pontificia Bolivariana - beatrize.marin@upb.edu.co

Colombia pasa por un momento histórico especial desde el 26 de septiembre del año 2016 cuando se oficializó ante la sociedad colombiana y ante el mundo la firma de un acuerdo de paz con tal vez una de las guerrillas más antiguas del mundo, en ese proceso acelerado 
para validar lo discutido en la Habana por un largo periodo de tiempo los medios, el gobierno y algunas entidades no gubernamentales implementaron estrategias para dar a conocer los acuerdo de todas la maneras posibles: texto, audio, video, cartillas, informes especiales, multimedias e infografías.

La intención de esta ponencia es analizar las formas narrativas y los múltiples discursos empleados así como el aprovechamiento de herramientas digitales, presentaciones infográficas impresas, audiovisuales y digitales, así como visualizaciones de datos, georreferenciaciones y líneas de tiempo que informarán a la sociedad el alcance de lo que se estaba pactando, y que sin ser reduccionista o restarle valor facilitó la comprensión de esencial de un documento amplio y extenso como son los acuerdos de paz.

Es así como se recuperó el valor de la imagen y sobre todo su característica de síntesis que facilita la interpretación de información y propicia la formación de la ciudadanía, así como se demuestra el gran carácter pedagógico y documental que tiene la infografía y la visualización de datos en el cubrimiento informativo de tal vez el tema más álgido de la agenda mediática colombiana.

051 - Infografías y visualizaciones de datos como estrategia formativa en los museos - Beatriz Elena Marín Ochoa beatrize.marin@upb.edu.co y Hernán Franco Higuita Universidad Pontificia Bolivariana - hernandfranco@gmail.com

El periodismo científico siempre ha tenido en medios de comunicación y en particular en sus formas narrativas aliados incondicionales para contar el desarrollo de los avances científicos en el mundo, en el país, en la universidad... es así como desde su aparición en medios la infografía y la visualización de datos ha permeado con sus características las piezas comunicacionales que se aprovechan no solo como herramientas informativas sino también formativas de forma impresa, audiovisual y digital en pequeño y en gran formato, como estrategia divulgativa o incluso de entretenimiento. 
El fin de un modelo de política

Los museos no han sido ajenos a ello y es así como en su tarea de atrapar los visitantes en ese mundo sorprendente de colecciones se presentan miles de posibilidades que por medio de la infografía y la visualización de datos cada vez más se apropia de un lenguaje y un mensaje que conjuga su verdadero objetivo que es facilitar la apropiación del patrimonio de una comunidad fortaleciendo así su acervo cultural.

Es ahí donde ambas, infografía y visualización de datos, aprovechando sus cualidades facilita la asociación y la comprensión de las propuestas que el conocimiento expuesto le propone por su valor cultural y que nos recuerdan el valor de transmisión alternativa de conocimiento porque la infografía y la visualización de datos facilitan la adquisición de conocimientos por parte de las personas.

052 - Estudio bibliométrico de la producción científica en comunicación de moda - Eduardo Villena Alarcón - Universidad de Málaga eduardo.villena@uma.es

La relevancia adquirida por la moda en los últimos años ha exhortado a los comunicólogos a efectuar revisiones periódicas de la bibliografía relacionada con el objeto de investigación. Particularmente, este trabajo procura un análisis bibliométrico de la producción científica recogida por Scopus de 2013 a 2017 con el objetivo de ofrecer una visión actualizada de la investigación en moda. El número de artículos publicados, sus citas, la adscripción de sus autores o el país son algunos de los ítem que se recogen aquí. Su pertinencia viene justificada por la necesidad de conocer cómo hemos afrontado los profesionales del sector la investigación en comunicación del sector textil, así como intentar favorecer nuevas líneas de investigación de cara a un futuro.

053 - Los eventos de moda en Twitter: el caso de Mercedes-Benz Fashion Week Madrid - Eduardo Villena Alarcón - Universidad de Málaga - eduardo.villena@uma.es

La moda ha encontrado en las redes sociales una plataforma donde poder compartir de manera efectiva sus mensajes a los diferentes públicos al instante y con carácter segmentado. Gracias a Twitter, y tras 
la incorporación de herramientas como Periscope, los eventos de moda han podido asimismo difundir y mejorar el alcance de sus comunicaciones. Sin embargo, a pesar de que esto es una evidencia dentro del sector, son escasas las investigaciones que profundizan en este asunto; por lo que este estudio propone un análisis de contenido de los mensajes publicados en Twitter por parte de Mercedes-Benz Fashion Week con el objetivo de conocer más sobre su contenido y la participación de sus públicos.

054 - Diásporas digitales. Una aproximación teórica y conceptual al estudio de las minorías online - Silvia Almenara Niebla Universidad de La Laguna - silvia.almenara@ull.edu.es

Los procesos migratorios del siglo XXI están fuertemente influenciados por el acceso a Internet y a las nuevas tecnologías de la información (TIC), donde las variables movilidad y conectividad clarifican y trasforman la experiencia migratoria. La mediación electrónica ha conseguido reforzar el mantenimiento de las relaciones personales con los lugares de origen a pesar de las fronteras y las largas distancias, lo que ha construido un nuevo sujeto migrante, definido por Dana Diminescu (2008) como "migrante conectado", que utiliza las nuevas tecnologías para desarrollar y mantener redes personales, culturales, lingüísticas, religiosas y sociales a nivel transnacional. En este sentido, son cada vez más los estudios que se centran en el impacto de las nuevas tecnologías en el proceso migratorio y en la construcción de identidades diaspóricas digitales (Andoni \& Oiarzabal, 2010; Gajjala, 2013; Madianou \& Miller, 2013; Leurs, 2015). La posibilidad de constituir redes online ha permitido a las comunidades diaspóricas, excluidas del mainstream de los medios tradicionales de comunicación, ganar acceso en el espacio público transnacional a través de blogs, redes sociales, foros, etc. Así pues, el análisis de las diásporas en el espacio virtual permite observar mecanismos de reforzamiento de las identidades étnicas y cómo estas se mantienen en nuevos contextos migratorios. Por este motivo, esta ponencia pretende poner el foco de atención en varios aspectos relevantes: por un lado, en las aportaciones teórico-metodológicas sobre la construcción del sujeto diaspórico digital y su análisis en el entorno virtual y; por otro lado, en el impacto 
El fin de un modelo de política

de las nuevas tecnologías en la construcción del migrante conectado y la configuración de su identidad online.

055 - El concepto de participación política en linea en Colombia, Ecuador y México. Un estudio sobre los jóvenes universitarios - Daniel Barredo Ibáñez - daniel.barredo@urosario.edu.co - Universidad del Rosario (Colombia); Daniel de la Garza danieldelagarza@gmail.com - Universidad Autónoma de Nuevo León (México) y Karen Tatiana Pinto Garzón karen.pinto@outlook.es - Universidad Técnica Particular de Loja (Ecuador)

A través de los medios sociales, las ciudadanías contemporáneas tienen la oportunidad de establecer un contacto directo con sus sociedades. De esta manera, la anulación de la intermediación tiene severos efectos para las organizaciones periodísticas, las cuales tienden a ser desplazadas como monopolizadoras de la gestión simbólica. Y esto es especialmente importante en países como Colombia, México y Ecuador, donde factores como la concentración mediática, el autoritarismo institucional y la falta de confianza generalizada por décadas de corrupción y exclusión, convierten a las plataformas en línea no solo como extensiones de la esfera pública, sino como inauguradoras de una esfera pública distinta, más democrática, horizontal, creíble y transparente. En este estudio comparamos las percepciones de un grupo estratégico de los tres países -los jóvenes universitarios-, sobre un factor que puede favorecer esa redemocratización que enunciábamos anteriormente: las prácticas y la conceptualización sobre la participación política en línea.

056 - La España de la primera mitad de 2016 a través de las viñetas de Padylla y Morgan - Araceli Álvarez Díaz - Universidad de La Laguna - Mofletespeque@gmail.com

Este trabajo se basa en el estudio y análisis de las viñetas publicadas por los humoristas gráficos Padylla y J. Jesús Verdú Medina (Morgan) en los periódicos La Opinión de Tenerife, el primero, y en Canarias 7, el segundo, entre los meses de enero y junio de 2006. Se trata del período comprendido entre las elecciones generales del 20 de diciembre de 
2015 en el que los partidos políticos sin mayoría para conformar un gobierno estatal negocian sin éxito y el proceso culmina con una nueva convocatoria electoral el 26 de junio de 2016. Se trata de un momento de incertidumbre en la política nacional que tiene repercusiones claras en todo el país y que afecta a todas las instituciones del Estado. Estos dos humoristas gráficos plasman la situación que se vive en Canarias donde los socios del ejecutivo regional viven también momentos de tensión y las consecuencias que dicha situación tiene para los canarios y los problemas que aquejan a la sociedad de las islas. Algunos autores consideran que la realidad reflejada por los humoristas constituye un acto subversivo de rebeldía contra el statu quo a través de la ridiculización de personas o de situaciones, que se acentúa en época de crisis.

057 - Internet y retroalimentación: las nuevas tecnologías al servicio de un mensaje político que habia olvidado escuchar - Guillermo Gurrutxagaguillermo.gurrutxaga@ehu.eus; Angerine Elorriaga angerine.elorriaga@ehu.eus y Maialen Goirizelaia Altuna UPV/EHU - maialen.goirizelaia@ehu.eus

Internet ha situado a la comunicación política ante la evidencia de su gran carencia: la retroalimentación. Ha obligado a quienes ejercen la política a concebir a la ciudadanía como un agente activo en la toma de decisiones cuyo papel ya no queda restringido a la emisión de un voto cada determinado número de años. La política se ha transformado porque la comunicación ha debido revisar las iniciales teorías de Harold Laswell, para quien el público era un mero receptor pasivo. Y aunque Claude E. Shannon identificaba ya al receptor como agente imprescindible en la eficacia del acto comunicativo, Wilbur Scharam advirtió de la necesidad de una relación dialógica entre ambos. Esta ponencia pondrá en relación ese creciente papel otorgado al receptor en la teoría comunicativa con la horizontalidad de la comunicación que tanto Mario Kaplún como Paulo Freire reivindicaban como herramienta para la transformación política y social. Mucho antes de que existiera internet apostaban ya por una comunicación política de ida y vuelta donde emisor y receptor intercambiaran sus papeles. 
El fin de un modelo de política

058 - La Educomunicación, un campo del saber en gestación en el entorno Universitario - Ana María Beltrán Flandoli - Universidad Técnica Particular de Loja - ambeltran@utpl.edu.ec

La situación que vive la sociedad actual con la utilización masiva de las tecnologías de la información y comunicación, reclama una profunda reestructuración del sistema educativo a todo nivel. El compromiso de reflexión sobre el proceso de enseñanza - aprendizaje de los futuros comunicadores, se erige como crucial para promover la transversalidad de las propuestas educomunicativas en la Universidad. Este trabajo realiza una valoración del la Educomunicación como «campo del saber» en la Universidad, a través de la perspectiva de los docentes y el coordinador de la titulación (carrera) de Comunicación Social de la Universidad Técnica Particular de Loja en Ecuador, como caso de estudio.

Este campo del saber en gestación, se presenta como una realidad interdiscursiva en movimiento, que no corresponde únicamente a una nueva disciplina a ser añadida rígidamente en un currículo académico, sino que se reconoce como un nuevo paradigma que se vivencia y se estructura desde sus actores sociales a través de distintas áreas deintervención (Soares, 2000, p. 25).

Los resultados muestran la diversidad de enfoques y formas que adquiere la práctica discursiva de la Educomunicación en la Universidad.

059 - El consumo de contenidos digitales entre los jóvenes universitarios en Colombia. Un abordaje de las prácticas de participación en los cibermedios - Daniel Barredo Ibáñez - daniel.barredo@urosario.edu.co Universidad del Rosario (Colombia); Daniel de la Garza danieldelagarza@gmail.com - Universidad Autónoma de Nuevo León (México) y Dania Lorena Días Castillo danialorena@gmail.com - Corporación Universitaria del Meta (Colombia)

Colombia es uno de los países con mayor conectividad en América Latina. Y ello a pesar de que todavía existe una brecha tecnológica, 
sobre todo entre los entornos urbanos y rurales, pero también entre unos barrios y otros de las ciudades, por cuestiones como la falta de desarrollo de las infraestructuras, la carestía de las conexiones a internet, entre otros. Además, la ciberesfera presenta una alta activación, tanto por la importancia que tienen los cibermedios nativos, como por su papel al inaugurar un espacio de encuentro social, muy distinto a la beligerancia y a la falta de inclusión de muchos de los medios tradicionales. En este estudio, tras realizar 581 encuestas a jóvenes universitarios colombianos, abordamos el consumo de contenidos digitales de esta población estratégica, en un intento de delimitar un perfil de las prácticas de participación en los cibermedios.

\section{0 - Calidad de la infografía periodística en los principales diarios del} País Vasco: análisis valorativo de El Correo, Diario Vasco, Deia, Garay Berria a partir de los atentados del 17-A - Aitor Castañeda Zumeta - Universidad del País Vasco / Euskal Herriko Unibertsitatea aitor.castaneda@ehu.eus

La infografía es un elemento gráfico y visual de excelente utilización en el periodismo, que permite mostrar gráficamente información que con mero texto puede resultar árida o poco comprensible. Habida cuenta del interés académico y didáctico de la misma, el siguiente estudio propone analizar la calidad informativa y visual de las infografías publicadas en agosto de 2017 en los principales diarios del País Vasco, región de mayor penetración periodística de España, y durante un mes en que la prensa local e internacional se hizo eco de los trágicos atentados sufridos el día 17-A en Barcelona por el Estado Islámico. Aplicando el método propuesto por el académico José Luis Valero Sancho de valoración numérica por códigos binarios para infografía de prensa, se concluye que los periódicos vascos analizados (El Correo, Diario Vasco, Deia, Gara y Berria) publicaron infografías de mencionable calidad periodística, si bien la misma es directamente proporcional a su alcance y recursos, destacando notoriamente los periódicos de Vocento sobre el resto. Queda pues de relieve la calidad informativa y el interés infográfico de los medios locales estudiados, a la vez que se insiste en la viabilidad del método ideado por Valero Sancho. 
El fin de un modelo de política

061 - Significatividad de la ficción transtelevisiva española como factor coadyuvante de la imagen-país mediante el análisis del cronotopo audiovisual - Enrique Tribaldos Macía - Universidad Camilo José Cela de Madrid - etribaldos@ucjc.edu

En el actual escenario de homogeneización donde los medios de comunicación son fuente primaria de información y conocimiento de un imaginario colectivo mundializado aparece una nueva televisión que denominamos Transtelevisión-que destaca tanto por su extensión y experiencia multiplataforma como por dotar al nuevo medio de un posicionamiento único y privilegiado y la confiere una destacada significatividad en el proceso de culturalización como estructurante de la comunidad global.

Sin embargo, esta sociedad globalizante vive marcada por la continua búsqueda de la propia identidad y opera con soltura conceptos más propios del marketing para manejar valores intangibles como prestigio y reputación.

En este punto toma especial significatividad la nueva ficción transtelevisiva. Un contenido que se expande más allá del viejo televisor en busca de nuevas experiencias a través de múltiples plataformas y que por su alcance y eficacia comunicativa genera un consumo mundial cada vez más activo y participativo entre los antiguos espectadores que ahora denominamos usuarios cuasi-prosumidores.

Bajo una perspectiva académico-profesional, el objetivo principal de esta investigación es revisar y actualizar el proceso de comunicación de la televisión y esclarecer la significatividad de la ficción transtelevisiva española en la creación y difusión del intangible imagen-país mediante el análisis del proceso de creación de «imágenes de realidad» propios del género gracias a la deconstrucción del cronotopo audiovisual transmediático esto es, el estudio de la terna diégesis, construcción del espacio fílmico y recodificación por parte del usuario en el nuevo ecosistema de la comunicación.

062 - El discurso populista de Nicolás Maduro en el marco de la convocatoria a la Asamblea Nacional Constituyente - Luis Miguel 
López Londoño - Universidad de Manizales (Colombia) lmlopez@umanizales.edu.co y Adriana Ángel Botero -

Universidad de Manizales (Colombia) aangel@umanizales.edu.co

El presidente venezolano Nicolás Maduro anunció el pasado primero de mayo la convocatoria a una Asamblea Nacional Constituyente. A pesar de las protestas ciudadanas, el descontento popular y la presión de la comunidad internacional, el 29 de julio se eligieron los 545 ciudadanos encargados de redactar una nueva constitución. La nueva Asamblea Nacional Constituyente se instaló e inició actividades el 4 de agosto.

La historia política de las naciones latinoamericanas se ha caracterizado por continuas reformas constitucionales. Los presidentes de Venezuela, Hugo Chávez, de Ecuador, Rafael Correa, y de Bolivia, Evo Morales, prometieron reconstruir sus naciones y convocaron Asambleas Constituyentes para incorporar nuevos modelos de participación popular. Antes de su muerte, Chávez designó a Maduro como heredero de su poder político, quien ahora se dispone a iniciar un proceso de refundación de la república sustentado en el poder soberano del pueblo. Este fenómeno de liderazgo político por parte de figuras paternalistas y mesiánicas ha sido denominado por algunos académicos e investigadores como populismo.

El actual momento de transición política que atraviesa Venezuela invita a examinar las dimensiones discursivas de dicho fenómeno. Partiendo de la concepción del populismo como una estrategia discursiva, este estudio se pregunta por las características del discurso populista de Nicolás Maduro en el contexto de la conformación e instalación de la nueva Asamblea Nacional Constituyente. Para este ejercicio, se llevó a cabo un análisis de discurso a partir de tres categorías: a) la identificación de un enemigo público y creación de un campo antagónico, b) la apelación al pueblo y c) la refundación de la nación.

Los resultados de este examen señalan, en cuanto a la primera categoría, una división antagónica de la sociedad desde la dicotomía nosotros el pueblo/ellos la burguesía y los partidos tradicionales. Con 
El fin de un modelo de política

respecto a la segunda, la apelación a un pueblo y a una multiplicidad de sectores sociales históricamente excluidos de las grandes decisiones políticas. La tercera, plantea la misión histórica y constitucional que debe adoptar el pueblo para refundar la patria.

063 - Mujeres y hombres en la prensa segregada: presencia, imágenes y representaciones de género - Paula Illera Miguel - Universidad de Burgos - paulaillera@hotmail.com

Encontramos que los medios de comunicación han tematizado sus contenidos, ofreciendo distintas opciones que buscan llegar a un sector concreto del público. Aunque se trate de una tendencia que podemos observar actualmente, lo comprobamos, sin ir más lejos, con los canales televisivos que nos ha dejado en estos últimos años la TD'T, lo cierto es que existe una larga tradición por parte de la prensa escrita de especializar sus contenidos.

En este sentido, la presente investigación pone el foco en la prensa española segregada en función del género y analiza la presencia de mujeres y hombres en las revistas femeninas y masculinas, ya que las dos opciones incluyen, dentro de sus páginas, a protagonistas de ambos sexos. Los objetivos son el de conocer ante qué tipo de representaciones nos encontramos, analizar si se generan diferencias de trato en función del sexo y qué consecuencias tendrían estas en el avance hacia una igualdad real.

Para lograr lo arriba mencionado, se han seleccionado las revistas de estilo de vida, tanto las dirigidas a mujeres como aquellas que son leídas por hombres, con más difusión en España. Además, se ha tomado como referencia el marco teórico de los Estudios de Género. Finalmente, se han elaborado una serie de categorías que nos permiten comprender qué función desempeñan los y las personajes que protagonizan las distintas unidades redaccionales de nuestra muestra.

064 - Desarrollo de las productoras audiovisuales en Extremadura en el S. XXI - Ana María Morales González - Universidad de Sevilla - anamorales10@outlook.com 
Extremadura contaba, a principios del siglo XXI, con tan sólo seis productoras audiovisuales que operan en la región de forma regular, centrándose mayoritariamente en el vídeo industrial y la publicidad. En su totalidad eran pequeñas pymes que empleaban a unas 156 personas entre fijos y colaboradores. Habría que esperar, como vaticinaba Vacas (2001) a la llegada de la televisión regional, que "deberá alterar para siempre el estancado panorama audiovisual extremeño". Según José Camello, Director de la productora audiovisual Libre Producciones, el sector "era muy duro" antes de la aparición de la televisión autonómica y "generalmente se dependía en el día a día de las instituciones y de un número ínfimo de iniciativas privadas".

Efectivamente, a partir del año 2006, fecha en la que inició sus emisiones esta televisión autonómica, llamada Canal Extremadura TV, comenzaron a proliferar las productoras audiovisuales en la región, llegando a duplicar el número inicial.

En la actualidad, son muchos los que consideran a este canal autonómico como "la locomotora del sector", entre los que destaca Pablo Sánchez, Director de Canal Extremadura TV entre 2006 y 2010. Sin embargo, aunque han aumentado en número las productoras audiovisuales, no así en tamaño. Siguen siendo pequeñas pymes de alrededor 10 trabajadores fijos, que aumentan su plantilla en función de la producción del momento. Esta producción, si antes era institucional y publicitaria, ahora está centrada, casi en su totalidad, en contenidos para el canal autonómico.

Muchas de estas productoras llegan incluso a tener dependencia de la televisión regional. A lo largo de estos quince años, un nuevo agente en el sector les ha dado la oportunidad de alcanzar un mayor desarrollo - aunque no comparable con el de otras comunidades autónomas -, sin embargo, se trata de un desarrollo limitado y controlado.

065 - La construcción de las rutas migratorias a partir de las representaciones mediáticas: el caso de los Cayucos en Canarias - Pietro Soddu - psoddu@correo.ugr.es; F. Javier García Castaño Universidad de Granada - fjgarcia@ugr.es y Rodrigo Fidel 
El fin de un modelo de política

Rodríguez Borges - Universidad de La Laguna rodriguez.borges@ull.es.

Nuestra intención con esta comunicación es continuar reflexionando sobre la noción de "ruta migratoria" y hacerlo en este caso a partir del fenómeno de la llegada de personas migrantes en cayucos a Canarias en el año 2006. Pero dicho fenómeno lo estudiaremos, en esta ocasión, a partir de las representaciones del mismo en la prensa regional. Comenzaremos situando todos los acontecimientos de la llegada de migrantes en cayucos a Canarias en dos reflexiones de contextos más globales que hace Gordenau (2007): la reducción de la permeabilidad fronteriza del Estrecho de Gibraltar (Carling, 2007) y el kick off por parte de la Unión Europea de externalización de las políticas de control de las fronteras exteriores y consecuentemente el principio de condicionalidad positiva (López Sala, 2006). Ello nos permitirá realizar un análisis geopolítico que situé las migraciones en un contexto de relaciones interregionales y ultra-periféricas de la Unión Europea. Desde este escenario comprobaremos que el endurecimiento exclusivo del control de fronteras provoca variaciones en los puntos de entrada, readaptaciones en los medios utilizados y en el grado de organización de la migración. Todo ello, entre otros muchos posibles asuntos a considerar. Lo novedoso de nuestro trabajo es que toda esta reflexión será analizada a la luz de cómo ha sido contada, comunicada, relata y narrada por los medios de comunicación regionales y como ello ayuda a construir (comunicar) la noción de "ruta migratoria". Nos centraremos, en primer lugar, en el discurso informativo sobre la inmigración en general y el tratamiento noticioso de la información sobre migraciones (Rodríguez Borges, 2010), puesto que la noticia en si misma puede y es diariamente policy oriented. Y, en segundo lugar, nos detendremos en mostrar como esos mismos medios presentan a los migrantes como una categoría etnificada, homogeneizada y con pocas posibilidades de verse como sujetos heterogéneos, participando de manera dramática en procesos complejos de movilidad humana.

066 - Comunicación turística 2.0 en Ecuador. Análisis de las empresas públicas y privadas - Verónica Altamirano Benitez Departamento de Ciencias de la Comunicación- Universidad Técnica Particular de Loja (UTPL), Ecuador- vpaltamirano@utpl.edu.ec; Isidro 
Marín Gutiérrez Departamento de Ciencias de la

Comunicación- Universidad Técnica Particular de Loja (UTPL), España - imarin1@utpl.edu.ec y Kruzkaya Ordóñez González Departamento de Ciencias de la Comunicación- Universidad Técnica Particular de Loja (UTPL), Ecuadorkordonez@utpl.edu.ec

La presente investigación parte de un estudio cualitativo para determinar la evolución de la comunicación turística en Ecuador. Objetivos. El objetivo de esta investigación es identificar y evaluar la comunicación 2.0 en las empresas públicas y privadas de Ecuador utilizando una metodología mixta, cualitativa y cuantitativa. Método. Se implementa una metodología cuantitativa que permite analizar como las empresas turísticas públicas y privadas promocionan al país en los medios sociales. Conclusiones. Hay que estudiar la comunicación turística 2.0 y su función en la promoción nacional e internacional de Ecuador como destino turístico.

067 - La imagen de las deportistas a través del lenguaje escrito en la prensa deportiva desde 1893 a 1923 - Iciar de Ozámiz - INEF de A Coruña - itziardeozamiz@hotmail.com y Cristina LópezVillar - INEF de A Coruña - cristinalopez19@gmail.com

La presente comunicación forma parte de un estudio centrado en la evolución de la imagen de las mujeres deportistas a través de la prensa deportiva española desde 1893 a 1923 con el fin de recuperar un segmento obviado de la Historia de las deportistas.

Al estudiar la imagen de las mujeres deportista en la presa escrita no nos basamos exclusivamente en el aspecto cuantitativo del contenido del texto o fotografía, sino también en el tratamiento de esa representación y sus causas. Aquí se realiza un estudio descriptivo que utiliza el análisis de contenido como técnica central de la investigación. Fueron 1193 las unidades de análisis extraídas de la prensa deportiva española, que se muestran siguiendo un orden cronológico. Empezando con Crónica del Sport en 1893, seguida de Barcelona Sport, Los Deportes, Gran Vida, Mundo Deportivo, Stadium, Heraldo Deportivo, Madrid-Sport, Aire Libre y, finalizando con Sports en 1924. 
El fin de un modelo de política

Se consideró necesaria la utilización de un programa informático, por ello la ficha de registro fue realizada con el programaFileMaker Pro Advanced 12. La aplicación de un sistema de categorías elaborado ad hoc permite analizar el imaginario de las deportistas a través de las publicaciones estudiadas. En este estudio nos centramos en la dimensión de análisis del lenguaje escrito de los 564 titulares y 973 pies de fotografía.

Los resultados muestran diferencias entre publicaciones y momentos históricos concretos. En cuanto a las conclusiones, podemos decir que la prensa deportiva española en sus inicios mostraba un gran respeto hacia las deportistas, especialmente si las comparamos con el tratamiento que se hace actualmente de las mismas. Aunque se han encontrado casos de expresiones negativas, en un número muy reducido en cuanto a alusiones a aspectos estéticos, la mayoría son positivas haciendo mención a sus cualidades deportivas.

068 - Inmigrantes y Extranjeros, ¿dos caras de una misma moneda? Amaia Garcia Azpuru - Profesora Agregada de la Escuela Universitaria de la Cámara Bilbao University Business School (CámaraBilbaoUBS) - amaia.garcia@camarabilbaoubs.com

En este trabajo se analiza la evolución que en la última década ha habido en la sociedad vasca en cuanto a su conocimiento y uso de dos términos totalmente vinculados a los flujos migratorios internacionales que recibe España de forma notoria, desde finales del siglo pasado: inmigrante y extranjero; y la influencia que sobre ello tienen los medios de comunicación.

Con tal objetivo, se ha planteado una investigación empírica de carácter cuantitativo en base a una encuesta realizada en dos centros educativos de la Comunidad Autónoma de Euskadi (CAE), seleccionados a través de un método no probabilístico, en dos momentos diferentes (2009 y 2017); y al rastreo con base en los medios de comunicación de aquellas noticias que recogieran los dos términos anteriormente citados; todo ello con el fin de comprobar si el tratamiento que de ellos se hace en 
los medios es vinculante sobre el imaginario social y su posterior uso popular.

Los resultados obtenidos muestran que, a pesar del transcurso del tiempo y de las campañas anti-rumores y de sensibilización que se están llevando a cabo en el País Vasco en el ámbito de la inmigración, sigue existiendo una gran falla entre lo que la población autóctona entiende por inmigrante y extranjero, y lo que dichos términos son en realidad. En este caso, el mal uso de las palabras por los medios de comunicación no hace sino dar una capa aún más gruesa de imprimación sobre la confusión y la desinformación de la sociedad, que mantiene, interioriza y utiliza erróneamente dos términos que retroalimentan los recelos de la propia sociedad receptora sobre los flujos migratorios recibidos, pudiendo traer consecuencias poco beneficiosas para la cohesión social.

069 - Abordaje y representación de las "Damas Blancas" en los diarios online de zona de frontera - Vianny Katherine Orcasitas Pérez Universidad Pontificia Bolivariana Bucaramanga.

Vianny.orcasitas.2015@upb.edu.co y Giovanni BohórquezPereira - Universidad Pontificia Bolivariana Bucaramanga Giovanni.bohorquez@upb.edu.co

El 5 de julio de 2016 en Ureña, Venezuela, un grupo de mujeres deciden atravesar el puente "Simón Bolívar". La prensa escrita on line registró lo ocurrido como un acontecimiento más de la frontera colombo-venezolana; llamó la atención, que las acciones de protesta eran lideradas por señoras vestidas de blanco.

Las denominadas "Damas Blancas" constituyen de repente un evento y acto político, no interpretado así por la prensa en general. Evidencia de ello, es que tan pronto aparecen en los titulares de prensa, así mismo desaparecen.

El objetivo es analizar las representaciones - por ausencia y/o presencia - de las "Damas Blancas" en el registro de la prensa online desde La Opinion.com.co y El Nacional.com.ve. Para ello nos apoyaremos en los conceptos de Enfoque y Coherencia, planteados por Lluís Gómez 
El fin de un modelo de política

(2001). Además, desde un enfoque exploratorio-descriptivo y un paradigma hermenéutico, usaremos el modelo Krippendorff (1990), el cual se aplicó al corpus constituido por 23 noticias. El material recolectado fue sistematizado de acuerdo a las categorías Responsabilidad y Humanidad definidas por Ethical Journalism Network (2017).

En el rastreo observamos una ausencia de Enfoque (Gómez 2001) en los registros de prensa y de otro lado, un sesgo en las representaciones de las "Damas Blancas" al mostrarlas como simples amas de casa. También encontramos algunas noticias en las que ellas aparecen en su esencia, dándoles así un carácter positivo a sus acciones y mostrándolas tal y como son en su lucha.

Esta indagación apunta a demostrar que la presencia de la "Damas blancas" en un contexto y momento claramente políticos, no es un mero hecho más en la convulsionada vida de la frontera colombovenezolana, sino un hecho de profundas representaciones $y$ repercusiones políticas.

070 - Creaciones literarias como medio de expresión: relatos migratorios y miradas alternativas de la experiencia migratoria entre África y EspañaJosé Manuel Maroto Blanco - Universidad de Granada jmmaroto@ugr.es

Las migraciones entre África y Europa han sido presentadas ante la opinión pública española como un problema social y una amenaza para el país. Términos como "avalancha", "carga" o "extrema presión migratoria" dominan el lenguaje de los medios de comunicación de masas y contribuyen a la "desciudanización" de los migrantes procedentes del continente africano y a la concepción del fenómeno migratorio como un problema de orden público (Fajardo y Soriano, 2016). De acuerdo con Van Dijk, "la función básica propia de un acto de habla es la de hacer cambiar de opinión a un oyente" (1987: 179). Por ello, en este trabajo presentamos una serie de obras literarias, generalmente relatos de vida, que han sido escritas por migrantes negroafricanos/as, como creaciones que tienen un interés muy concreto en mostrar una mirada alternativa del fenómeno migratorio. 
A través del análisis de las obras, pretendemos mostrar la experiencia de los y las migrantes negroafricanas como parte de la experiencia colectiva de un grupo presente que forma parte del país, a fin de humanizar unas experiencias que son sistemáticamente invisibilizadas ante el poder de un discurso racista y xenófobo.

071 - Los "gordos" del sorteo de Navidad, la primera infografía de la prensa tinerfeña - Lucas Morales Domínguez - Escuela Universitaria de Turismo de Santa Cruz de Tenerife lucas.morales@eutur.es

La infografía, siempre a caballo entre el género periodístico y el fotoperiodismo, ha sido un producto difícil de datar en el tiempo, con un origen incierto que divide a la academia a la hora de datar su primera aparición en la prensa. Si bien podría establecerse que su origen en España está en 'Prodigioso volcán de fuego', una obra con 379 años de antigüedad que describe de forma episódica el nacimiento de una isla a través de una erupción volcánica, en Canarias encontramos mayores dificultades para establecer su comienzo, ya que no destaca una tradición infográfica en particular dentro de la prensa, así como tampoco se detecta una continuidad en el tiempo en su producción.

Esta comunicación, que deriva de un trabajo exploratorio sobre la infografía de Canarias, señala que el posible origen de la infografía en la prensa tinerfeña se sitúa en 1926, año en el que la publicación 'La Tarde' narró un hecho noticioso de una manera gráfica innovadora, posiblemente inédita hasta la fecha.

072 - El conflicto no nació con un arma en la mano - Santiago Torres Sánchez - Magister en educación de la Universidad de Los Andes, Comunicador social periodista de la Universidad Santo Tomás con énfasis en educación. Profesor universitario de la Universidad Minuto de Dios - santorres46@gmail.com

Esta ponencia pretende hacer un aporte a los avances que algunos teóricos han hecho en el campo de la formación ciudadana y dentro de este, más específicamente, en el análisis de ciertas causas del conflicto que se consideran fundamentales en el escalonamiento del mismo, 
El fin de un modelo de política

convirtiendo estas bases en detonantes de violencia en escenarios que no necesariamente están involucrados directamente con las dinámicas del conflicto armado en Colombia pero que terminan por aportar a su gestación. Además, llamar la atención del público sobre su reconocimiento y su visibilización, superando el punto de vista de que un conflicto, desde su nacimiento, es armado; provocando así un cambio de postura sobre el mismo para entenderlo desde otras perspectivas y de la misma manera, abordarlo con otras herramientas, formas y actitudes.

Dentro de estas causas, que analizaré en esta reflexión, se encuentran la falta de inteligencia emocional, la cultura de la trampa y la ventaja en condiciones desiguales, y las situaciones en las que el matoneo se convierte en una forma de violencia selectiva promoviendo, de igual manera, conductas violentas en el otro.

Tras identificar en situaciones cotidianas las causas de un conflicto, será posible que este sea asumido como algo que puede surgir de nuestras acciones como ciudadanos convirtiéndonos en actores fundamentales del mismo con un alto compromiso de responsabilidad en él y además como protagonistas de su cambio a través de herramientas y escenarios comunicativos construidos desde una voluntad colectiva.

* 073 - El individualismo como estrategia improvisada en la dispersión de vídeos yihadistas en YouTube - Francisco Ramón Trujillo

Fernández - Universidad De Málaga - frtrujillo@uma.es, Jorge

Gallardo Camacho - Universidad Camilo José Cela, jgallardo@ucjc.edu y Ana Jorge Alonso - Universidad de Málaga - aja@uma.es

El movimiento yihadista global ha modificado su mecánica de difusión ideológica, amplificando su mensaje gracias a la viralidad de las redes sociales y a la determinación de usuarios individuales. Expondremos un adelanto de una investigación cuantitativa para identificar cómo la organización yihadista Jabhat al Nusrah no dispone de la capacidad de controlar plenamente su discurso propagandístico en YouTube. Por el contrario, numerosos usuarios individuales muestran una notable capacidad de generar canales de contenidos sorteando las herramientas 
de restricción o censura de la red social. Se verifica una difusión y reedición de material multimedia de tipo fundamentalmente amateur, violento, con estética yihadista, sin apenas posproducción y con escasa presencia de medios de comunicación tradicionales actuando como amplificadores del discurso violento.

074 - Dimensiones comunicativas en los procesos organizacionales. La etnografía organizacional como recurso metodológico para comprender las interacciones comunicativas - José Alfredo Andrade García Universidad Autónoma Metropolitana-Cuajimalpa afredo@hotmail.com y Rafael Ávila González - Universidad Autónoma Metropolitana-Cuajimalpa - ravila99@gmail.com

Una somera revisión a la historia de los estudios organizacionales dejará ver que la investigación más destacada llevada a cabo en el ámbito organizacional con enfoque etnográfico es la obra de Roethlisberger y Dickson; el estudio de la planta de la Western Electric en Hawthorne, Chicago, EUA; realizado en 1927. Obra destacada por ser la precursora con estas características de abordaje y que además centró la atención en la dimensión humana del trabajador. A casi cien años de aquella iniciativa, vale la pena reflexionar lo que las aproximaciones etnográficas aportan al estudio de las organizaciones y más particularmente, lo qué permiten conocer de las interacciones comunicativas.

Antes, habrá que tener presente que dicha investigación se vio coartada en el momento en que los investigadores empezaron a encontrar informaciones que escapaban al control cuantitativo de las variables del estudio. Tal hecho deja apreciar el pensamiento científico positivista contemporáneo que dominó dicha investigación. En las décadas posteriores no se replicaron investigaciones de este tipo, sino hasta pasados los años sesenta, cuando las metodologías cualitativas cobraron un auge inusitado.

Con estos datos precedentes, bien cabe formular algunas preguntas que pueden abrir distintos horizontes al futuro de los métodos etnográficos para estudiar interacciones comunicativas en las organizaciones. Entre otras, ¿Cómo proceder metodológicamente con las narrativas 
El fin de un modelo de política

obtenidas y la observación realizada en la organización?, ¿A qué marcos teóricos apelar para entender las racionalidades expresadas en las narrativas de los sujetos organizacionales?, ¿Las dimensiones económicas impactan a la comprensión del sujeto?, etc.

Si bien, son válidas todas las preguntas que podamos hacer teniendo presente la experiencia de la Hawthorne, la principal atención del presente escrito se centra en visualizar cómo los abordajes etnográficos en el estudio de los fenómenos comunicativos al interior de las organizaciones, aportan elementos significativos de la experiencia subjetiva que metodologías empíricas cuantitativas no alcanzan a reconocer. De fondo, este texto trata de explicar que las interacciones comunicativas en las organizaciones, para su plena comprensión requieren trascender la racionalidad positivista.

Para lograr tal objetivo, realizaremos la revisión de algunos conceptos fundamentales como organización, comunicación, información y etnografía. Antes, como recurso introductorio abordaremos brevemente el caso de la planta de la Hawthorne y lo que ello significó en los albores del siglo pasado.

075 - Representación mediática de las terapias alternativas en los diarios digitales - Isabel Mendoza-Poudereux - Isabel.Mendoza@uv.es y Lorena Cano-Orón - Lorena.Cano@uv.es - Universidad de Valencia

En el contexto internacional, las noticias sobre terapias alternativas han aumentado y el encuadre utilizado para abordarlas ha sido positivo (Weeks y Strudsholm, 2008), aunque es necesario puntualizar que la opinión sobre el tema de los profesionales de la información está muy polarizada (Arendt, 2016; Cortiñas, 2015). En el ámbito español, Escribà-Sales et al. (2015) detectaron una baja frecuencia de artículos equidistantes sobre la homeopatía y, en general, la prensa española no la consideraba como una terapia eficaz.

El presente estudio tiene como objetivo analizar el tratamiento informativo de los titulares de las noticias sobre las cinco terapias complementarias más usadas en España (OTN, 2008), clasificadas por 
el Ministerio de Sanidad (2011) como que repercuten directamente a la salud: acupuntura, drenaje linfático, homeopatía, quiromasaje y reflexología podal. Para ello, se trabaja con un corpus compuesto con todas las noticias publicadas en periódicos digitales de cobertura nacional, concretamente en los 391 medios que recoge la base de datos MyNews, que mencionan alguna de esas terapias durante el periodo temporal de 2015-2016. En total se cuenta con 1.788 noticias netas. A partir de un análisis de contenido se analiza la tendencia informativa sobre estas terapias. Las categorías de análisis utilizadas son: favorable, para aquellas que tratan la homeopatía como una cura; neutro, para el tratamiento aséptico o institucional; escéptico: para el tratamiento crítico con esta terapia; y equidistante, para el tratamiento que revela la controversia sin posicionarse. Los resultados muestran que el tratamiento mayoritario (52\%) es neutro, mientras que los de encuadre favorable $(20 \%)$ y escéptico $(19 \%)$ se encuentran relativamente proporcionados. Asimismo, es curioso también destacar que la gran mayoría de las noticias son monotemáticas, es decir, el porcentaje de noticias que mencionan más de una terapia en el texto es solo del $8 \%$.

076 - Análisis sobre procesos y mecanismos de diferenciación personas de nacionalidad extranjera desde la normativa sobre extranjería y empleo de hogar. El caso de las empleadas de hogar de nacionalidad extranjera en España - Rosalía López Fernández - rosalf@ugr.es y José Manuel Maroto Blanco - Universidad de Granada jmmaroto@ugr.es

A través del análisis de los marcos normativos desarrollados en España sobre extranjería y empleo de hogar, en este texto se quieren poner de manifiesto una serie de prácticas y mecanismos a través de los cuales se desarrollan procesos de diferenciación de la población de nacionalidad extranjera y, más específicamente, de aquellas personas que trabajan en el sector del servicio doméstico. En concreto se abordará cómo desde la propia legislación se establecen distintitos procesos de estratificación y segregación; cómo la categoría analítica "nacionalidad" puede ser tomada como un elemento discriminador para el acceso al empleo; se abordarán igualmente los procesos de etnificación de las mujeres empleadas de hogar (y otras intersecciones) que redundan en una mayor estratificación, deslegitimación, 
El fin de un modelo de política

generización y pauperización de este colectivo. En las conclusiones se señalará la importancia de seguir profundizando en los mecanismos de diferenciación y en la necesidad de seguir poniendo de manifiesto las consecuencias que se derivan desde los marcos normativos a nivel simbólico e ideológico, así como en la praxis social.

077 - El impacto de las promociones en precio en la venta de productos complementarios - Sandra Lizzeth Hernández Zelaya-Universidad Pontificia de Salamanca- Slhernandezze@upsa.es

La gestión de las categorías de productos en el punto de venta requiere una buena comprensión de la relación entre las categorías porque las decisiones que afectan a una categoría pueden tener consecuencias en otras complementarias. Para evaluar las complementariedades entre categorías, esta investigación se centra en las promociones en precios que pueden producir un efecto positivo en las categorías complementarias y pueden tener un efecto negativo en las categorías sustitutas; el efecto complementario también podría ser asimétrico. En estas relaciones complementarias es importante considerar la influencia de la marca en la categoría, la cual podría fortalecer las relaciones en los productos complementarios.

La investigación realiza diferentes experimentos para probar las hipótesis. Diferentes consumidores alemanes fueron asignados al azar para responder a diferentes escenarios propuestos. Los resultados muestran que es importante considerar las complementariedades de las categorías al diseñar el plan de marketing y las promociones. Así mismo se muestra evidencia sobre las asimetrías complementarias que pueden existir en productos complementarios. La investigación brinda información relevante para los distribuidores en la gestión de sus categorías y para los fabricantes en la promoción de los productos complementarias donde tengan presencia.

078 - Los peligros de la realidad percibida en la era de la posverdadIgnacio Blanco Alfonso - Universidad CEU San Pablo iblanco@ceu.es 
Los seres humanos estamos instalados en un sistema de creencias que condiciona nuestra percepción de la realidad. Entendemos "creencia" en el sentido orteguiano, como construcciones intelectuales que determinan nuestro modo de percibir la realidad y que, a diferencia de las ideas, no sometemos a duda (José Ortega y Gasset, Ideas y creencias, 1925).

Esta noción de creencia coincide con la que Leon Festinger desarrolla en los años 50 al formular la "Teoría de la Disonancia Cognitiva", según la cual "un hombre convencido es un hombre difícil de cambiar" (Festinger, When Prophecy Fails, 1957). La creencia arraigada en el ser humano le lleva a ratificarse una y otra vez en sus convicciones, aunque los hechos indiquen lo contrario. Ya Walter Lippmann había señalado en su tratado Public Opinion (1920) que "cuando creemos que algo tiene que ser verdad, casi siempre encontramos casos en los que lo es, o personas que lo creen así”.

El problema de la percepción se sitúa en la raíz de la comunicación social y nos invita a considerar esta acción humana desde la fenomenología y la psicología social. No es, sin embargo, una cuestión de interés exclusivamente filosófico. Cuando confirmamos que nuestra percepción de la realidad determina nuestras decisiones políticas, pasa a convertirse en un problema de gran calado en las democracias modernas.

Esta comunicación propone un análisis de la campaña política del Brexit, basada en una propaganda (fake news) dirigida a exacerbar las falsas creencias de los británicos (post-truth) en dos pilares básicos que determinaron el resultado: la inmigración y la relación económica con la UE. A raíz de los estudios demoscópicos de IPSOS MORI (2016), se propone una relación de los referentes informativos enfatizados en dicha campaña con los resultados del referéndum que ha llevado a Reino Unido a abandonar la Unión Europea.

079 - Factor emocional y participación democrática en la sociedad digitalizada: sombras y luces de un nuevo modelo de hacer política - Luis Nuñez Ladevéze - ladeveze@ceu.es - Universidad CEU San Pablo, Margarita Núñez Canal - Universidad Camilo José Cela. 
El fin de un modelo de política

Madrid y José Antonio Irisarri Núñez. Centro Universitario

Villanueva-Universidad Complutense de Madrid

Los fracasos del comunismo y del maoísmo acabaron con las ilusiones empeñadas en el proceso ilustrado de alcanzar un mundo igualitario. Esta frustración coincide con el comienzo de la sociedad digital. No es que ambas cosas estén relacionadas por que ocurran en las mismas fechas. Es que la capacidad de cambio de los nuevos medios proporcionó paradójicamente un nuevo e inesperado servicio a los que pensaban en sociedades utópicas donde la igualdad social fuera a la vez el sello de una democracia participativa

Desde diversas perspectivas se ofrece un confuso abanico de propuestas para adoptar las posibilidades de comunicación abiertas por las nuevas tecnologías. Bien un proceso de empoderamiento participativo, bien de adaptación de la representatividad democrática a las vías abiertas por la digitalización.

En ese nuevo entorno digital, los procesos burocráticos se extienden y se simplifican. Las instituciones democráticas quedan forzosamente expuestas a ensayar iniciativas diversas para aplicar las nuevas tecnologías. La democracia representativa es puesta en cuestión. Responde a una fase histórica en que las grandes distancias de los espacios geográficos impedían la comunicación instantánea y generalizada. Los proyectos de renovación propenden a sustituir la democracia indirecta por la directa, la débil por la fuerte, la jerárquica por la igualitaria.

Pero hay otros muchos aspectos que concurren en el nuevo escenario. El auge de los populismos, la invasión de la postverdad a través de las redes, la continuidad de la sociedad de masas en la cultura digital.. El sujeto deliberativo ilustrado, es ahora un ciudadano observador de un espectáculo social. Las emociones y los sentimientos sustituyen a la deliberación y al debate. La mirada, más que el cerebro, puede ser el órgano que decida el voto. La democracia ocular se pone al servicio tanto de la democracia directa como de la representativa. 
Comprobado que las reglas del método cartesiano no dan más de sí, el pensamiento hace tiempo que volvió la mirada a Aristóteles. Damasio, Nussbaum, Ryle, el pragmatismo de los actos de habla, han convergido en este diagnóstico. La retórica, donde el ethos nutre al pathos, y viceversa, gana la partida a la razón pura. Los sentimientos hacen valer su fuerza en la vida pública. El ciudadano posmoderno descubre que, tanto como un ser racional, es un ser emocional. Lo dijo Aristóteles hace dos milenios y medio. Describe ahora Zubiri cómo la razón es sentiente.

080 - La defensa de intereses en el sector sanitario. Un análisis de la presencia en medios de la campaña sobre bebidas azucaradas - María Sánchez Valle - mvalle.fhum@ceu.es y Verónica Crespo Val Universidad CEU San Pablo - veronicacrespo3@gmail.com

La defensa de intereses ante las administraciones es una labor que vienen desarrollando durante décadas organizaciones y asociaciones de todos los sectores. En una campaña de presión orquestada por un grupo de interés, la estrategia de comunicación es una piedra angular y los medios de comunicación constituyen un adecuado termómetro para medir e indagar acerca de las acciones de lobbying llevadas a cabo por los grupos.

El 11 de octubre de 2016, la Organización Mundial de la Salud publicó un informe en el que alertaba de la necesidad de aplicar una tasa especial a las bebidas azucaradas. A partir de ahí, industria, asociaciones de dietética, organizaciones médicas y otros actores se movilizaron para defender su postura.

Este estudio pretende conocer la presencia, el tratamiento y el enfoque ofrecido por los medios de comunicación en esta campaña. Se ha realizado para ello un análisis de contenido a noticias publicadas en cinco medios de comunicación españoles en el periodo comprendido entre octubre de 2016 (publicación del informe de la OMS en el que alertaba sobre la necesidad de aplicar una tasa a bebidas azucaradas) y junio de 2017 (aprobación de los Presupuestos Generales por el Gobierno de España, donde se constata que tal tasa no ha sido aplicada). Las acciones de comunicación como la publicación de 
El fin de un modelo de política

informes y las declaraciones en foros públicos son las que consiguen más cobertura por parte de los medios de comunicación.

081 - Entre la solidaridad y la defensa del territorio. Europa ante la crisis de refugiados a través los medios de comunicación - Maritza Sobrados León - sobrados@us.es y Patricia Muñoz Chacón - Universidad de Sevilla- isapat2017@gmail.com

Las secuelas de la primavera árabe y los conflictos en Libia, Siria o Irak provocaron un goteo constante de personas que huían con destino a una Europa relativamente acostumbrada a los flujos de migración económica irregular que se vienen dando desde los años 90. Sin embargo, el desarrollo del conflicto en Siria ha dado lugar a una auténtica riada de personas que ha llegado a desbordar a los países europeos.

En este artículo abordamos lo que se ha llegado a denominar como "crisis de refugiados" a través de las noticias publicadas en el diario El País en 2015, un año determinante para la agenda política de la UE sobre política de admisión y asilo. Con el objetivo de analizar la confluencia de los mensajes de la elite política europea a través de los medios de comunicación, seleccionamos para su estudio acontecimientos claves de 2015 tales como el trágico suceso en el Mediterráneo de abril, la muerte del pequeño Aylan Kurdi en septiembre, que supuso un despertar de conciencias, o el cierre de fronteras de Hungría en ese mismo mes. Los medios de comunicación recogen esta situación de crisis ampliamente y no sin falta de crítica, sin embargo, no pasa desapercibido que aunque la solidaridad aparece como un término muy utilizado por los actores políticos, el mensaje central se orienta al control y protección de las fronteras dentro de una retórica identitaria excluyente.

082 - Imagen y representación del liderazgo politico en Twitter. Análisis de la gestión de los partidos políticos españoles en la campaña electoral de 2016 - Pablo López-Rabadán - rabadan@uji.es y Hugo

Doménech-Fabregat - Universidad Jaume I - hdomenec@uji.es 
la gestión de la fotografía ha representado, tradicionalmente, un ámbito clave para construir una imagen estratégica del líder político. En el contexto digital, las redes sociales se han convertido en una potente herramienta comunicativa que abre nuevas posibilidades para la producción y distribución autónoma de imágenes por parte de los partidos. En concreto, características como su inmediatez, riqueza multimedia, o capacidad de viralización, convierten a redes como Twitter o Instagram en plataformas óptimas para el desarrollo de estrategias específicas sobre la imagen y liderazgo político.

El objetivo de esta comunicación es analizar la gestión de la imagen realizada por los partidos políticos españoles en Twitter en el contexto de la campaña electoral de 2016. A partir de una tipología propia sobre la gestión de la fotografía política, la metodología utilizada se basa en la técnica de análisis de contenido y contempla el estudio de tres cuestiones concretas relativas al liderazgo: principales atributos personales y profesionales de los candidatos; y grado de espectacularización en la fotografía. La muestra analizada se centra en las cuentas oficiales de los cinco principales partidos en España a nivel estatal (PP, PSOE, Podemos, Ciudadanos, e Izquierda Unida) y sus líderes respectivos. A nivel temporal, se han seleccionado las dos semanas de la campaña de las elecciones generales del 26 de junio de 2016. Este contexto electoral resulta muy relevante debido al equilibrio en las expectativas de resultados y a la alta competitividad entre partidos tradicionales y nuevas formaciones políticas.

Los resultados iniciales confirman un uso intenso y estratégico de la fotografía en Twitter por parte de los partidos españoles, donde prima lo profesional sobre lo personal, pero donde los recursos expresivos de base espectacular (multimedia, vida cotidiana, estilo directo, humor, etc.) adquieren una presencia habitual e innovadora. Este trabajo se incluye dentro del proyecto de investigación CSO2014-52283-C2-1-P, financiado por el Ministerio de Economía y Competitividad (Plan Estatal 2013-2016).

083 - La participación social, los usos mediáticos y los riesgos de los adolescentes y jóvenes a través de Internet - Rebeca Martín Nieto Rebeca.martin@urjc.es - Ricardo Vizcaíno Pérez - 
El fin de un modelo de política

Ricardo.vizcaino@urjc.es y Yolanda Pastor Ruiz yolanda.pastor@urjc.es - Universidad Rey Juan Carlos

La comunicación revisa los estudios realizados en la última década a partir de grupos de discusión que afrontan el consumo de medios, los riesgos y la participación ciudadana de menores y jóvenes a través de internet como fase de preparación para la planificación y el trabajo posterior de los diferentes grupos de discusión que se van a realizar,en el marco de un proyecto nacional.

Los resultados permiten describir temáticas predominantes en las investigaciones, características metodológicas, así como una taxonomía de las mismas. Los resultados son dispares: en los trabajos relativos al uso de internet entre los menores y jóvenes, las principales temáticas abordadas hacen referencia a los perfiles de uso y motivaciones de los usuarios, la incorporación progresiva de internet en la vida cotidiana y las experiencias de apropiación, las relaciones sociales a través de las redes sociales, la competencia digital y la brecha digital de género. En cuanto a los riesgos, las investigaciones se centran sobre todo en temas relativos a las posibles consecuencias del uso excesivo de las TIC, así como de los usos para fines poco éticos entre iguales. Por su parte, los estudios sobre ciudadanía digital tratan ésta fundamentalmente desde la perspectiva de la participación política.

La comunicación se centra en el análisis de las investigaciones que han utilizado el grupo de discusión como parte fundamental de su metodología en este campo. Se ha observado que es frecuente la utilización de metodologías cuantitativas y cualitativas, que habitualmente combinan la encuesta con los grupos de discusión. Y es habitual el trabajo con muestras de características variadas desde los 12 años hasta 24 años, aunque las hay que se extienden hasta los 30. Tras la revisión se discute críticamente diferentes propuestas de diseño de grupos así como los tópicos que deberían estar presentes en cada uno de ellos.

084 - Lobby social y las redes sociales. El caso de Plataforma Stop Impuestos de Sucesiones - Emilia Smolak Lozano; Paloma 
Villafranca; Ruth Gómez de Travesedo y Antonio Castillo

Esparcia, Universidad de Málaga.

Desde el boom de las redes sociales, los ciudadanos fueron equipados con una potente herramienta de influencia social que favorece un activismo social por las cuestiones de alta importancia política y social para los grupos involucrados. Uno de estos ejemplos es el caso de plataforma ciudadana que emprende una variedad de acciones de presión social hacia un cambio dentro del marco de los impuestos de sucesiones dentro de Andalucía. Este caso resalta por el amplio abanico de las estrategias de tipo "grassroot"y lobby social, a través de su página de Facebook, destacando el impacto no sólo en autonomía sino también en nivel nacional. Para identificarlas, además de definir el grado de rendimiento e influencia de esta plataforma ciudadana de lobby social, hemos recurrido a una metodología de estudio de caso que conlleva varias técnicas de estudio sobre todo el análisis del contenido y analítica web. Las conclusiones determinan que la presencia y comunicación en Facebook de esta plataforma le otorga el elevado grado de repercusión en esta red y sirve como el núcleo de una multitud de actividades offline y en otros medios de comunicación.

085 - La Competencia Comunicativa en el marco de la Competencia Digital - Gustavo Antonio Huerta; Carlos Arturo Torres Gastelu Universidad Veracruzana, México; Joel Angulo Armenta Instituto Tecnológico de Sonora.

El objetivo de la presente investigación giró en torno a la conceptualización de la competencia comunicativa en el marco de la competencia digital, retomando su origen en la lingüística y su reconceptualización generada a partir del empleo de las TIC en la educación. Para ello se realizó una investigación documental que implicó la revisión de literatura en bases de datos científicas, evaluación y selección de documentos como libros, tesis y artículos de revista que se analizaron y dieron la pauta para la configuración de este trabajo, las líneas temáticas giraron en torno al origen del término competencia comunicativa, su inclusión como competencia transversal en el ámbito educativo y en los modelos o marcos de la competencia digital. A partir de ello se encontró que el concepto de competencia comunicativa se 
El fin de un modelo de política

ha fortalecido ante el auge tecnológico y en este contexto resulta imprescindible su desarrollo en todas las personas, ya que además del uso y manejo correcto de la lengua y gramática en al menos la lengua materna, contempla actualmente el manejo de dispositivos para comunicarse en entornos digitales, mediáticos y audiovisuales. Con lo anterior, se busca aportar en la ampliación del alcance de la competencia comunicativa, dando pauta a la conformación de nuevos marcos de la competencia digital que incluyan descriptores más específicos y niveles de desempeño de la competencia comunicativa.

086 - "Esto me suena": el recitado de letras de canciones como ready-made publicitario - Eduardo Viñuela - Universidad de Oviedo eduvisu@gmail.com

En los últimos años han proliferado las estrategias publicitarias relacionadas con la música. La música no es simplemente el sonido de fondo de un spot, tampoco el soporte para cantar las bondades de un producto o servicio en forma de jingle. Ahora, la música se concibe como una herramienta con entidad propia en la construcción de mensajes. Musicidad, "audio branding", "literal versions", son algunas de las estrategias que se han generalizado recientemente. La exploración de fórmulas para captar la atención del espectador da como resultado nuevos formatos que desafían las fronteras que definen los lenguajes.

En este contexto, planteamos un acercamiento al recitado de letras de canciones de música popular como texto de un spot publicitario. Esta estrategia ha sido puesta en práctica en recientes campañas publicitarias de nuestro país: Vodafone, HBO, Aldi, Seguros Reale, etc. El objetivo de esta investigación es analizar las implicaciones que esta forma de ready-made publicitario tiene tanto para la marca como para la canción y el artista implicado. Así, estudiaremos el grado de musicalidad que mantiene el texto, su tratamiento poético y su funcionamiento como mecanismo de apelación a un target definido.

087 - "Branded content y crisis de los media" - José Vicente García Santamaría - Universidad Carlos III jvicente.santamaria@telefonica.net 
El branded content o marketing de contenidos se ha convertido, sin duda, en una de las herramientas más eficaces para conectar con la audiencia, con "campañas-estrella" que han atraído a un buen número de prescriptores (Red Bull, Estrella Damm, Jhonny Walker...) en los últimos años. Incluso algunas de las marcas que acabamos de mencionar mantienen ventajosos acuerdos con algunas de las grandes cadenas generalistas mundiales.

En la prensa española, el branded content se viste con el ropaje de los contenidos "pagados" y se confunde en algunos diarios de referencia con el contenido habitual del medio. Existen contenidos aparentemente periodísticos- que ocupan localizaciones preeminentes tanto en la prensa escrita como on line; por ejemplo, abriendo las páginas de la sección de nacional. Es de temer, por tanto, que por la crisis de los medios y de los grupos que los soportan, sea cada vez más habitual el uso habitual de esta técnica. Y es previsible también una mayor invasión de noticias pagadas en radio y televisión.

Esta ponencia pretende, por tanto, analizar las razones por las que los media en España -incluidos los grandes diarios de referencia- se han sometido a las exigencias publicitarias de las empresas; una intromisión que va en detrimento de la necesaria credibilidad y calidad del medio y de sus contenidos.

088 - Medios de comunicación digital y derecho al olvido en la Unión Europea - Alicia Chicharro - Profesora Contratada Doctora de la Universidad Pública de Navarra alicia.chicharro@unavarra.es

En mayo de 2014, el Tribunal de Justicia de la Unión Europea emitió una sentencia histórica en la que reconocía el denominado derecho al olvido. El caso enfrentaba a Google, principal buscador de Internet, con la Agencia Española de Protección de Datos y un particular que deseaba borrar del entorno digital una notificación de embargo dirigida contra él y publicada en un periódico. Gracias a este derecho, hoy regulado en el artículo 17 del nuevo Reglamento General de Protección de Datos, los ciudadanos europeos pueden ocultar las huellas que han 
El fin de un modelo de política

ido dejando en la red si esa información les causa algún tipo de perjuicio o lesión.

Sin embargo, cuando se trata de instituciones periodísticas, las obligaciones que se derivan de ese reconocimiento se verán matizadas por las circunstancias concretas del caso y la necesidad de garantizar la protección de otros derechos, como la libertad de información y de prensa.

En la presente comunicación analizaremos algunos de los desafíos que conlleva la consagración del derecho al olvido para los medios de comunicación digital ante la inminente entrada en vigor del citado Reglamento General de Protección de Datos el próximo mes de abril de 2018.

089 - Interacción entre medios convencionales y agregadores de noticias. El caso de 'Menéame' - Idoia Camacho Markina; Santiago Urrutia Izaguirre; Begoña Zalbidea Bengoa y Jose Mari Pastor González, Universidad del País Vasco/Euskal Herriko Unibertsitatea.

La web 2.0 ha propiciado la interacción de los usuarios en el espacio comunicativo, lo que ha hecho que pasen de ser audiencia - pasiva y receptora- a ser generadores y distribuidores de los contenidos informativos. Gracias a los agregadores de noticias, personas anónimas productoras de contenido viral alcanzan igual o mayor atención por parte del público que los tradicionales contenidos elaborados por las empresas mediáticas. Además, ya no son solo los medios de comunicación los que difunden sus noticias, sino que los propios usuarios recopilan las informaciones para su publicación. Así, aumentan las visitas de los medios, no solo a partir de los agregadores, sino también a partir de las redes sociales a través de las que se difunden los enlaces de los agregadores. Por otro lado, se propicia un cambio en los hábitos de consumo informativo en la red, una nueva manera de consultar información por parte de los usuarios, que ya no acuden directamente a los medios. 
Esta comunicación analiza la procedencia de las noticias publicadas en la portada de Menéame, el agregador de noticias de mayor éxito en habla hispana. Su objetivo principal es conocer el origen de las informaciones que ha publicado a lo largo de los diez primeros años de su existencia (2006-2015), para averiguar cuáles son los medios de comunicación más enlazados por los usuarios, aquellos que más atraen su atención. El segundo objetivo es conocer la evolución del peso de los diferentes medios durante el periodo analizado.

Los resultados indican que los medios convencionales (prensa, radio y TV) son los más enlazados, con un 38,1\% de las noticias, seguidos por los blogs $(22,9 \%)$, los portales web $(14,8 \%)$, los medios exclusivamente digitales $(15 \%)$, las redes sociales $(4,2 \%)$, las agencias de comunicación $(3,5 \%)$ y otros medios $(1,5 \%)$.

* Esta investigación forma parte del Proyecto del Ministerio de Economía y Competitividad CSO2014-59077-R y del Proyecto de la UPV/EHU GIU/27.

090 - Internet, Comunicación y Capital Social en red: retos para las organizaciones en el contexto digital - Roberto Alejandro López Novelo y María Antonieta Rebeil Corella - Universidad Anáhuac México

Con la llegada de Internet, asistimos a una revolución de carácter técnico y social, donde las relaciones y la comunicación, adquieren una nueva dimensión no sólo para los usuarios de la red, sino también para las organizaciones. Esto se debe a que, esta red modifica sustancialmente los procesos comunicativos, expresivos, lúdicos, laborales, económicos, sociales, políticos, educativos, culturales y empresariales, de un gran segmento de la población.

Lo anterior ha ocasionado que Internet sea conceptualizado como un nuevo espacio para la construcción y distribución del capital social, que puede ser aprovechado tanto por los usuarios como por organizaciones de diversa índole. Esto se debe fundamentalmente a que Internet, a través de los diversos entornos digitales que ofrece y de la aparición de la web 2.0 con toda la gama de aplicaciones con las que cuenta, presenta 
El fin de un modelo de política

posibilidades de comunicación y relación social, que están revolucionando la forma en la que las organizaciones pueden aprovechar el capital social acumulado en entornos como las redes sociodigitales, en las que es posible generar confianza, lazos fuertes y débiles con públicos externos, para cumplir con su visión, misión y filosofía.

Este contexto representa un reto altamente complejo para las organizaciones, ya que estas tienen que hacer una gestión cada vez más eficiente de los entornos y herramientas digitales para comunicarse no sólo con públicos que son más activos, participativos, demandantes y exigentes; sino también, mejorar la gestión integral de la comunicación dentro de una organización. Así, esta aproximación en la que se vincula a Internet, el Capital Social y las Organizaciones, permite ampliar los alcances de la Comunicación Integral como parte de un enfoque teórico-conceptual que trata de responder a los retos emanados del actual contexto digital.

091 - Comunicación y mujeres inmigrantes: las lenguas de las trabajadoras filipinas - Maria Cama - Universidad de Granada mariacama@correo.ugr.es

Los flujos migratorios en Italia se caracterizan por una significativa presencia de mujeres. Entre este colectivo se pueden encontrar a numerosas mujeres procedentes de Filipinas. Para la mayor parte de ellas, la experiencia migratoria se caracteriza por la mejora de las condiciones económicas, pero al mismo tiempo por la dificultad de adquirir prestigio social. A este respecto, un importante papel lo desarrollan el uso de la lengua italiana y el uso de las lenguas de origen que desafortunadamente no tienen el mismo reconocimiento en la sociedad de acogida.

En este trabajo pretendemos abordar la cuestión de las lenguas de las mujeres "extranjeras inmigrantes" a través de los hábitos lingüísticos de un grupo de mujeres filipinas que viven en la ciudad de Mesina (Sicilia). Trataremos de hacer una serie de consideraciones sobre las peculiaridades que durante muchos años han vivido estas mujeres como situaciones de "invisibilidad" y "segregación". 
El análisis de las relaciones entre prácticas cotidianas y condiciones de vida en la sociedad receptora y de las explicaciones que las mismas mujeres dan sobre su gestión de las lenguas ponen de manifiesto sus dificultades, pero también la naturaleza dinámica de la comunicación y la posibilidad de que las estrategias comunicativas desarrolladas produzcan éxitos en el tiempo. En las conclusiones se señalará que en la experiencia de las mujeres entrevistadas las lenguas no constituyen un impedimento para la actuación del proyecto migratorio y que realidades aparentemente incomunicables pueden evolucionar hacia situaciones de encuentro y formas de convivencia pacífica.

\section{2 - Historia organizacional del fútbol de una determinada urbe: caso} Loja-Ecuador - Pedro Camilo Monteros Valdivieso y Luis Javier Ontaneda Vivanco - Universidad Nacional de Loja luis.j.ontaneda@unl.edu.ec

La presente ponencia proyecta lo resultados de la investigación realizada sobre la organización del fútbol profesional y amateur de una determina urbe, caso Loja-Ecuador. Fue ejecutada como un módulo del macroproyecto "Propuesta metodológica para la construcción oral, escrita y audiovisual de la historia del fútbol de una determinada población, caso Loja-Ecuador" que fue ejecutada durante 2017 por investigadores de la Carrera de Comunicación Social de la Universidad Nacional de Loja. Hace más de sesenta años la organización institucional deportiva tuvo cabida en esta ciudad del sur del Ecuador, pero hasta la actualidad no existen datos, información, documentos y registros, debidamente ordenados ni sistematizados sobre la organización del fútbol en la urbe, lo que dio la apertura al objetivo de conocer, ordenar y recuperar información organizacional e histórica del Fútbol en la ciudad de Loja. En la realización de este estudio se ha aplicado la metodología cualitativa, usando la técnica de la entrevista como instrumento para recuperar el conocimiento a través de testimonios de directivos y deportistas que han pasado por las instituciones encargadas de regir el deporte y específicamente el fútbol en la ciudad. Además, se realizó la recolección de información y digitalización de documentos oficiales con la finalidad de exponer la 
El fin de un modelo de política

evolución de una estructura organizativa, avances, desarrollo y estado actual de la organización del fútbol de la urbe estudiada.

093 - Tratamiento informativo y uso de los recursos de la Web 2.0 en la divulgación cientifica y de la pseudociencia: Estudio comparativo de las principales revistas españolas - Dr. Santiago Tejedor Calvo santiago.tejedor@uab.cat y Marta Portalés Oliva - Universidad Autónoma de Barcelona, España - marta.portales@uab.cat

El siguiente estudio pretende analizar la ecología comunicativa online y el tratamiento informativo de 6 revistas de tirada en papel sobre divulgación científica y pseudociencia.

La investigación de carácter exploratorio responde a las siguientes preguntas de investigación: ¿Qué instrumentos y recursos informativos propios dela Web 2?0 utilizan estas revistas en su medio online? ¿Qué atributos informativos y tipología de fuentes de información predominan en los contenidos en la red? La metodología está compuesta por un análisis de contenido cuantitativo y cualitativo, en primer lugar, se hace una apreciación general del perfil y presencia online de estos medios. Posteriormente se elabora un análisis de contenido cuantitativo y cualitativo de 232 unidades de análisis, se trata de una muestra probabilística seleccionada de forma aleatoria perteneciente a un universo de 1434 publicaciones en Web, Facebook, Twitter, Youtube e Instagram durante una semana de octubre 2017. Los resultados demuestran que la adaptación al medio online es básica, puesto que no se emplean prácticamente elementos propios de las redes sociales, ni de la web 2.0. Existe una gran presencia de imágenes, pero abundan las noticias acompañadas de vídeos o infografías y tampoco de otro tipo de interactivos, además la explotación de datos estadísticos de forma visual es inexistente. El tratamiento informativo también tiene bastantes aspectos a mejorar, una gran parte de las noticias no tiene autoría y las imágenes que las acompañan no suelen tener fuentes de procedencia. Finalmente, el trabajo aporta una serie de pautas y recomendaciones sobre el periodismo de divulgación científica online a partir de los resultados observados. 
094 - La pregunta por el cuerpo en la formación para la ciudadanía.

Estudios de casos - Carlos Eduardo Sanabria Bohórquez -

Universidad Jorge Tadeo Lozano, Colombia -

carlos.sanabria@utadeo.edu.co

La presente propuesta de ponencia surge de la práctica pedagógica y docente en la educación superior, en el marco de una oferta de asignaturas de temáticas humanísticas y artísticas en el ciclo o componente de formación básica o transversal para estudiantes de diversos programas de formación profesional, que hace énfasis en el desarrollo de capacidades ciudadanas, así como de lectura crítica y expresión escrita.

En cuanto a sus antecedentes y presupuestos teóricos, parte de una comprensión de la educación como servicio público y como acción y experiencia de formación política, en el sentido de la construcción de capacidades ciudadanas de pensamiento crítico, argumentativo, cuestionador y tendiente a la empatía o comprensión imaginativa de la alteridad; por otra parte, se hace partícipe del debate que autores como Martha Nussbaum (USA), Robert Redeker (Francia) y Guillermo Hoyos (Colombia), plantean en torno a la actual crisis de la educación en términos de la supresión o debilitamiento de la formación humanística y artística y sus efectos nocivos en la formación de capacidades de ciudadanía democrática deliberante y crítica; y, finalmente, propone una reflexión (sobre la base de la exposición y el análisis de unos ejemplos situados) sobre prácticas pedagógicas ensayadas desde el diálogo entre las artes, la filosofía y la comunicación, que pueden ofrecer posibilidades de formación y transformación de las emociones y el pensamiento para una acción política democrática.

095 - Intercruzes e interacciones entre comunicación, cultura y deporte Sergio Ricardo Quiroga - Instituto Cultural Argentino de Educación Superior (ICAES) sergioricardoquiroga@gmail.com

En este trabajo, buscamos analizar el desarrollo latinoamericano de los fenómenos de carácter interdisciplinarios que son conformados por el espacio singular integrado entre la cultura, la comunicación y el 
El fin de un modelo de política

deporte. En los últimos veinticinco años se ha sucedido un dinámico desarrollo de ese campo interdisciplinario e híbrido con débiles fronteras. Existe en la academia un creciente reconocimiento y conocimiento académico de amplias temáticas existentes entre la comunicación y el deporte y un número creciente de estudios que ensanchan sus fronteras y echan luz sobre estos fenómenos.

096 - Product Placement: Hibridación entre contenido y publicidad en la ficción española y británica - Celina Navarro navarrobosch01@gmail.com y Sheila Guerrero - Universitat Autònoma de Barcelona - sheila.guerrero@uab.cat

El product placement ha aumentado su presencia en las ficciones europeas desde su regulación por la Directiva Europea de Servicios de Comunicación Audiovisual (2010). Mientras que en España esta práctica ya era muy habitual antes de la normativa, en Reino Unido no estaba tolerada y la entrada en vigor de la ley supuso un cambio en las prácticas de los productores domésticos. Tras varios años de su implementación, en esta comunicación nos proponemos analizar la presencia y uso del product placement en las series de ficción más vistas en Prime Time haciendo una comparativa entre las cadenas comerciales españolas y británicas. Se ha realizado un análisis de contenido cuantitativo para determinar el volumen y duración del product placement, los sectores de los productos anunciados y su modo de presentación en pantalla. Los resultados indican que esta práctica está más extendida en las ficciones españolas remarcando la hibridación entre los contenidos culturales y los mensajes comerciales.

097 - Transparencia y participación ciudadana. Análisis de las berramientas de participación en las webs de los principales municipios de Baleares (2016-2017) - Dra. Ángeles Durán Mañes - Centro de Enseñanza Superior Alberta Giménez-Universidad Pontificia Comillas - aduran@cesag.org y Dr. Joan Josep Matas Pastor

La información es esencial en una sociedad democrática y la comunicación y la transparencia de las instituciones públicas con la ciudadanía debería ser una obligación ineludible. En diciembre de 2015 entró en vigor la Ley de Transparencia 19/2013 que obliga a las 
administraciones central, autonómica y local a publicar en sus páginas web toda la información de interés para el ciudadano. Esta comunicación tiene como objetivo básico elaborar un diagnóstico sobre la transparencia de las webs de las principales corporaciones locales de las Islas Baleares que son capitales administrativas de cada una de las islas. Esto es: Palma, Mahón, Ibiza y Formentera. Más concretamente, se aborda un estudio cuantitativo-cualitativo de las herramientas de participación ciudadana que ofrecen las webs de los ayuntamientos antes mencionados.

Para ello utilizamos 7 de los 52 indicadores creados y validados en el Laboratorio de Comunicación Pública Local de la UAB (Mapa Infoparticipa http://www.mapainfoparticipa.com/index/home/4) y que hacen referencia a las herramientas de participación ciudadana. De cada uno de estos indicadores se analizan tres aspectos. Primero, saber qué información y contenido ofrecen. En segundo lugar, dónde están o deberían estar ubicados en la web. Y, tercero, recomendaciones cualitativas que deben ofrecer.

Pretendemos saber cómo han evolucionado estos indicadores durante los años 2016 y 2017. Por este motivo, los momentos de análisis son dos. La primera oleada se realizó durante el mes de enero de 2016 e incluyó 22 ayuntamientos con más de 10.000 habitantes de las Islas Baleares, en una investigación que formaba parte del proyecto $\mathrm{I}+\mathrm{D}+\mathrm{I}$ (CSO2013-46997-R) "Comunicación pública, transparencia, rendición de cuentas y participación en los gobiernos locales" (Globalcom). La segunda oleada se desarrolla durante el mes de noviembre de 2017 de forma autónoma por los firmantes.

098 - Pseudociencia y Sociedad en España: ¿Qué hemos aprendido hasta ahora? - Sergi Cortiñas Rovira - Grup de Recerca en Comunicació Científica (GRECC) - Observatori de la Comunicació Científica (OCC) - sergi.cortinas@upf.edu y Miguel Angel Moya Arrabal - Universitat Pompeu Fabra (UPF) - Grup de Recerca en Comunicació Científica (GRECC) miguel_1213@hotmail.es 
El fin de un modelo de política

La pseudociencia es un fenómeno de masas que se manifiesta de forma oportunista con un mismo sentir: extender un desconocimiento dogmático mediante la falsa percepción de estatus científico. A través de teorías invalidadas por el método científico y el apelo a las emociones, la pseudociencia ejerce un efecto hipnótico sobre la población, aspecto que, no solo amenaza al conocimiento científico, sino que atenta directamente contra la salud pública, al fomentar, en algunos casos, el abandono de la medicina clásica.

El propósito de esta ponencia es analizar la presencia de pseudociencia en diferentes escenarios sociales. Y de esta manera determinar el comportamiento que adopta la pseudociencia para propiciar su inserción en el discurso público. La investigación utiliza una metodología de revisión bibliográfica de cuatro artículos elaborados en el marco de un proyecto competitivo del Ministerio sobre Pseudociencia y Sociedad en España (CSO2014-54614-P), como método para explorar la situación de la pseudociencia en la esfera pública. Los datos ofrecidos corresponden a la presencia de pseudociencia en: 1) la prensa escrita española, 2) el sistema público de bibliotecas en España, y 3) las universidades españolas.

Los resultados revelan una considerable permisividad ante la pseudociencia por los tres entes sociales analizados, más evidente en la prensa española. Parece que, la pseudociencia utiliza un discurso directo, irracional y fraudulento, propenso a sembrar miedo y desconfianza hacia la ciencia. Se trata de una creencia disfrazada de conocimiento. La desinformación que impera en la sociedad sobre esta cuestión parece acreditada, a partir de los datos obtenidos. Por ello es necesaria la implementación por parte de los diferentes actores implicados de medidas específicas en cada uno de los escenarios. Se hace más imprescindible que nunca la divulgación científica sólida y robusta que capacite la formación de un juicio crítico sobre la pseudociencia a los ciudadanos.

099 - Comunicación comunitaria: Lógicas, dimensiones y participación social. Notas para una conceptualización desde la epistemología del SurJosé Cisneros Espinosa, ulises33@yahoo.com, José Antonio Cisneros Tirado, joseantonio.cisneros@correo.buap.mx, María 
Carolina Restrepo Gómez, restrepocarolina91@gmail.com, Erick Solís Pedroza, erick.sls@hotmail.com-Benemérita Universidad Autónoma de Puebla, México

El término de comunicación comunitaria ha sido empleado en América Latina a lo largo de los años como un calificativo para atribuirlo a un grupo social y/o territoriales específicos, pero sin que se cuestione el concepto mismo de comunicación, que lo mismo puede referirse los modelos unidireccionales norteamericanos (Laswell, Nixon, Schramm, etc.) que a los dialogales de Freire, Habermas o Pasquli. Sin embargo, en el trabajo de campo, recientemente hemos encontrado que ninguno de estos conceptos hace referencia a las múltiples dimensiones que la práctica de la comunicación comunitaria lleva implícitas, pues vamos descubriendo que no basta ubicar las prácticas de comunicación en un contexto cultural determinado para entenderlas con los conceptos de comunicación usuales.

En las prácticas observamos diferentes dimensiones sin las cuales no se puede entender su funcionamiento real: la dimensión étnica, la valoración moral del hablante, los procesos migratorios, la ubicación en la estructura de cargos, la dimensión espiritual y relación con la tierra, la evolución de los temas a tratar, desde el ámbito familiar, vecinal y laboral, hasta la asamblea comunitaria, la distribución de roles, la deliberación y tomas de decisiones, la reconceptualización de la racionalidad entre otras.

Todas las dimensiones tienen una integración orgánica que le confieren al proceso de comunicación comunitaria características específicas y diferentes a las formas y dimensiones de otros conceptos de comunicación conocidos. Pero además estas dimensiones se ubican dentro de una dinámica compleja y amplia en su relación con la sociedad extra-comunitaria, a través del tiempo y de los procesos históricos.

100 - Comunicación Experiencial, el nuevo rol de la Gestión Estratégica de Comunicación (Basado en el sector de la restauración de Tarragona) Javier Mayorga - PhD por la Universitat Autònoma de Barcelona - javierandres.mayorga@e-campus.uab.cat 
El fin de un modelo de política

La comunicación experiencial, es fundamental para la consecución de objetivos estratégicos sustentados en la experiencia. Esta corriente aparece con las propuestas de Schmitt, Pine y Gilmore. Se empezó a hablar de que los consumidores no sólo eligen motivados por la racionalidad, sino además, por otros factores como las vivencias, experiencias, sensaciones y emociones.

Se ha venido incluyendo los términos "emociones y experiencia" al mundo empresarial. Investigadores han relacionado estudios con la emoción que se genera a partir de una experiencia, construida alrededor de la marca, y cómo esto debe generar una respuesta esperada, claramente, la re-compra y a mediano plazo la relación. El resultado final de la relación entre audiencia y marca, es el enamoramiento, que según (Garzón, A., Mayorga, C., Solano, F., 2013) es un estado psico-relacional que conjuga la alegría, el deseo, la excitación y una sensación de bienestar, en presencia del individuo que la evoca. La comunicación experiencial pretende generar una relación entre marca y consumidores, al igual que la que existe entre individuos. Partiendo de la base que la relación es una red en la que cada uno de los involucrados, es influido e influye en el otro de forma sucesiva y circular, en donde cada uno expresa su propio sentir y manifiesta sensaciones, emociones y percepciones del otro (Garzón et al., 2013), la Comunicación Experiencial persigue como objetivo generar un estado de lealtad supremo por parte de los clientes, con el fin de crear una relación que trascienda al intercambio comercial.

Por todo esto este trabajo tiene como objetivo, partiendo de la valoración de los insumos genéricos comunicacionales para la fabricación de experiencias realizada en Tarragona, proponer un modelo de comunicación experiencial que persiga el fortalecimiento de relaciones de las marcas con las audiencias. Este trabajo utilizó técnicas mixtas de investigación, para alcanzar una mejor comprensión de la información obtenida y arrojo como resultado un modelo conformado por cuatro factores (Invitación, Relación, Esencia y Trascendencia).

101 - Construcción de redes entre universidades nacionales, comunidades y movimientos sociales en los territorios. El caso de la RICCAP (Argentina) - Andrea Noelia López - Unidad de Investigación en 
Comunicación, Cultura y Sociedad, Universidad Nacional de Jujuy/Centro de Estudios de Historia, Cultura y Memoria, Universidad Nacional de Quilmes/CONICET/ Fundación Carolina -andynlopez@gmail.com, y Ramón Burgos - Unidad de Investigación en Comunicación, Cultura y Sociedad, Universidad Nacional de Jujuy/Facultad de Humanidades, Universidad Nacional de Salta -monchoburgos8@gmail.com

En los últimos años -y al calor de los acontecimientos producidos en torno a la Ley de Servicios de Comunicación Audiovisual (LSCA)-, el campo de la comunicación en Argentina se vio profundamente interpelado. Este trabajo reflexiona en torno al proceso de conformación y desarrollo de la Red Interuniversitaria de Comunicación Comunitaria, Alternativa y Popular (RICCAP), que nuclea a docentes e investigadores de una decena de carreras de Comunicación Social. Dicha red fue creada en 2014 a partir de la necesidad de promover la formación de comunicadores sociales universitarios comprometidos con las causas populares, como así también fortalecer los vínculos entre las universidades nacionales, las comunidades, las organizaciones y los movimientos sociales en los territorios.

El objetivo principal de la comunicación es dar cuenta del proceso de creación y los ejes de trabajo a partir de los cuales se aglutina la RICCAP, los avatares institucionales y políticos que condicionan su desarrollo y los objetivos delineados para el período 2017-2018.

102 - Periodismo inmersivo y radiotelevisiones públicas europeas: comparativa de las aplicaciones móviles de consumo inmersivo de no ficción - Sara Pérez-Seijo - saraperezseijo@gmail.com y Xosé LópezGarcía - Universidade de Santiago de Compostela xose.lopez.garcia@usc.es

El periodismo se sumió en una crisis de identidad a comienzos del siglo XXI. Formas y formatos debían ser replanteados para adaptarse al ecosistema en red. A raíz de este contexto surge un aluvión de nuevas corrientes y narrativas periodísticas vinculadas, en gran parte, al auge y calado de nuevas tecnologías. En medio de este panorama nace el 
El fin de un modelo de política

periodismo inmersivo, cuyas narrativas basadas en técnicas de grabación 360 grados y de realidad virtual o recreación sintética tridimensional permiten acercar, en mayor nivel que otro formato tradicional, el escenario informativo al receptor. Esta inmersión espacial y sensorial permite que el usuario experimente la sensación de "estar ahí" -conocida también como presencia-. Junto al usuario, el smartphone también adquiere mayor protagonismo al erigirse como el mediador idóneo para el consumo de los productos inmersivos, bien sean 360 grados o de realidad virtual. Por esta razón, el 27,27\% de radiotelevisiones públicas de los países de la Unión Europea y adscritas a la Unión Europea de Radiodifusión (UER) que hasta marzo de 2017 implementaron en al menos una ocasión las técnicas inmersivas, han lanzado una o más aplicaciones móviles para el consumo de este tipo de piezas informativas y no ficción. En este sentido, esta comunicación pretende ofrecer una comparativa entre las diferentes plataformas móviles de consumo 360 grados desarrolladas, mostrando especial interés en las posibilidades de consumo, las temáticas y el número de descargas de cada una de ellas. Para su consecución se ha procedido a un estudio cuantitativo por medio de fichas de análisis, junto a uno cualitativo basado en entrevistas a expertos del sector.

103 - Relaciones públicas, responsabilidad social empresarial y capital social: una perspectiva teórica para las organizaciones comerciales a partir de las campañas ganadoras del Festival de Creatividad Cannes Lions 2017 - Dr. Raúl Santos Morales - raul.santos@anahuac.mx y Dra. Rebeca Illiana Arévalo Martínez - Universidad Anáhuac México rebeca.arevalo@anahuac.mx

Con la aparición de la web 2.0, las relaciones públicas de una organización comercial se van alejando poco a poco de los procesos de comunicación unidireccional para enfocarse más en procesos bidireccionales donde la clave es la interacción con sus grupos de interés.

Este cambio, potenciado por la web 2.0, ayuda a incrementar el capital social de una organización comercial al generar relaciones personales, redes sociales de apoyo, normas de cooperación, confianza y/o un compromiso cívico con sus diferentes públicos. 
Sin embargo, son pocas las organizaciones que de manera consciente asumen y comprenden su papel como agentes sociales, además de adoptar una postura ética y moral que las lleve a establecer un compromiso socio-cultural y un impacto positivo en las comunidades donde tienen injerencia. Todo esto como parte de una responsabilidad social empresarial que puede vincularse con la comunicación para el desarrollo y el cambio social dentro de un esquema democrático que fomente la representación y la participación ciudadana.

Por lo tanto, es importante conocer el capital social que propician las relaciones públicas en diferentes partes del mundo mediante el análisis de veinticuatro campañas que resultaron ganadoras en la categoría "Digital \& social" del Festival de Creatividad Cannes Lions 2017, las cuales, usaron alguna plataforma o medio digital para vincular a una determinada organización comercial con sus grupos de interés.

Los resultados demuestran que los viejos modelos del agente de prensa y de la información pública están quedando atrás para dar paso a modelos más bilaterales, por lo que esta investigación aporta evidencias empíricas y teórico-conceptuales del capital social producido por las relaciones públicas a través de la web 2.0.

\section{4 - Biomimesis comunicativa: una nueva perspectiva en comunicación} organizacional - Dr. Alejandro Álvarez Nobell - Universidad Nacional de Córdoba (Argentina) - CONICET - Universidad Católica de Córdoba (Argentina) aalvareznobell@unc.edu.ar y Mgter. María Belén Barroso - Universidad Siglo 21 (Argentina) mbelenbarroso@gmail.com

Ochenta años después -si consideramos los orígenes ingleses en los años '30 previo a su salto y auge en Estados Unidos-, pareciera que los vestigios del funcionalismo aún recalan en diversas perspectivas, modelos e intervenciones del campo de la comunicación, fundamentalmente en lo que respecta a su influencia en las organizaciones. Sus postulados ontológicos entienden la sociedad como un organismo integral e interrelacionado, en el que si se afecta una parte, todo el organismo se perturba. Sus premisas sostienen que 
El fin de un modelo de política

los estímulos comunicativos deben buscar respuestas efectivas y competitivas y las conductas deben alinearse a enfoques organizacionales como mecanismos de adaptación, estabilizadores y legitimadores del poder. Para ello, deben emplearse dispositivos informativos de control y regulación de lo disfuncional en procesos comunicativos persuasivos eficaces, pero con finalidad unidireccional y asimétrica.

Sin embargo, han surgido miradas críticas revisionistas como el enfoque contingencial, que desde la teoría de los sistemas abiertos sostiene que la eficiencia resulta del grado de adaptación de las organización (estructura, política, prácticas, etc.) a la dinámica situacional determinada por las variables tecnológicas, ambientales, humanas, culturales y socioeconómicas. En esta línea, cobra forma una nueva perspectiva que promueve la planificación estratégica prospectiva en comunicación a partir de relaciones bidireccionales y simétricas, producto de interacciones colectivas, participativas y sostenibles.

Esta visión surge de la aplicación al campo de la comunicación de procesos de bioinspiración o ecoinnovación, de uso emergente en otras disciplinas como la bioingeniería, la bioarquitectura o la ecosemiótica. La biomímesis, mediante la emulación consciente del genio de la naturaleza, procura integrar diversas áreas del conocimiento en un espacio creativo común, con el propósito de promover nuevos puntos de vista a los desafíos globales y locales. Es una invitación a reconocer, saber y transformar en forma colaborativa nuestro propio mundo.

Se abren así discusiones e innovaciones conceptuales necesarias en el debate académico disciplinar, pero fundamentalmente, se tensionan los modos en que se gestionan los procesos de comunicación en las organizaciones y su contribución a los proyectos productivos. Por ello, esta ponencia tiene por objetivo aportar un conjunto de elementos que permiten entender, abordar y profundizar estos procesos de innovación en comunicación aplicados a la planificación y la gestión de las organizaciones. La biomímesis comunicativa pretenden reformular postulados teóricos obsoletos a los contextos y necesidades actuales e innovar procesos desde una mirada que busque el "equilibrio natural 
en las relaciones de las personas y las organizaciones" a partir de imitar los sistemas básicos de vinculación en el ecosistema comunicativo y con el medio ambiente en sentido amplio.

105 - Redes sociales en el contexto de la comunicación deportiva en España. Estudio de caso de los clubes de fútbol-Francisco Javier Herrero Gutiérrez - javiherrero82@usal.es - Universidad de Salamanca

En esta comunicación se pretende abordar el empleo de las redes sociales por parte de los equipos de la Primera División española. Se parte de la base de que el uso de las redes sociales es fundamental en el devenir publicitario de prácticamente cualquier ámbito, también el deportivo. Y dichas redes sociales son uno de los más importantes canales de comunicación en el mundo actual. Por ello, la necesidad de cuidar qué redes se utilizan, con qué frecuencia y con qué finalidad.

El análisis se aborda desde un punto de vista cuantitativo y cualitativo. Dentro del apartado cuantitativo, se analizan variables tales como el número de redes sociales presentes, el número de publicaciones, el número de mensajes de retroalimentación, etc. En el apartado cualitativo, se aborda la tipología de mensajes empleados por los CM de dichos clubes.

Para realizar este estudio se ha escogido la muestra de los 20 clubes que forman parte de la Primera División española durante la temporada $2017 / 18$.

106 - La transparencia municipal a través de las páginas web de los Ayuntamientos. Estudio de caso: Comunidad de Madrid (España) Francisco Javier Herrero Gutiérrez - Universidad de Salamanca - javiherrero82@usal.es y Soledad Ruano López - Universidad de Extremadura - solruano@unex.es

La legislación existente a día de hoy en España entiende a la transparencia y la participación ciudadana como un derecho del ciudadano. Aunque España no es un país especialmente avanzado en 
El fin de un modelo de política

la transparencia municipal, lo cierto es que las mejoras son considerables con respecto a cómo estaba la situación años atrás.

En esta comunicación se presentan los resultados del Mapa InfoParticipa (http://mapainfoparticipa.com/index/home/) obtenidos con respecto a los Ayuntamientos de la Comunidad de Madrid durante el año 2017. Durante este periodo se han analizado las páginas web de los 34 ayuntamientos con más de 10.000 habitantes de dicha Comunidad Autónoma; se ha observado un cumplimiento medio-bajo (menos del 50\% en su conjunto). Se puede afirmar que las páginas web de los Ayuntamientos con más de 10.000 habitantes distan de un cumplimiento óptimo, si bien es cierto que hay evaluaciones extremadamente positivas, llegando en algún caso al 100\% de los indicadores, y otros muy negativas, por debajo del $25 \%$.

La metodología llevada a cabo, puramente cuantitativa, se basa en un análisis a través de 52 indicadores repartidos en 2 grupos y 5 subgrupos. El primer grupo sobre "Transparencia de la Corporación" está compuesto por tres cuestiones: Quiénes son los representantes políticos, cómo gestionan los recursos colectivos y cómo se gestionan los recursos económicos: presupuestos, salarios, contrataciones, subvenciones. El segundo grupo, "Información para la Participación", responde a dos interrogantes: Qué información proporcionan sobre el municipio y la gestión de los recursos colectivos y qué herramientas se ofrecen para la participación ciudadana.

107 - Fotografía de prensa: reflexión en torno a las imágenes de los terremotos de Ecuador e Italia - Lilia Carpio-Jiménez lkcarpio@utpl.edu.ec, Patricio Barrazueta Molina - Universidad Técnica Particular de Loja - pbarrazueta@utpl.edu.ec y Rosario Puertas-Hidalgo - Universidad Técnica Particular de Loja rjpuertas@utpl.edu.ec

Las fotografías en los medios escritos se convirtieron en unos de los principales elementos de comunicación para informar sobre los terremotos del 16 de abril en Ecuador y del 24 de agosto en Italia durante el 2016. El artículo analiza comparativamente las imágenes publicadas por los principales medios escritos El Universo y El 
Comercio de Ecuador y Repubblica y Corriere Della Sera de Italia, profundizando en los elementos que componen la imagen y el mensaje que las fotografías expresan a los lectores.

108 - Seguridad de periodistas y la cuestión de la impunidad en América Latina. Agresiones a los profesionales de la información en el s. XXIDr. B. Díaz Nosty. Catedrático de Periodismo y director de la Cátedra Unesco de Comunicación - Universidad de Málaga, UMA, España-nosty@uma.es y Dra. R. A. de Frutos García. Coordinadora de la Cátedra Unesco de Comunicación Universidad de Málaga, UMA, España - ruth.defrutos@uma.es

Cerca de medio centenar de periodistas han sido asesinados o desaparecidos por ejercer su profesión en América Latina durante este siglo. Desde el 2000, las agresiones no solo no han decrecido con la instauración de nuevos sistemas democráticos, sino que se han intensificado en contextos nacionales complejos caracterizados por la violencia, la actuación de múltiples perpetradores y la impunidad.

El objetivo de esta investigación es analizar los 452 casos de asesinatos y desapariciones de periodistas en América Latina desde el 2000 hasta el 30 de junio de 2017, así como elaborar una profusa revisión bibliográfica de las principales fuentes de información y programas nacionales e internacionales al respecto.

Los resultados evidencian desajustes considerables entre la voluntad internacional de creación de programas de monitoreo, protección y lucha contra la impunidad, las realidades nacionales complejas e inseguras en la región y el número de profesionales de la información muertos o desaparecidos violentamente en América Latina.

109 - Los ecuatorianos en Barcelona. Visibilidad en la prensa y sus formas de integración - Nelly Gabriela Guamán Guadalima ngguaman1@gmail.com y Christian Nivardo Ortiz Chamba Universidad Técnica Particular de Loja, Ecuador cnortiz2253@gmail.com 
El fin de un modelo de política

Los medios de comunicación juegan un papel determinante como difusores de hechos sociales, mediadores e influenciadores y, que a través de la difusión de contenidos contribuyen en la construcción social de una realidad de uno o varios grupos de personas.

En esta investigación se describe la visibilidad que la prensa le ha otorgado a los ecuatorianos en Barcelona, a través de los temas que se lo asocian; además de describir las formas en cómo los ecuatorianos se integran al país donde habitan. Y, con el interés de contribuir desde el punto teórico y empírico, en la concepción de cómo los medios de comunicación se establecen como influenciadores en la construcción de la realidad de un grupo de personas que emigran a otros países y de qué manera éstas, como audiencias, perciben esa realidad, le otorgan valor o importancia; se indagó en la percepción de los ecuatorianos residentes en Barcelona sobre el tratamiento que la prensa española le da a su país.

Para la consecución de resultados se recurrió al análisis de contenidos, análisis documental y las entrevistas semiestructuradas, determinando así que la comunidad ecuatoriana se muestra como un grupo trabajador, que se ha integrado en el lugar donde vive, que así como muchos cualquier otro colectivo de personas, éstos también tienen problemas económicos; y, a éstos se los encuentra en su mayoría en trabajos denominados: Trabajadores de los servicios de restauración, personales, protección y vendedores.

110 - Quién es quién en el Hot 100 de Billboard de 2016: Una propuesta de análisis sobre géneros, edades y corrientes musicales Tatiana Hidalgo-Marí - Universidad de Alicante tatiana.hidalgo@ua.es

El Hot 100 del Billboard es una lista que posiciona del 1 al 100 las canciones de mayor éxito de ventas en la industria discográfica en Estados Unidos desde 1955. Por su trayectoria y su impacto en la industria discográfica, consideramos que el análisis de los videoclips de esta lista, merece especial análisis desde una perspectiva social. Si los videoclips son los contenidos publicitarios que promocionan a los artistas, nos preguntamos: ¿Quién es quién en este ranking? 
¿Predomina algún género o existe paridad en la presencia de hombres y mujeres? ¿Es la edad un factor determinante en una trayectoria musical de éxito?

La presente comunicación propone un estudio exploratorio sobre las variables género y edad de los artistas asociados al Hot 100 de Billboard, con el objetivo de conocer si la adscripción de género y la juventud o madurez del artista son valores representativos en el ranking. Para ello, se toman como referencia los treinta primeros videoclips del Hot 100 de Billboard de 2016 y se analiza la edad, adscripción de género y sector musical al que pertenecen. La finalidad es doble: por una parte, valorar si existe relación entre el éxito musical, género y edad de los artistas y, en segundo lugar, conocer si existen diferencias significativas entre unos géneros musicales y otros

\section{1 - Naturaleza de los patrocinadores principales en los clubes de La}

Liga para la temporada 2017/2018 - Santiago Mayorga Escalada Universidad Pontificia de Salamanca smayorgaes.com@upsa.es

Tanto La Liga como los clubes que forman parte de ella se encuentran sumergidos en un proceso constante de profesionalización hacia la excelencia en diferentes ámbitos: deportivo, administrativo, comunicativo, de gestión y negocio, marketing, etc. Este esfuerzo de carácter interno se suma a la repercusión comercial que adquieren los clubes siendo parte de una de las ligas de fútbol profesional con mayor prestigio del mundo lo que además facilita la globalización de su marca introduciéndose en amplios mercados internacionales. De acuerdo con esta coyuntura es necesario ahondar en la cultura de gestión estratégica de marca, aplicada en este caso a los clubes de fútbol profesional españoles que forman parte de La Liga con el fin de ganar en valor, identidad, imagen, mercado, rentabilidad, eficiencia y fidelización de sus públicos más incondicionales.

Dentro de las diferentes vías de financiación con que cuentan los clubes está el patrocinio que, tras los derechos conjuntos de televisión y la venta de jugadores, se convierte en una de las técnicas recaudatorias más potentes en la actualidad. De entre el conjunto de patrocinadores 
El fin de un modelo de política

que puede acumular un club sobresale el principal que es quien alcanzará una posición protagonista tanto en la web del club como en el estadio, en las acciones y eventos de la marca, y sobre todo en el frontal de las camisetas. Además de ser una vía muy importante de financiación para los clubes, el patrocinio se convierte en una inversión estratégica potente en awareness, imagen y notoriedad para la marca patrocinadora. Se conforma de igual manera una fuerte simbiosis entre marca patrocinadora y marca patrocinada que afectará a la imagen, identidad, reputación, valores y atributos de ambas. Por este motivo es importante que se elija de forma estratégica la que será marca patrocinadora de un club, buscando una compatibilidad conjunta.

112 - Percepción de la audiencia tras el consumo de noticias con "bots" Hada M. Sánchez Gonzales - Universidad de Sevilla misago@us.es y María Sánchez González - Universidad de Málaga - m.sanchezgonzalez@uma.es

El acceso a la información en Internet a través de dispositivos móviles es cada vez mayor. De igual forma, que cobra importancia la segmentación y personalización de contenidos (Sánchez, 2012). Está cambiando la producción y distribución de noticias, así como se hace más estrecha la relación entre periodismo y los sistemas de inteligencia artificial. En este contexto, aparecen los bots conversacionales, aplicaciones que distribuyen contenido personalizado (Al Johri et al, 2016) en las redes sociales y en las apps de mensajería instantánea . Es el caso de Politibot, lanzado en España durante la campaña electoral (26J) en 2016 y un mes después, ya contaba con más de 8.400 suscriptores.

Los estudios realizados sobre el llamado periodismo robot ofrecen una visión general del fenómeno y aún no se han abordado estudios desde la perspectiva del uso de las herramientas y percepción por parte de los ciudadanos. El objetivo de la presente investigación pretende dar a conocer el grado de conocimiento de la audiencia sobre Politibot y determinar cuál sido la experiencia tras su uso por parte de la audiencia. Aplicamos el método empírico-analítico utilizando el análisis documental, la observación directa, la entrevista y cuestionarios para recoger su percepción acerca de la experiencia de consumo, facilidad 
de uso y comprensión de contenidos, considerando la conexión emocional que se establecen en este tipo de aplicaciones.

Los resultados revelan la aceptación por parte de la audiencia. Las tres cuartas partes reconocen que le ha ayudado a estar informado. Más de la mitad admite el buen funcionamiento de la aplicación, así como valora los datos contrastados y la relación cercana que se establece con el bots.

113 - La comunicación ciudadana en face y twitter en la emergencia del 19 de septiembre en la Ciudad de México - Dra. Edna Nelly Becerril Lerín - UNAM - ednanelly@yahoo.com.mx

El pasado 19 de septiembre de 2017, un sismo de magnitud 7.1 grados en la escala de Richter, se registró en la Ciudad de México, como resultado de este acontecimiento diversos edificios colapsaron y una gran cantidad de personas quedó atrapada en su interior, el sismo se registró en horas hábiles, la mayor parte de la gente se encontraba aún en sus espacios laborales, pero el evento se convirtió en emergencia derivado de la gran cantidad de edificios colapsados en la capital de país. Ante la falta de reacción inmediata por parte de las autoridades capitalinas, los ciudadanos se organizaron, la solidaridad y el respeto por el otro desconocido, ajeno, se convirtió en interés real por rescatarlo, con las manos, la gente comenzó a mover los escombros para ayudar a los que estaban sumergidos en edificios caídos. La falta de reacción inmediata por parte de las autoridades de la capital generó que miles de ciudadanos se dieran a la tarea de utilizar las redes sociales: twitter y Facebook para generar sinergias y equipos de rescatistas, establecer albergues, publicar listas de alimentos y enseres necesarios para dar apoyo a la gente que se quedó sin casa. La presente comunicación tiene como objetivo mostrar la forma en que las redes sociales fueron utilizadas por el ciudadano común ante la emergencia derivada del sismo del 19 de septiembre de 2017. Al tiempo de mostrar las diversas comunidades generadas en Facebook, formadas a partir de diversas necesidades: información fidedigna, centros de acopio, solicitud de rescatistas, lista de medicamentos. Palabras clave: comunicación ciudadana, Facebook, twitter, comunidades virtuales. 
El fin de un modelo de política

114 - La importancia del sector cultural y creativo de Cataluña en el marco de las Comunidades Autónomas españolas - Marcial Murciano - marcialmurciano@gmail.com - Universitat Autónoma de Barcelona

Los Sectores Cultural y Creativo (SCC) forman en Cataluña un dinámico ecosistema donde cohabitan y se retroalimentan ámbitos tractores, consolidados, con actividades de dinámica distribuida, que se benefician de un entorno socio-económico relativamente favorable en el contexto español y de las oportunidades abiertas por el cambio tecnológico. La presente comunicación constata la existencia de relaciones recíprocas (correlaciones) entre algunos indicadores fundamentales para contextualizar las actividades creativas en el marco autonómico español, en general, y en Cataluña en particular: el PIB per cápita y el alto nivel de formación en la población adulta se retroalimentan positivamente; la educación también se asocia a una menor tasa de riesgo de pobreza y a un elevado índice de oportunidades, infraestructuras y usos digitales; y esta disponibilidad y manejo intensivo de las tecnologías de la información y las comunicaciones (TIC) es inherente a un mayor consumo cultural y al disfrute de unas condiciones económicas favorables. La comunicación propuesta muestra por primera vez el peso desagregado de los sectores cultural y creativo (SCC) en Cataluña en relación con las comunidades autónomas de España. Se establecen los desequilibrios entre los territorios, se dimensionan los efectos negativos de la crisis sobre el sector y se identifican los polos de mayor desarrollo y potencialidad. A partir del modelo MELICC desarrollado por el grupo de investigación Localcom, se ha generado una amplia base con más de 26.000 datos estadísticos: 18.300 datos originales sobre los SCC y cerca de 8.000 datos de fuentes externas hasta ahora dispersos en múltiples entidades (institutos de estadística, ministerios, asociaciones, gremios profesionales, etc.).

115 - El emplazamiento publicitario en los videoclips de YouTube. El caso de Pablo Alborán - Jesús Segarra-Saavedra - Universidad Internacional de La Rioja - jesus.segarra@unir.net 
El emplazamiento publicitario, también conocido como product y brand placement, ha sido y es un elemento presente en numerosos productos culturales como películas, series y programas de televisión entre otros. El videoclip, un formato audiovisual que transita entre la industria musical y la publicitaria, no escapa a esta herramienta de promoción y fuente de financiación y colaboración. El presente trabajo analiza la presencia publicitaria en los videoclips. Para ello, por una parte, realiza una revisión bibliográfica para conocer el estado de la cuestión, los antecedentes, investigadores y principales métodos y herramientas de análisis utilizados y, en segundo lugar, analiza el caso del cantautor español Pablo Alborán, un fenómeno de masas cuya proyección internacional nació en 2010 en YouTube.

116 - Los influencers en las series de televisión pública: nuevas estrategias para los nuevos públicos - Isaac Maroto González - Universidad de Santiago de Compostela - isaac.maroto@rai.usc.es y Talia Rodríguez Martelo - Universidad Complutense de Madrid, Facultad de Ciencias de la Información - talrodri@ucm.es

La narrativa interactiva no es una novedad en las parrillas televisivas; en los últimos años y en especial con el auge de internet y las redes sociales, cada vez son más los ejemplos que intentan, con mayor o menor éxito, explorar esta vía.

Televisión Española acaba de terminar la emisión de Si fueras tú, un thriller para público mayoritariamente adolescente cuyo guión se ha ido escribiendo a través de los comentarios y aportaciones de los espectadores que al final de cada capítulo debían decidir cómo procedería la protagonista en el siguiente. Bajo esta premisa y una red de perfiles en redes sociales, tanto del contenido como de los protagonistas, se ha ido emitiendo esta serie que además introduce una novedad como es la participación de Óscar Casas, actor e influencer con más de un millón de seguidores en su perfil de Instagram, y el desarrollo de un perfil de la protagonista como interlocutor con el público.

La estrategia digital multiplataforma, así como el fichaje de Óscar Casas, cuyo perfil es de alta relevancia en redes sociales, ponen de 
El fin de un modelo de política

manifiesto el deseo de los medios de comunicación, de encontrar nuevas fórmulas para conectar con nuevos públicos "conectados" a la red.

A través de este artículo, trataremos de analizar la relación que existe entre la interacción de Oscar Casas como actor y su condición de influencer dentro de la estrategia transmedia de la serie. Para ello se analizarán las redes sociales de Oscar Casas así como el perfil que proyecta e intentar descubrir si de esta forma se consigue arrastrar a una nueva generación de espectadores utilizando perfiles personales afines a un nuevo público.

117 - El debate europeo sobre el futuro de la financiación de las radiotelevisiones públicas - Francisco Campos Freire francisco.campos.freire@gmail.com, Marta Rodríguez Castro marta28793@gmail.com, Oscar Juanatey Boga y Valentín Alejandro Martinez - valejand@udc.es - Universidade de Santiago de Compostela y Universidade de A Coruña

La gobernanza del servicio audiovisual público en Europa se enfrenta actualmente a tres grandes retos: reforzar y mejorar su legitimidad, sostener su financiación y adaptarse a través de la innovación a los cambios y nuevos usos de los ciudadanos en la sociedad digital. Salvo pocas excepciones, la situación económica de las corporaciones europeas de radiotelevisión pública en los últimos años ha sido de estancamiento o retroceso en la evolución de sus presupuestos anuales ordinarios. Esto ha sido debido, en primer lugar, a la crisis económica que ha golpeado con fuerza a algunos países y, en segundo término, al agotamiento de los modelos tradicionales de financiación. Dichos modelos de financiación son el canon que se paga por hogares o individualmente en 17 países de la Unión Europea, la publicidad y patrocinio, los ingresos por derechos de producción y la subvención que conceden los estados a través de los presupuestos de los gobiernos de turno. En varios países y sectores se están revisando y cuestionando esas fuentes de financiación de un servicio audiovisual público que los operadores privados alegan que estarían dispuestos a ofrecer sin contraprestación. Frente a esos argumentos interesados, también se ha reactivado en Europa una corriente activa de defensa sobre la 
necesidad y vigencia del servicio audiovisual público en el seno de un ecosistema digital fragmentado, disruptivo, escaso en cohesión y trufado de fake news.

118 - La integración de las marcas en los videoclips de OK Go - Cande Sánchez-Olmos - Universidad de Alicante cande.sanchez@ua.es y Ester Monfort - Universidad de Alicante-monfort.ester@gmail.com

Debido a la dificultad que tienen las marcas a ser escuchadas en un contexto cada vez más saturado de mensajes publicitarios, la publicidad busca en las bandas de rock una alternativa para conectar con su público objetivo. Esta investigación pretende analizar la relación que tiene en la actualidad el branded content con la música, concretamente en su formato de promoción audiovisual más común: el videoclip. En este sentido, se analizarán los videoclips realizados por la banda der rock alternativo OK Go, debido a su interés publicitario y a la creatividad de sus videoclips.

Para ello, se observa qué marcas y de qué forma aparecen dichas marcas en los videoclips de OK Go. La muestra de esta investigación la componen todos los videoclips que se encuentran en el canal oficial de YouTube de la banda (OkGo y Ok GoVEVO). Los resultados que se han obtenido son sorprendentes, ya que se concluye que OK Go realiza una publicidad integrada en el contenido que contrasta con la publicidad convencional que se realiza en la actualidad.

\section{9 - Tendencias de brand placement en videoclips de bandas superventas} en 2016 - Cande Sánchez-Olmos - Universidad de Alicante cande.sanchez@ua.es

El brand placement gana terreno en la industria publicitaria porque la imagen de la publicidad convencional se ha deteriorado hasta tal punto que en los últimos años el rechazo a los anuncios que interrumpen el entretenimiento ha crecido de manera considerable. En este sentido, los videoclips se han convertido en uno de los contenidos de entretenimiento más preciado por las marcas para integrar sus productos. Por todo ello, es conveniente analizar cómo las tendencias 
El fin de un modelo de política

de brand placement que las marcas han llevado a cabo en los videoclips de 2016. De este modo, tendremos una perspectiva de la presencia de marcas en videoclips. No en vano, de los 100 videoclips más vistos en la historia de YouTube 92 se corresponden con videoclips.

La metodología combina técnicas cualitativas y técnicas cuantitativas. En primer lugar, aplicamos un análisis de contenido a los videoclips del top 30 de la Hot 100, la lista que mide las canciones más vendidas en Estados Unidos. A partir de esta muestra observamos qué videoclips registran brand placement, qué marcas aparecen en los videoclips, a qué artistas pertenecen las canciones y el modo en el que los productos se integran en la narrativa audiovisual. De este modo, podremos obtener una radiografía de las tendencias de brand placement en videoclips.

120 - Los Millenials despiertan con el terremoto en México - Fernando Esquivel Lozano - Catedrático de la Facultad de Ciencias de la Comunicación, Universidad Autónoma de Nuevo León (UANL) - feresquivel@hotmail.com

Un gran terremoto sacudió a México el pasado 19 de septiembre, exactamente 32 años después de aquel de 1985 que hasta ahora había sido el más devastador que se recuerde. El sismo sacudió al país entero, pero también sacudió las conciencias de los jóvenes mexicanos que mediante el uso de las nuevas tecnologías se volcaron a prestar ayuda y alivio a los damnificados.

Considerados hasta ahora como apáticos y poco participativos, salvo la emisión de likes, los miembros de la generación digital Millenials sorprendieron al mundo por su decidida participación en las labores de rescate $y$ de apoyo, sin que mediara ninguna convocatoria gubernamental.

Mediante aplicaciones y redes sociales los jóvenes se organizaron rápidamente para realizar distintas labores que fueron desde levantar escombros, hasta repartir víveres o brindar ayuda profesional, según su preparación académica. 
Ante la desorganización imperante y la poca utilización de nuevas tecnologías en las labores de rescate, los Millenials poco a poco crearon aplicaciones digitales y sitios web para organizar a los voluntarios e identificar los edificios dañados o los sitios donde se necesitaba más ayuda.

El teléfono celular junto con los cascos y chalecos que portaban, se convirtieron en las principales herramientas de trabajo de estos jóvenes que sin importar el cansancio y la falta de sueño, decidieron hacer algo por su país.

Su participación generó una flama de esperanza entre la sociedad mexicana, la cual espera que estos ciudadanos digitales sean ya la punta de lanza que rescate a la nación azteca.

121 - La deportividad como inspiración para el ejercicio de un periodismo ético - Dr. Francisco Javier Montero Ramos - Universidad Complutense de Madrid - fjrmontero@ucm.es

La presente comunicación busca tender un puente entre dos éticas aplicadas: la del periodismo y la del deporte, de tal forma que la primera pueda aprovechar determinadas potencialidades de la segunda. Para ello se toma como base el concepto de 'deportividad', una noción surgida para hablar de la voluntad de justicia y honestidad en el comportamiento de los atletas que ha trascendido su raíz extrapolándose su uso en sentido figurado a cualquier ámbito de la vida, incluido el periodismo.

A través de una revisión bibliográfica del tema el artículo ofrece un análisis del concepto de 'juego limpio' y de sus principales manifestaciones, así como un estudio sobre la concepción del fair play como base para la formulación de un sistema moral compuesto por una serie de principios básicos que guíen la conducta. Además de atender al aspecto normativo, de forma complementaria se presenta un estudio de la dimensión axiológica del deporte, identificando tanto los valores positivos como los negativos que comporta esta práctica con el fin de entender el papel que pueden jugar en el sistema social. 
El fin de un modelo de política

El objetivo último es comprender la capacidad que tiene el deporte para articular una serie de normas y valores morales que el periodista (principalmente el especializado en la actualidad deportiva) tiene la oportunidad de difundir a la sociedad a través de los medios de comunicación, desempeñando así una labor educativa. Pero también (y esto sería aplicable tanto al periodista deportivo como a cualquier profesional de la información) el artículo pretende subrayar la posibilidad de concebir la ética deportiva como un modelo capaz de inspirar al periodista en la manera en la que ejerce su profesión, entendiendo la moral deportiva como una valiosa fuente para la deontología periodística.

* 122 - Terminal informático y derechos fundamental; TIC,s y derechos fundamentales - Cristina Zoco Zabala - Profesora Contratada Doctora de la Universidad Pública de Navarra cristina.zoco@unavarra.es

El secreto de las comunicaciones constituye el objeto de un derecho fundamental que garantiza la inaccesibilidad del proceso de comunicación a través de medio técnico; lo "oculto" o "secreto" es el proceso comunicativo como tal, con independencia del contenido de lo comunicado; al margen de que el mensaje sea ilegible o inexistente; o con independencia de que tal transmisión carezca del contenido propio de una comunicación intersubjetiva.

Tras cuatro décadas de vigencia de la Constitución, la evolución de las tecnologías de la información y de la comunicación no ha sido expresión, sólo, de novedosos instrumentos de comunicación mediante soporte; ha repercutido, fundamentalmente, en dispositivos tecnológicos que lo mismo han soportado innovadoras modalidades comunicativas mediante instrumento técnico (correos electrónicos no leídos, chats en curso), que acomodado comunicaciones ya sin soporte (correos electrónicos leídos, chats finalizados), datos personales, informaciones, imágenes y comunicaciones directas no protegidos por el art. 18.3 CE.

Este trabajo analiza el secreto protegido por el art. 18.3 CE con el pretexto de verificar que la captación técnica de las conversaciones, o 
la intervención del dominio virtual no quedan protegidos por las garantías del art. $18.3 \mathrm{CE}$

El "secreto" protegido por el art. 18.3 CE es el proceso de comunicación a través de instrumento técnico, pero no el proceso de grabación de comunicaciones directas o sin soporte.

Así mismo, el art. 18.3 CE protege el secreto del proceso comunicacional mediante soporte, pero no el proceso virtual potencialmente comunicativo; en tal sentido, se cuestiona el entorno virtual propio como objeto de un derecho no fundamental que hace abstracción de otros derechos fundamentales que resultan del variado contenido virtual que puede ser interceptado (intimidad, protección de datos personales, o secreto de las comunicaciones). También se plantea la dificultad de definir qué sea el espacio virtual propio por contraposición al entorno virtual ajeno, o los límites temporales de la protección de un espacio virtual permanente aunque el usuario haya apagado el soporte de acceso a tal dominio virtual.

Finalmente, se recomienda valorar si el entorno virtual propio debe ser regulado como derecho fundamental en la Constitución; o bien puede ser manifestación de derechos fundamentales ya regulados en la Norma Fundamental: intimidad o protección de datos personales.

123 - Normas deontológicas de los lobistas. Arrastra a políticos y banqueros a situaciones de corrupción - $\mathrm{M}^{\mathrm{a}}$ Ángeles San Martín Pascal - Universidad Rey Juan Carlos mariaangeles.sanmartin@urjc.es

El presente artículo, trata algunas de las cuestiones más controvertidas y relevantes que se presentan actualmente en nuestra sociedad como es la corrupción, el tráfico de influencias, la opacidad en las gestiones políticas y empresariales, la incidencia de una falta de ética tanto en el sistema judicial, como en el político y económico, con una clara conexión que resulta tener especial transcendencia en el ámbito del derecho penal. 
El fin de un modelo de política

En una sociedad regida por un modelo de economía prácticamente desregularizada, poniendo énfasis en la obtención de beneficios de forma rápida y a corto plazo, el lobbying ha encontrado su caldo de cultivo para crear de forma políticamente correcta aunque éticamente reprobable, una forma de actuar muy alejada de la responsabilidad social que originalmente suponía y que por lo tanto conlleva realizar unos cambios en los códigos de conducta que contribuyan a una mayor transparencia, y a la disminución de actos de corrupción que lesionan y ponen en peligro nuestra democracia.

124 - Posicionamiento de marca. Gestión estratégica e implementación global de la marca Durex - Santiago Mayorga Escalada Universidad Pontificia de Salamanca smayorgaes.com@upsa.es

El posicionamiento de marca se conforma como una técnica estratégica vital para cualquier marca que desee ser reconocida por su público y diferenciada de su competencia en un sector determinado. Se persigue el fin de conformar una imagen única que logre conectar con el target aumentando el valor de la marca y la eficiencia de sus resultados. El desarrollo evolutivo de las técnicas de management, comunicación estratégica y marketing son evidentes a lo largo del paso del tiempo con el objetivo de adaptarse al momento, tanto en el plano comercial como en las formas de consumo. Este proceso ha conformado una serie de paradigmas a través de los cuales las marcas han llegado hasta nuestros días convertidas en el activo más importante de las corporaciones, ejerciendo una influencia social, cultural y simbólica muy potente sobre las personas.

La aceleración del tiempo a través de los cambios vertiginosos en el plano tecnológico, comunicativo y social, la realidad líquida en la que se difuminan los límites establecidos, y la posición de protagonismo que adoptan los usuarios provoca que el proceso de gestión de marca se convierta en el arma estratégica fundamental para hacer frente a la coyuntura actual. De esta forma las marcas conectan con sus públicos y utilizan el posicionamiento como una pieza estratégica imprescindible que debe llevarles hasta el largo plazo a través de una implementación coherente. En este sentido vamos a centrarnos en un caso de estudio 
paradigmático como es el de Durex que, a través de su posicionamiento estratégico "Love sex" y una implementación creativa planificada de forma coherente, ha logrado convertirse en una marca de éxito global reconocida con un gran engagement con su público, recordada en torno a una serie de atributos, y asociada con un sector muy determinado que ha logrado democratizar a lo largo del tiempo.

125 - Las estadísticas padronales del INE y su relación con las migraciones. El caso de sus notas de prensa - Ariet Castillo Fernández - arietcastillo@ugr.es, F. Javier García Castaño - Universidad de Granada-fjgarcia@ugr.es y Antolín Granados Martínez Universidad de Granada-granados@ugr.es

La mayoría de la población recibimos los acontecimientos que suceden en el mundo a través de fuentes de información bien diversas. Entre ellas, los medios ("cuarto poder" según Carlyle), por su influencia en la configuración de la opinión pública, a través de los cuales construimos una parte de nuestras interpretaciones de aquello que nos rodea (cercano y lejano, "real" o virtual). El campo de estudio interdisciplinar del discurso ha sido el que más conocimiento ha producido en relación con la representación de esta realidad. En este campo, hemos identificado tres posibles áreas temáticas sobre las que indagar en relación con el fenómeno migratorio: la producción por los medios, la noticia en sí misma y los efectos que causa su conocimiento.

A partir del análisis de 17 notas de prensa desde 2002, y que cada año emite el Instituto Nacional de Estadística sobre los resultados estadísticos del Padrón Municipal de Habitantes, los medios elaboran las noticias y es por ello que nos interesa estudiar el proceso que conlleva este "cocinar noticias". Esta fuente estadística se ha convertido en la "contabilidad" y en una manera de tratar el "control" de las migraciones en España. Las referencias que se hacen a la población nacional y a la población extranjera en las Notas desvelan ciertas representaciones del fenómeno y los sujetos de las migraciones y es desde ellas que los medios de comunicación construyen las noticias que luego consumimos. Mediante un análisis exhaustivo de la estructura (título, titulares, apartados, tablas y gráficos), la evolución, un estudio de los términos utilizados, sujetos (poblaciones) nombrados 
El fin de un modelo de política

y la dedicación (extensión), se observa un tratamiento de la población extranjera que refleja indirectamente un proceso de alterización, una forma de representar al "otro" (extraño) mientras se construye el "nosotros". Detrás de todo ello se encuentra el fenómeno de la Migraciones y, por supuesto, el llamado "problema de la Inmigración" además de contribuir a lo que nosotros llamamos la construcción de la diferencia.

126 - ¿Machismo en la televisión pública? Un polémico sketch de Juan y Medio en Canal Sur Televisión - Nuria Sánchez-Gey V. Universidad de Sevilla - nuriacris@yahoo.es

A través de esta comunicación vamos a analizar un caso que se convirtió en actualidad y en tema de debate en septiembre de 2017. Se trata de un sketch emitido en el programa de tarde de la televisión pública andaluza, Canal Sur Televisión, y que ha provocado revuelo y debate social en la sociedad en general y en los estudiosos de la Comunicación en particular. Una polémica que surgió después de que el programa en cuestión comenzara su emisión en septiembre de 2009 , es decir llevaba ocho años en antena, con altas cuotas de audiencia y con múltiples premios recibidos. El programa objeto de la polémica se emitió el 4 de septiembre de 2017. Dicho programa, La tarde, aquí y ahora, suele constar de tres partes bien diferenciadas; una cabecera de programa, una parte con invitados que buscan acabar con su soledad y cierra con una mesa de información de Actualidad. La cabecera de inicio -que suele durara unos diez minutos- frecuentemente incluye contenidos cómicos, originales, frescos... y en ella aparece el presentador, Juan y Medio, y la copresentadora, Eva Ruíz. Dentro de estos contenidos también se han incluido en ocasiones "pruebas" en las que rivalizan el presentador y la copresentadora. En este caso el sketch consistía en quién de los dos cortaba más ropa a su oponente. Empezó la copresentadora que tijereteó la chaqueta de Juan y Medio y después era Eva Ruíz la que iba a sufrir la tijera del presentador. Hasta aquí todo podía haber quedado en un sketch más -que puede gustar más o menos a la audiencia-, si no hubiera sido porque la portavoz de la formación política Podemos en Andalucía, Teresa Rodríguez, escribió en la red social Twitter un comentario, un tuit, cuatro días después de la emisión, en el que ponía en duda la corrección de la inclusión de este contenido en una televisión pública y en horario en el 
que lo pueden ver menores, ya que se emitió en torno a las cuatro de la tarde.

- ¿Y si nuestros hijos cambiando de canal se encuentran con esto en la televisión pública andaluza? ¿Creerán que es divertido hacerlo a otras niñas?"

La pregunta lanzada por Rodríguez fue compartida 33.400 veces, comentada 3.874 veces y le gustó a 23.495 personas, a través de la Red, según consulta realizada el mes de noviembre de 2017. Pero no solo esto, durante dos semanas fue un tema comentado tanto en las redes sociales, como en los medios de comunicación, motivos de conversación en la calle, pero también llegó a los políticos e incluso al Consejo audiovisual de Andalucía. ¿Qué podía haber detrás de este supuesto "desliz"? ¿Qué efecto puede tener este contenido en los espectadores? ¿Quién dirigía la productora audiovisual que realizaba este programa y por qué fue la líder de Podemos en Andalucía, ¿'Teresa Rodríguez, la primera en encender la llama de la discusión a través de las redes sociales? ¿qué pensaban los estudiosos de la materia sobre lo sucedido? ¿Por qué ocurrió en ese momento? Estos y otros puntos son los que hemos tratado en esta Comunicación.

127 - La imagen de las periodistas en los programas televisivos de actualidad informativa y su influencia en su desarrollo profesional Naiara Vink Larruskain - Universidad del País Vasco naiara_vl@hotmail.com

Desde la década de los setenta son muchos los trabajos de investigación que han estudiado el binomio formado por comunicación y género y que han abordado, de manera más específica, qué imagen de mujer, como objeto de las informaciones, difunden los mass media. Por otra parte, la falta de actividad investigadora destinada a analizar qué ocurre con la imagen de las profesionales que trabajan en ellos, aquella que se difunde y crea imaginario colectivo. Así, es necesario tener en cuenta, tal y como se señala en el estado de la cuestión, que no existe una tradición investigadora relacionada con el estudio de la imagen de mujer periodista y su influencia en la trasmisión de estereotipos que 
El fin de un modelo de política

fomenta, a su vez, una desigualdad de género que podría impactar de manera directa en su labor y desarrollo profesional.

Esta investigación nace de las conclusiones obtenidas en el estudio "Las periodistas en los programas televisivos de actualidad informativa y la construcción de la identidad femenina" en el que, tras el análisis de las entrevistas a mujeres periodistas que desarrollaban su función ante la cámara en la televisión pública vasca, se pudo constatar la existencia de un estereotipo sexista de mujer periodista que desvirtúa la realidad y desprestigia a la profesión. Desde esta perspectiva, el propósito del actual estudio, aumentado al ámbito a estatal y a las televisiones privadas, es estudiar la imagen de mujer periodista que desde las principales cadenas de televisión de nuestro país se traslada a la sociedad, identificar si existe un modelo de mujer periodista sostenido en estereotipos de género. Asimismo, se aborda la identificación de condicionantes que definan la imagen de las periodistas y limiten su trabajo.

128 - Reforma Energética en México. La bumorística desde la mirada de cinco caricaturistas del periódico La Jornada - Luis Alfonso Guadarrama Rico - Universidad Autónoma del Estado de México - Facultad de Ciencias Políticas y Sociales aguadarrama.famecom@gmail.com

Los caricaturistas políticos, como sujetos de la enunciación, han jugado un papel relevante de cara a los hechos sociales que ocurren diariamente; especialmente de aquellas acciones, decisiones, discursos, planes o programas que llevan a cabo los gobernantes.

El presidente de México, Enrique Peña Nieto, desde que tomó posesión el $1^{\circ}$ de diciembre de 2012 , ha sido objeto de un sinnúmero de caricaturas políticas (como sus dos antecesores) así como de una gran cantidad de memes y de videos, en los que la tónica ha sido la burla, la sorna, el chiste, la mordacidad o el sarcasmo.

Al inicio de su gestión, el presidente Peña convocó a los tres líderes de las principales fuerzas políticas (PRI, PAN y PRD) a firmar lo que se conoció como "Pacto por México". En ese marco, se anunciaron una 
serie de reformas estructurales; una de ellas fue la energética y, se ha puesto en marcha desde que el Senado de la República la aprobó el 11 de diciembre de 2013.

Con ello, en materia energética se tocó uno de los aspectos históricosociales, ideológicos e idiosincráticos que han estado relacionados con la «propiedad» simbólica que en México se siente con respecto al petróleo y que se liga tanto a la época cardenista como con una de las paraestatales más poderosas: Petróleos Mexicanos.

En el trabajo se ofrece un análisis de corte socio-semiótico, basado en el objeto discursivo "Reforma Energética", misma que fue retomada por cinco caricaturistas del diario La Jornada, en su versión digital. Se trata de: El Fisgón, Helguera, Hernández, Rocha y, de Magú. Dichos cartones se publicaron entre febrero de 2013 y mayo de 2017. El acento analítico está puesto en el papel que desempeña el humor y sus figuras retóricas, para desenmascarar --frente a los lectores-- el discurso político.

129 - Cómo informan El País y El Mundo sobre la estrategia preventiva PrEP contra las infecciones del VIH - José Luis Terrón Blanco, InCom-UAB, Barcelona, joseluis.terron@uab.cat, Flor Micaela Ramírez Leyva, Universidad de Guadalajara, Guadalajara, México, flor.ramirez@cuc.udg.mx, Simón Vialás Fernández y InCom-UAB, Barcelona, simovf@gmail.com y Pedro Jacobetty, UOC, Barcelona, pedro.jacobetty@gmail.com

Introducción. La profilaxis Pre-exposición (PrEP, siglas en inglés) es una estrategia de prevención contra el VIH donde los individuos VIH negativos toman antirretrovirales antes de de su exposición al virus, reduciendo notablemente el riesgo de infección. La OMS considera que es una estrategia efectiva para los grupos vulnerables. Cada vez más países lo incluyen en sus planes de prevención del VIH. En España cada vez más individuos hacen uso de ella, pero vive en un limbo legal. Metodología. La investigación se inscribe en el análisis de contenido; las piezas se seleccionaron a partir de las siguientes palabras clave: vih; sida; PrEP; retroviral. En síntesis, pretende averiguar de qué se hablaba cuando supuestamente se escribe sobre el PrEP, cuándo se informa, de 
El fin de un modelo de política

quiénes se habla, qué fuentes se utilizan (¿los miembros de la comunidad VIH/sida se utilizan como fuente?), cómo se informa, con qué carácter, qué características tienen esas informaciones (género, sección, edición, autoría, etc.), si se explica qué es el PrEP y si en las piezas analizadas se valora positiva o negativamente esta estrategia preventiva. Muestra. Para el análisis se han utilizado todas las piezas que tratan del VIH/sida en los diarios El Mundo y El País durante un año (de junio de 2016 a julio de 2017); son los dos diarios con más difusión en España (en sus ediciones en papel y digital) y que más han cubierto el tema del VIH/Sida. Resultados. Se han contabilizado 694 piezas susceptibles de análisis (242 de El Mundo y 452 de El País); de ellas sólo 22 tratan sobre el PrEP (el 3,17\%) -6 de El Mundo (el 2,4\% en relación a la muestra de este diario) y 16 de El País (el 3,53\% en relación a la muestra de este periódico) -. En todos los casos se habla del PrEP como una estrategia preventiva y en ninguno de ellos se cuestiona su bondad para disminuir en número de infecciones entre la población más vulnerable (se suele hablar de HSH, prostitutas y transexuales). La mayoría de las piezas se incluyen en el macrogénero interpretativo, lo que da pie a que se explique qué es el PrEP, quiénes son sus potenciales destinatarios y cómo ha de suministrase. Las fuentes más utilizadas son las institucionales, los expertos y las ONG, y la mayoría de las informaciones hacen referencia a España en comparación con los que está pasando en otros países de Occidente (excepto 3 piezas que nos hablan de campañas en el África Subsahariana). Conclusiones. El PrEP no es un tema prioritario en la agenda de los medios ni tan siquiera cuando se trata del VIH/sida, pero cuando se escribe sobre él prevalece la ponderación, la información y la explicación. Se aprecia como algunas ONG del ámbito VIH son capaces de influir, aunque sea levemente, en la agenda de los medios y como son recurrentes las críticas a las autoridades sanitarias españolas por no haber incorporado el PrEP a sus estrategias antisida. En comparación con investigaciones precedentes, los medios analizados hablan menos del VIH/sida.

130 - La creación de un canal transmedia y su implicación en la producción de contenido informativo: el caso de betevé - Aida Martori Muntsant - Universitat Autònoma de Barcelona (UAB) Aida.martori@uab.cat 
Barcelona Televisió nació de la mano de un grupo de televisiones de barrio que tenían la voluntad de emitir mediante un canal compartido. Sin embargo, a lo largo de los años, lo que comenzó como un proyecto de televisión se convirtió en un medio multiplataforma y, más recientemente, en un sistema transmedia. El compromiso del canal de avanzar en esta dirección se refleja en su reciente cambio de nombre a betevé. En comparación con otros canales de televisión locales en Cataluña, betevé ha experimentado el mayor desarrollo, especialmente en términos de innovación, ya que dispone de un presupuesto mucho más elevado. El objetivo de este trabajo es analizar la evolución de betevé, y examinar cómo se ha adaptado a la era digital y se ha convertido en un sistema transmedia, poniendo el foco en las afectaciones a la hora de producir contenido informativo. La investigación se ha llevado a cabo utilizando una metodología cualitativa, que consiste en revisar documentos y realizar entrevistas en profundidad. Los resultados concluyen que el canal ha pasado de ser un conglomerado de medios de comunicación hiperlocales orientados a la comunidad a ser un sistema profesional, metropolitano y transmedia. La transformación de betevé a un canal transmedia se debe a una serie de factores clave, como su amplia gama de plataformas de transmisión, su constante esfuerzo por introducir innovación tecnológica y la voluntad de transmitir contenido adaptado al potencial de cada plataforma. Además de describir los elementos transmedia del canal, este trabajo también presentará los desafíos a los cuales tiene que hacer frente, tales como alejar el diseño de los contenidos del enfoque telecentrista. Esta investigación ha adoptado un punto de vista novedoso ya que establece los desafíos y oportunidades que el transmedia representa para los medios locales, no solo en lo que respecta al contenido y la narración de historias, sino también en relación con la estructura interna.

131 - Análisis de valores personales y sistemas de valores de estudiantes de formación empresarial indios y españoles - S. Md. Karimulla Basha Sanskrithi School of Business, Puttaparthi, India k4karim@gmail.com y Miguel González Santos - Universidad Complutense de Madrid, España miguelgonzalezsantos1@gmail.com 
El fin de un modelo de política

Analizar los distintos valores personales de los estudiantes de formación empresarial es una investigación significativamente importante, porque ellos serán los futuros líderes de empresas y organizaciones. Los valores personales de estos estudiantes, por tanto, influirán en su comportamiento y decisiones y determinarán la dirección de las empresas y de las organizaciones en nuestra sociedad. Es por ello útil y necesario aprender más sobre sus valores. Además, a medida que más escuelas y compañías están reclutando y admitiendo estudiantes de India y de España, es muy clarificador entender si los valores de los estudiantes indios difieren de los españoles.

Este artículo examina los valores personales y los sistemas de valores de los estudiantes de empresa en India, mediante la Encuesta de Valores de Rokeach y la tipología de Musser y Orke, y compara los resultados con el estudio que hemos hecho en España, con una metodología similar. El estudio también examina las diferencias en valores y sistemas de valores de los estudiantes españoles por género, edad y procedencia. Aunque hay pocas diferencias entre los estudiantes españoles por género, nuestros hallazgos muestran menor coincidencia en los rankings de valores de los estudiantes de India y los españoles, así como diferencias en los sistemas de valores. Los datos ofrecen un muestreo para el debate subsiguiente de indicadores para la educación empresarial.

Los resultados comparativos de estudiantes de empresa españoles e indios los hemos verificado en áreas rurales y urbanas, con la ayuda de la correlación del Rank de Spearman.

132 - Representación de la diversidad sociocultural en la publicidad audiovisual: materiales para un tratamiento inclusivo - Nicolás Lorite García - nicolas.lorite@uab.cat - Universitat Autònoma de Barcelona

¿Cuál es el tratamiento que le otorga la publicidad audiovisual a la diversidad sociocultural y en particular a los fenotipos de origen distinto al centroeuropeo? $\mathrm{Y}$ ¿cuál puede ser el más adecuado para dinamizar la interculturalidad inclusiva y evitar el racismo y la 
xenofobia? Esta comunicación va destinada a responder estas y otras preguntas y sugerir algunas propuestas para el debate sobre las buenas prácticas inclusivas, a partir de los resultados obtenidos de los tres proyectos de investigación, llevados a cabo desde el MIGRACOM (Observatorio y Grupo de Investigación de Migración y Comunicación de la Universidad Autónoma de Barcelona), desde el 2012: Estudio multimodal de la representación de la diversidad en la publicidad española y efectos interculturales en las ciudades del Mediterráneo en tiempos de crisis), para el MINECO (CSO2012-35771); Publicitat audiovisual i diversidad sociocultural a Catalunya. Materials per a un tractament inclusiu: estereotips, llenguatge, imatge, gènere i valors, para la Mesa por la Diversidad en el Consejo del Audiovisual de Catalunya (CAC); y la investigación comparativa con Brasil: Publicidad, propaganda, alteridad y ciudadanía: estrategias transmetodológicas de análisis de la diversidad en contextos de cambio económico y social en Brasil y España, subvencionada por CAPES (Brasil) y MECD (HPB1400030). Son estudios realizados desde los modelos de investigación-acción e investigación audiovisual aplicada con los que venimos estudiando los procesos de dinamización sociomediática, desde mediados de los 90, y que consisten en vincular la Academia con la realidad social, en concreto con sus organizaciones y rutinas mediáticas, en este caso la publicidad, anteriormente con la información. Son sinergias que permiten implicar al Colegio de Publicitarios de Catalunya, la Asociación de Empresarios de la Publicidad, Publicitarios Implicados, la Mesa por la Diversidad al Audiovisual del Consejo del Audiovisual de Catalunya, entre otras, en el diseño de un marco de recomendaciones sobre prácticas publicitarias inclusivas.

133 - Movilización de un grupo de mujeres en las redes sociales: una perspectiva del capital social - Carol Correia Santana carolcorreia0@gmail.com y Jacques Ibanez Bueno Jacques.Ibanez-Bueno@univ-smb.fr - LLSETI Research Group - Université Savoie Mont Blanc, Francia

El trabajo pretende estudiar las motivaciones para participar y comunicarse en las redes sociales. El funcionamiento de un grupo de mujeres en Brasil utilizando Facebook esta analizado con preguntas de 
El fin de un modelo de política

investigación integrando el concepto de capital social (Bourdieu: 1980). La temática del grupo trata de las consecuencias de las hormonas producidas por la industria multinacional de medicinas y ofreces una información alternativa al marketing de las empresas. Desde un enfoque interdisciplinario, los objetivos de los investigadores tratan de los modos de comunicación y de sus efectos sobre las mujeres de este grupo. Además del análisis de contenido y de las entrevistas, la metodología se refiere a los visual methods (Pink: 2009) con consecuencias sobre la forma y el contenido de los resultados. Un website hipermedia permite de descubrir una parte de los resultados y la metodología.

\section{4 - Fórmulas para la prevención, formato narrativo vs expositivo.} Análisis comparativo de sus efectos en el conocimiento, actitudy conducta de los jóvenes sobre el VPH - Luz Martínez Martínez luzmar03@ucm.es; Olga Serrano Villalobos olga.serrano@gmail.com; José Ignacio Niño González josenino@ucm.es y Ubaldo Cuesta Cambra - Universidad Complutense de Madrid - ucuestac@ucm.es

En enfermedades como el VPH, conocimiento, actitud y conducta preventiva son factores cruciales para evitar su contagio y desarrollo en un futuro cáncer de cuello de útero y otros (pene, ano, boca o garganta). Con el fin de ofrecer información útil a la ciudadanía y reducir el riesgo de infección entre los jóvenes son necesarias intervenciones en formatos más accesibles y atractivos, que permitan un mayor conocimiento del VPH y provoque un cambio en las actitudes y en el comportamiento en relación a su prevención. Con este objetivo se ha realizado un diseño experimental unifactorial inter-sujetos, utilizando el tipo de formato (narrativo vs expositivo) como variable independiente, que nos permitiera comparar sus efectos en el cambio de conocimiento, en la actitud y conducta de los jóvenes hacia la prevención del VPH. Para el análisis se crearon dos perfiles de Facebook sobre el VPH (narrativo-expositivo) que trataban su relación con el cáncer de cuello de útero, información general, importancia de revisiones y prueba del Papanicolaou, afección a hombres y prevención. Ambos perfiles están formados por el mismo número y tipos de publicaciones, cabecera y fotografía de perfil. Los sujetos 
fueron distribuidos aleatoriamente al visionado de uno u otro formato. $\mathrm{El}$ análisis muestra un incremento significativo en el conocimiento de los jóvenes tras el visionado de ambos perfiles aunque éste es mayor en el caso del expositivo. Por otro lado, los participantes del perfil narrativo mostraron un mayor cambio hacia una actitud e intención de conducta preventiva más responsables. Los datos confirma una mayor eficacia persuasiva del perfil narrativo sobre la actitud y comportamiento de los jóvenes que el perfil narrativo. Sin embargo, al realizar intervenciones en este formato debemos considerar nuevas estrategias que ayuden a integrar información más especializada y a normalizar la educación sexual entre los jóvenes.

\section{5 - Uso de twitter en campañas de la Plataforma de Afectados por la} Hipoteca - Leticia Quintana Pujalte - Universidad de Málaga leticiaquintanap@gmail.com y Antonio Castillo Esparcia Universidad de Málaga - acastilloe@uma.es

La Plataforma de Afectados por la Hipoteca (PAH) es una organización que nació en el año 2009 con la intención de canalizar las protestas y reclamos en contra de los desahucios en España, producto de la burbuja inmobiliaria que explotó junto con la crisis.

Este estudio evalúa de qué modo la organización gestiona su comunicación en twitter, para dar a conocer las siete campañas que tiene vigentes en la actualidad; también considerar las acciones de ciberactivismo que llevan adelante en los perfiles; y la capacidad de generar diálogo desde los contenidos que publican.

Desde la comunicación política, el ciberactivismo y la gestión estratégica de la comunicación, evaluamos los contenidos publicados en una muestra de perfiles de la $\mathrm{PAH}$ en twitter.

136 - Las nuevas narrativas en el ciberperiodismo - José Luis Valero Sancho - Universidad Autónoma de Barcelona y Francesc Morera - Escola Massana (UAB), Universitat Oberta de Catalunya y Escola Municipal d'Art de Terrassa 
El fin de un modelo de política

Los relatos en multimedia han permitido crear nuevos documentos en los cibermedios de comunicación, que permiten expresar contenidos para la ciudadanía, de forma distinta a como se presentaban en los sistemas de comunicación tradicionales en la prensa y primeras etapas del periodismo digital. El cambio continuo se está experimentando en la forma de presentar importantes noticias en algunos medios relevantes, a la hora de exponer relatos de asuntos clave en las principales noticias generadas en un territorio. Hoy día están apareciendo nuevos lenguajes y distribuciones, organizados en forma de lo que se está dando en llamar nuevas narrativas, que suponen algunas transformaciones complementarias en las clásicas estructuras de los géneros periodísticos, pero también cambios radicales de presentación, que hacen reflexionar sobre la aparición de nuevos géneros que la sociedad entiende fácilmente. En este documento se analiza la denominada nueva narrativa, teniendo en cuenta aspectos que el término incluye o margina, en algunas de las diversas modalidades que aparecen en los cibermedios, prestando especial atención a modelos sobre los eventos sociales, en esta época tumultuosa de Catalunya.

* 137 - Las marcas comerciales en los perfiles personales de Instagram como valor añadido y refuerzo del autoconcepto y la autoestima - Amagoia Otaola Agote - Amagoia.ataola@ehu.eus e Irene García Ureta - Universidad del País Vasco - Irene.garcia@ehu.es

En nuestro día a día, tomamos fotografías de nuestras elecciones de consumo constantemente, de viajes, restaurantes, zapatillas...con la idea de subirlas a nuestras redes sociales de forma instantánea o en un futuro próximo. Ahora bien, ¿Por qué invertimos gran parte de nuestro tiempo libre y esfuerzo en esta práctica?

La respuesta a esta pregunta parece estar relacionada con nuestro autoconcepto y nuestra autoestima, y por tanto, con nuestro bienestar psicológico. Ambos aspectos dependen fundamentalmente de las opiniones que emiten otras personas de la forma en la que nos presentamos ante ellos. 
En la sociedad de consumo nos presentamos ante los demás, en gran medida, mediante nuestras elecciones de consumo, apropiándonos de la imagen de las marcas comerciales mostrando a los demás la relación que mantenemos con ellas.

En este contexto, las redes sociales se han convertido en herramientas esenciales a la hora de mostrar esa relación a otras personas: multiplican exponencialmente el número de interlocutores ante los que presentar los símbolos de consumo, y facilitan el conocimiento de las evaluaciones que los demás hacen sobre nosotros al instante mediante el botón "me gusta" y los comentarios.

Hemos monitorizado todas las publicaciones (5859) realizadas con uno de los veinte hastagh más utilizados a nivel mundial, \#photooftheday, en el periodo de un día con el software Zapier: contabilizamos la presencia de las marcas en los hastagh de dichas publicaciones y proponemos una tipología de las mismas.

Además, creamos una muestra probabilística del total de las publicaciones y analizamos la relación entre la presencia de las marcas comerciales, los "me gusta" y los comentarios, y también los seguidores del perfil.

Los resultados indican que las marcas: a) estan presentes en más de la mitad de las publicaciones de los perfiles personales de los usuarios y, b) añaden valor a las publicaciones personales aumentando los "me gusta", los comentarios de las publicaciones en concreto y de los seguidores totales del perfil.

138 - Neurociencia y bienestar. El poder de la actitud - Ubaldo Cuesta Universidad Complutense de Madrid - ucuestac@ucm.es

El objetivo de esta investigación fue analizar, mediante técnicas de neurociencia, el heurísticos "estado emocional", con el fin de detectar patrones psicofisiológicos asociados a estos estados. El objetivo posterior será crear programas de entrenamiento mediante biofeedback para gestionar estas respuestas y mejorar el bienestar. Trabajos recientes indican que los estados emocionales inciden en las 
El fin de un modelo de política

evaluaciones (actitudes) que se realizan de los acontecimientos y en la recuperación de información. Sin embargo, no se ha investigado suficientemente los procesos psicofisiológicos subyacentes, ni su empleo mediante biofeedback en la modificación del heurístico y del bienestar subsiguiente.

Existe sólida evidencia que revela la importancia de este heurístico en los procesos de comunicación, especialmente en aquellos donde los aspectos emocionales juegan un rol importante, como los que aparecen en el ámbito de la comunicación y la salud.

Hipótesis: la inducción de estados emocionales mediante la proyección de vídeos (Positivos vs. Negativos) provocará patrones de respuestas psico-fisiológicas que se podrá evaluar mediante técnicas de neurociencia.

Procedimiento: Se asignan aleatoriamente 8 sujetos, estudiantes universitarios (edad media 21) para el visionado de los vídeos (4 sujetos por tratamiento experimental, hombres y mujeres balanceados). Los vídeos fueron creados por expertos en realización audiovisual. Se evaluaron las siguientes medidas psicofisiológicas durante el visionado: 1. Electroencefalograma (EEG) 2. Respuesta dermoeléctrica (GSR: Galvanic Skin Response) 3. Tasa cardíaca 4. Reconocimiento facial de emociones 5. Dilatación pupilar. 6. Eye tracking.

Resultados: los patrones de respuesta son netamente diferentes en función del heurístico activado. Las variables que mostraron mayor sensibilidad en la discriminación del patrón han sido: (1) el EEG a través de la asimetría frontal hemisférica, el reconocimiento facial de emociones, la GSR y la dilatación pupilar. Se propone que el EEG y la GSR sean las variables a manejar, en futuros trabajos, en programas de entrenamiento mediante biofeedback.

139 - "Periodismo y punto". Un estudio de las formas de expresión de nuevos medios digitales en el escenario cubano actual - Aimiris Sosa Valcarcel - Universidad de Málaga - aimirissosa@gmail.com 
Esta investigación realiza un análisis de tres medios de comunicación que han surgido en Cuba en los últimos años: El Toque, Periodismo de Barrio y El Estornudo; los cuales piden paso a través de la web para contar la realidad cubana desde diversos puntos de vista. Nuevas fórmulas de periodismo experimentan estos medios en la Isla a pesar de las limitaciones que suponen el acceso a Internet, y la inexistencia de un marco legal que reconozca los derechos fundamentales relacionados con la profesión, y garantice plenas libertades para la búsqueda de alternativas de gestión independientes de la estructura oficial. Desde una perspectiva cualitativa, este estudio tiene un alcance descriptivo que favorece la búsqueda de las características y rasgos fundamentales de los medios de comunicación analizados. El método empleado fue el Análisis de contenido, aplicado con categorías específicas de naturaleza mediática. Como técnicas de recolección de datos se utilizaron la Observación no participante, la Revisión bibliográfica-documental y la Ficha de contenido, que incluyó cada uno de los aspectos constitutivos del análisis, manifiestos en los objetivos específicos de la investigación. Entre los resultados obtenidos destaca que estos medios han reconfigurado el escenario mediático cubano actual, con el tratamiento de temas especialmente cercanos a la realidad del país, y abiertamente críticos con algunas formas de organización y gestión estatal en Cuba. Sus contenidos demuestran la práctica de un periodismo de calidad, cercano, comprometido y útil que pretende crear comunidad y abrir cauces de implicación y participación ciudadana desde la perspectiva de lo "glocal", y con el sello distintivo de la investigación rigurosa y el periodismo narrativo.

140 - El uso de Whats App como herramienta de verificación en la era de las fake news: el caso de B de Bulo - Jon A. Sedano - Universidad de Málaga-jon@uma.es

La adicción por producir y consumir mensajes inmediatos, donde España se sitúa como el país del mundo con mayor penetración de Whatsapp para el consumo de noticias (26-28\%) según el Digital News Report 2016 del Reuters Institute, determina los objetivos de este estudio: medir el impacto que Whatsapp ha tenido en las redacciones españolas, analizar cómo se utiliza la aplicación para verificar 
El fin de un modelo de política

contenidos, cómo se gestiona esta actividad y qué beneficios obtienen de esta interactividad.

La saturación de contenidos en Internet y la distracción que generan los móviles han exigido que los periodistas realicen un esfuerzo extra para adaptarse a un escenario de cambios constantes donde desarrollar nuevas estrategias que faciliten que su trabajo llegue a los lectores y que transmita confianza (Williams, 2012). Implicar a la audiencia de forma activa en un periodismo colaborativo (Kröll, 2016) basado en la comunicación inmediata, experimentando e introduciéndola en los procesos de fact-checking y gatekeeping, es un reto pero también una oportunidad para el crecimiento y la fidelización de los públicos.

Iniciativas puestas en marcha por Reddit, Propublica, the Guardian (Lichterman, 2015), BBC o the Washington Post demuestran que los medios se pueden beneficiar de las audiencias activas (Bradshaw, 2015) al incrementar cualitativamente las fuentes disponibles, el tráfico del cibermedio, e incluso la participación, obteniendo más comentarios con links a evidencias (Reid, 2016). En España, medios como Eldiario.es o Diario Sur también han lanzado en 2017 proyectos donde involucran a las audiencias en tareas de verificación aprovechando la omnipresente telefonía móvil, Twitter, y el servicio de mensajería instantánea más utilizado, Whatsapp.

Para cumplir los objetivos establecidos, se ha diseñado un directorio de medios y se ha aplicado una metodología mixta, que combina técnicas cuantitativas y cualitativas (entrevistas con responsables del mantenimiento de dicha cuenta y observación participante), a un estudio de caso: la sección B de Bulo, en Sur.es. Los resultados confirman el éxito de la relación de proximidad que se establece entre la redacción y los lectores vía Whatsapp. A través de esta red, la audiencia condiciona regularmente la agenda del cibermedio, incluso en el ámbito local.

141 - La renovación de la marca turística de la ciudad de Puerto de la Cruz en Tenerife - Jacqueline González Díaz - Universidad de La Laguna - gonz.jacqueline@gmail.com 
Puerto de la Cruz fue la primera ciudad turística de Tenerife con una etapa de esplendor que comenzó en la década de los 50 y que fue diluyéndose con el paso del tiempo. Centrada en una estrategia de atracción del turista por el sol y la playa, ese modelo turístico supuso para la economía de la isla y para el norte de la misma un sostén, que no supo mantenerse debido a diferentes causas: crisis económica mundial, falta de renovación de infraestructuras y establecimientos hoteleros, aumento de destinos competidores externos e incluso dentro de la propia isla y falta de renovación del concepto de marca turística. Esta situación comenzó a cambiar con la creación en 2010 del Consorcio urbanístico para la rehabilitación de Puerto de la Cruz, quien a través de Turismo de Tenerife, diseñó en 2015 un nuevo modelo de marketing basado en la experiencia del turista en la ciudad y en el resto de la isla. En esta comunicación se analizará la nueva imagen de marca "Puerto de la cruz, parte de ti" desde su implantación hasta la actualidad, así como las consecuencias que ha generado la creación de esta.

142 - Tecno-Adicción al sexo en la población juvenil: Propuesta de items para el diseño de una escala de detección y cribado - Olga Serrano Villalobos. Departamento CAVP II (Comunicación Audiovisual Publicitaria II) - olgaserr@ucm.es, Luz Martínez Martínez. Departamento CAVP II - luzmar03@ucm.es y José Ignacio Niño González. Departamento CAVP II Universidad Complutense de Madrid. josenino@ucm.es

Introducción: No existen muchos cuestionarios que expliquen el uso de Internet centrados en la actividad sexual en la red y en los problemas sexuales que derivan de la misma a partir del uso de la tecnología con fines sexuales, y estos cuestionarios son menos frecuentes si nos referimos a la población infantil, adolescente y juvenil (Stefano Eleuteri, Francesca Tripodi, Irene Petruccelli, Roberta Rossi, Chiara Simonelli, 2014).

Objetivo: Presentar unos ítems-parámetros para el diseño de una escala de detección temprana y cribado sobre el uso problemático de Internet para actividades sexuales en los adolescentes y jóvenes, que nos informe si un individuo tiene o no un problema, o riesgo de tenerlo 
El fin de un modelo de política

respecto a la actividad sexual en Internet, que luego, dará píe a poder crear en un futuro una herramienta que pueda evaluar el origen-causal de los comportamientos sexuales a través de Internet y su relación con la falta de control de impulsos y la perturbación en la vida diaria.

Método: El método empleado para diseñar la escala consistió en la creación de un modelo teórico a parir de un meta-análisis bibliográfico, en la propuesta de factores psicosociales que integran el fenómeno, y en el análisis de las escalas existentes previas en este campo, de lo cual se obtuvieron unos ítems-factores independientes. Para hallar el modelo teórico que se expone se intentó identificar las carencias, entender las coincidencias y buscar el trastorno como origen.

Resultados: Como resultado obtenemos a través de unos factores extraídos previamente así como a partir de modelos teóricos anteriores, unos ítems determinados asentados en el DSM-5 que en el futuro nos ayuden a construir una escala de detección temprana y cribado para la población juvenil, y basados en el origen-causal del comportamiento cuando un individuo decide "buscar sexo por Internet".

Conclusiones: Se presentan 11 ítems-factores como sólidas propuestas anteriormente no consideradas para la creación de una futura herramienta clínica válida de medición para la problemática del uso de Internet con fines sexuales basados en el DSM-5, y que se fundamentan en: la depresión, la ansiedad, la agresividad, la fobia social, el déficit de atención e hiperactividad, la compulsividad, la obsesión y la impulsividad. Al mismo tiempo, en el futuro, se pretenderá poder recoger información sobre la naturaleza del problema.

143 - 'Las fronteras cuentan': narración, resignificaciones y desanclajes Gladys Adriana Espinel Rubio- Universidad Francisco de Paula Santander, Cúcuta, Colombia - gladysespinel@ufps.edu.co

'Las Fronteras Cuentan' fue un proyecto de formación en creación de contenidos mediáticos en zonas de frontera se adelantó desde el 2009 en cinco departamentos de Colombia caracterizados por ser zonas binacionales: Guajira, César, Pasto, Putumayo y Norte de Santander. 
Esta ponencia reflexiona sobre las diversas formas de narrar la frontera que surgieron a partir de la implementación del proyecto financiado y orientado por el Ministerio de Cultura de Colombia y apoyado por la Universidad de Pamplona y la Biblioteca Pública Julio Pérez Ferrero, en Cúcuta, Norte de Santander.

A partir de los resultados de la sistematización de la experiencia adelantada por Gualdrón, Nayra; Pérez, Johanna y Espinel Rubio, Gladys Adriana (Gualdrón, Pérez, \& Espinel Rubio, 2015), se logran identificar re significaciones de la noción de 'frontera'; así como aproximaciones a la comunicación para el cambio social entre los colectivos que participaron del proyecto.

En estos territorios, la doble acepción de la palabra 'cuentan' sirvió para promover la participación de diversos actores que le apostaron a la creación y la re creación de relatos sobre las dinámicas fronterizas interculturales y pluriétnicas; y para reivindicar el interés del Estado colombiano de valorizar estas zonas, pretendiendo romper con la idea de lugares remotos, ajenos al centro y únicamente visibles por ser una línea divisoria.

Así las cosas, 'Las Fronteras Cuentan' apalancaron el surgimiento de nuevas formas de narrar las realidades fronterizas, ya no únicamente desde las cifras de comercio internacional o los índices de violencia, sino a partir de las singularidades del hombre y la mujer de la zona con identidades móviles, en donde -como lo sostiene Jesús Martín Barbero, se evidencian redes, flujos, movilidades, instantaneidad y desanclaje. (BARBERO, 2002).

144 - Características de la infografía como lenguaje visual de las nuevas narrativas - Francesc Morera - profesor de la Escola Massana (UAB), Universitat Oberta de Catalunya y Escola Municipal d'Art de Terrassa - francescmorera@gmail.com y José Luis Valero Sancho - profesor titular de la Universidad Autónoma de Barcelona - joseluis.valero@uab.cat

En esta comunicación se analizan las características que hacen de la infografía un producto y un lenguaje apto para enriquecer las nuevas 
El fin de un modelo de política

narrativas. La infografía, síntesis de lenguajes, se adapta a la perfección al medio digital y deviene un gran aliado en las comunicaciones que se producen en este entorno y que se han venido en llamar nuevas narrativas.

Hay dos razones fundamentales por las que la infografía encaja a la perfección en los formatos de estas nuevas narrativas. La primera, si consideramos la infografía como un producto elaborado cerrado, se adapta al medio digital de manera idónea y goza de un estatuto privilegiado en su incorporación como ente vinculado a las nuevas narrativas. La segunda de las razones es más difusa y tiene que ver con la incorporación del lenguaje infográfico — síntesis de lenguajes - en la forma en que se desarrollan las nuevas narrativas. El lenguaje infográfico aparece o se suma a la narración en múltiples formas. Su virtud de ordenar el contenido es determinante.

\section{5 - Gestión de marcas de los grupos audiovisuales Atresmedia y}

Mediaset España: la percepción de los receptores - Gema Alcolea-

Díaz-gema.alcolea@urjc.es y Diego Sánchez-Rubio-

Universidad Rey Juan Carlos - d.sanchezrub@alumnos.urjc.es

Los grupos que conforman el duopolio del sector audiovisual español en abierto, Atresmedia y Mediaset España, gestionan un conjunto de marcas de televisión que confluyen, en ambos casos, tras un proceso de concentración del mercado. Dichas marcas, previamente arraigadas, se han gestionado de forma dispar. Mediaset España ha optado por una estrategia de respaldo, complementando el perfil de las mismas con los atributos de identidad corporativa del grupo. Atresmedia, en cambio, ha seguido una estrategia multimarca, con perfiles de identidad diferenciados.

La razón principal se debe al distinto punto de partida de la imagen que sus canales principales (Telecinco y Cuatro, por un lado, y Antena 3 y LaSexta, por otro) tenían antes de los procesos de fusión. Cuando Gestevisión Telecinco y el Grupo Antena 3, matrices de los nuevos grupos Mediaset España y Atresmedia añaden a su elenco de canales a Cuatro y LaSexta, respectivamente, afrontan dos situaciones claramente diferenciadas. Mediaset incorpora un canal, Cuatro, cuya 
imagen difiere de forma menos sustancial de Telecinco, que LaSexta de Antena 3. Estos dos últimos canales, tienen una imagen muy diferenciada, debido fundamentalmente a la línea ideológica percibida, y algunos elementos de programación, lo que se refleja en sus públicos receptores. A ello se añaden los interesantes datos de audiencia alcanzados hasta entonces por LaSexta, teniendo en cuenta que se trata de un mercado de oferta muy fragmentada y siendo un canal de nueva aparición (a diferencia de los históricos que nacen en los orígenes de la televisión analógica privada en España). Por lo que la estrategia seguida buscará, o bien diluir la identidad de marca de los canales incorporados en la del grupo, o bien dejarla al margen de ella. Este trabajo analiza la imagen de estos canales y de sus grupos audiovisuales a través de la percepción de los receptores.

146 - El periodismo pausado basado en la reflexión y el análisis, puede estar relacionado con la competencia lectora del alumnado de periodismo Udane Goikoetxea Bilbao - Universidad: UPV/EHU udane.goikoetxea@ehu.eus

En la década de los 2000, fruto del análisis de la comunicación tanto desde la teoría como desde la práctica, aparecen propuestas de slow journalism que "ponen en entredicho géneros y formatos que usan la concisión extrema, que conlleva simplificación, descontextualización y fragmentación de realidades más complejas". (Rosique, Barranquero 2015). La cada vez más visible obsesión por lo inmediato relega la duda, la reflexión y el análisis contextualizado y construye periodismo de fácil consumo orientado a gente que no dispone de tiempo para concentrarse y saborear la información hasta "integrarla en un marco que le dé sentido" (Morin 2011).

En este trabajo planteamos si esta cuestión puede estar ligada a la lectura, que según Quintanal (2011) “es básicamente comprender, y comprender resulta un camino para llegar a un fin, el que el propio lector se propone cuando se encamina por el acto lector. Así, el fin puede ser el mismo cuando se trata de descubrir una información desconocida o al recrear la imaginación". La lectura supone siempre atención, concentración, compromiso y reflexión, y nos pone en contacto con otras experiencias, otras culturas... 
El fin de un modelo de política

¿La lectura puede ser una estrategia clave para favorecer el aprendizaje que requiere lo slow? Esto nos lleva a analizar la relación entre la capacidad lectora del alumnado de periodismo con sus resultados académicos. Utilizando diferentes pruebas se demuestra, como principal conclusión, que el alumnado con mejores resultados académicos presenta mejor competencia lectora. Esta competencia está muy relacionada con la idea de Periodismo lento con el que tomar el pulso a una actualidad compleja, que requiere de pausa y reflexión para poder analizarla. Mejorar la comprensión lectora puede alejarnos del ritmo rápido que funciona a golpe de click y acercarnos a la pausa necesaria para atender y conocer mejor esta sociedad y caminar hacia una nueva cultura de la sustentabilidad, basada en otros modos de hacer periodismo.

* 147 - Las relaciones públicas y la percepción de la identidad corporativa por el sector de padres y familiares de estudiantes de comunicación - Dra. Yolanda López Lara - yolandalopezlara_uanl@hotmail.com y Daniela Paloma García Mendoza - Universidad Autónoma de Nuevo León - danielagarcia.m@hotmail.com

El estudio que se presenta se desarrolló conforme al método científico, con un alcance descriptivo y un diseño de investigación noexperimental transaccional descriptiva y cuya premisa indica: La percepción de la identidad corporativa por parte de los padres y familiares de los estudiantes de la Facultad y la carrera de Ciencias de la Comunicación no ha sido analizada con amplitud. El universo de los estudiantes de Comunicación del 6to. Semestre es de 60 alumnos en el turno matutino, mismos que fueron seleccionados en su totalidad para la muestra del estudio, se consideró convenirte tomar la cantidad completa por ser un estudio piloto de alumnos que forman parte de los que han cursado casi la tercera parte de la carrera (posteriormente se considera llevarlo a cabo con los estudiantes del primer semestre, para conocer la opinión de sus padres, porque hay alumnos que estudian la carrera en contra de los deseos de sus progenitores). La selección de la muestra se caracteriza por medir la opinión de los padres y familiares de alumnos inscritos en la Dependencia. Las técnicas de recolección de datos utilizada fue la encuesta, con un cuestionario de 
creación propia que mide los elementos tangibles de la identidad corporativa en diez subcategorías, de las cuales se podrán obtener datos generales que indiquen las tendencias de opiniones, así como la consulta de fuentes bibliográficas impresas y digitales. De los resultados obtenidos se podrán sugerir estrategias para ser adicionadas al programa de Relaciones Públicas e incluir en las actividades de la dependencia a los padres y familiares de los estudiantes, sector que muy pocas veces son convocados para los eventos y convivios institucionales.

148 - Las Relaciones Públicas y el desarrollo del sentido de pertenencia de los padres de familia en una Institución de Educación Superior - Dra. Yolanda López Lara - yolandalopezlara_uanl@hotmail.com y Dr. Sergio Manuel de la Fuente Valdez - Universidad Autónoma de Nuevo León - Dr. Sergio Manuel de la Fuente Valdez.sermanfuen@yahoo.com

El objetivo del presente estudio es indagar que tan amplio es el sentido de pertenencia que los padres de los estudiantes de la carrera de Comunicación tienen respecto a la institución donde sus hijos estudian, es una investigación que se desarrollo con el método cuantitativocualitativo, con un alcance descriptivo, y un diseño no experimental transeccional descriptivo. La premisa indica: el sentido de pertenencia se adquiere por los actos incluyentes y el consenso personal de la práctica de la filosofía de la Institución. La investigación forma parte de la segunda etapa del proyecto piloto que trata sobre el impacto de la identidad corporativa y en esta ocasión, toca indagar sobre el sentido de pertenencia que los padres de los alumnos de comunicación del 6to. Semestre tienen de la Facultad y carrera de Ciencias de la Comunicación, en el aspecto intangible de la identidad corporativa. El universo de los estudiantes de Comunicación del 6to. Semestre es de 60 alumnos en el turno matutino, mismos que fueron seleccionados en su totalidad para la muestra del estudio, se consideró convenirte tomar la cantidad completa por ser un estudio piloto de alumnos que forman parte de los que han cursado casi la tercera parte de la carrera. Los atributos de la selección de la muestra se distinguen por medir la opinión de los padres y familiares de alumnos inscritos en la Dependencia. Las técnicas de recolección de datos utilizada fue la 
El fin de un modelo de política

encuesta, con un cuestionario de creación propia que mide los elementos intangibles de la identidad corporativa en catorce subcategorías, para obtener indicadores de tendencia que brinden datos para contrastarlos con el piloto de la primera etapa, también se consultaron fuentes de primera y segunda mano en las modalidades impresa y en línea. De la recolección de datos se espera obtener información que aporte elementos de relevancia, para continuar con la tercera etapa piloto y medir a los alumnos del 1er. semestre de las tres carreras, Ciencias de la Comunicación, Mercadotecnia y Gestión de la Imagen y la de Periodismo Multimedia, las dos últimas de reciente creación. Uno de los beneficios del estudio sería la propuesta de estrategias de inclusión al público externo de los padres a la cultura organizacional de la Facultad.

149 - Usos didácticos de la crónica deportiva en el aula de Lengua

Española en la enseñanza secundaria - Próspero Manuel, Morán

López - Universidad de Oviedo, moranprospero@gmail.com, moranprospero@uniovi.es

La vitalidad de la crónica y su primacía como género periodístico en el contexto de un periodismo deportivo cada vez más universalizado y el hecho de que el contenido periodístico global por excelencia sea en este momento la información deportiva en general y la futbolística en particular son el punto de partida de un proyecto de herramienta informática con formato de blog que plantea la enseñanza de la lengua española en secundaria, tanto desde la perspectiva de la lecto-escritura como en el plano morfóligico y sintáctico.

La enseñanza de la lengua española en las etapas tanto obligatorias como postobligatorias necesita en la sociedad de la información apoyarse en una comunicación constante con la realidad social y cultural, amén de tecnológica, siendo un terreno común y estandarizado, como la comunicación deportiva, el caldo de cultivo idóneo para ello.

Nuestra propuesta ha sido modelizada con herramientas de la Web 2.0 y está siendo ensayada en el ámbito de la asignatura de Lengua 
Española en cursos de la ESO y Bachillerato de centros del Principado de Asturias.

150 - Los Intelectuales frente a la identidad - Juan Luis García Arvelo-Juanluisarvelo@gmail.com

Los intelectuales, sobre todo en el último tercio del siglo XIX y primero del XX, fueron personajes que se dejaron oír. Por esa época, la política vino a sustituir lenta y progresivamente a la religión como constructo de ejercicio teórico y práctico de la actividad intelectual de esa minoría. Esta elite de escritores y periodistas comprometidos con su entorno y frente a las coyunturas ideológicas y sociales de ese concreto momento, intentaron mantener su espíritu y autonomía crítica cuestionando - para así intentar superar (y mejorar) - el orden de su presente. En el contexto de este estudio - aproximarse a una suerte de vocación de identidad nacional desde su vertiente de plebiscito permanente, consciente y deliberadamente voluntaria - el constructo de nación o nacionalismo, puede estar en deuda con estos prohombres hoy en franca pérdida de protagonismo.

\section{1 - Evaluación para demostrar la efectividad en comunicación} estratégica. Una mirada a las prácticas profesionales - Dr. Antonio Castillo Esparcia - Universidad de Málaga - acastilloe@uma.es y Diego Villabona Beltrán - Universidad de Málaga dvillabona@gmail.com

Las organizaciones invierten grandes cantidades de recursos económicos y humanos para escuchar y entender a sus públicos buscando establecer relaciones dialógicas, de confianza y credibilidad en medio de un competitivo entorno empresarial. Con los presupuestos en aumento, un número creciente de canales de comunicación on line y off line, y la acelerada implementación de estrategias basadas en contenidos diferenciales y creativos; los profesionales de la comunicación están siendo presionados para generar resultados y "hechos concretos" en términos de efectos reales sobre los públicos que puedan ser medibles a partir de variables como conocimiento, recordación y recomendación de los mensajes, 
El fin de un modelo de política

motivación a la acción y cambio de conductas, comportamientos o percepciones en función de los intereses corporativos.

Frente a esta exigencia es la evaluación, vista como parte del proceso de planificación estratégica bajo el modelo RACE (Research, action, communication, evaluation), la que permitirá a los profesionales de la comunicación demostrar el valor y la efectividad de generan sus actividades, programas o campañas en beneficio de las organizaciones y responder a la alta dirección que está exigiendo conocer los resultados, el retorno de la inversión de sus asignaciones presupuestarias y el impacto en la estrategia corporativa.

A partir de una revisión de los resultados publicados en los últimos 10 años del European Communication Monitor y su comparación con los recientes informes del Asia Pacific Communication Monitor y del Latin America Communication Monitor, analizaremos el reconocimiento y el nivel de importancia que le dan los profesionales al uso de la evaluación como herramienta para demostrar la eficacia y los resultados obtenidos, al igual que las actividades que son objeto de mayor medición, los principales aportes que los profesionales consideran que desde la comunicación se puede realizar a las organizaciones y los argumentos que serán más empleados para explicar cuál es el valor de la comunicación y su relevancia ante la dirección y los públicos internos.

152 - La sátira como medio de expresión y de ofensa: ¿Es el humor un delito? - María López de Ramón - Universidad Carlos III de Madrid - mlr.lopezramon@gmail.com

Desde hace siglos, la sátira se ha constituido como un elemento esencial de participación en el debate político y social, ya que, a través del humor y la ironía, y mediante la distorsión o exageración de la realidad, ha buscado provocar y agitar a los ciudadanos, y con ello contribuir a la construcción de una opinión pública libre.

Sin embargo, la libre expresión de la sátira no es limitada, y ésta, no solo debe respetar los derechos constitucionales de quienes son objeto de manifestación satírica (derecho al honor, a la intimidad o a la propia 
imagen), sino otros bienes constitucionalmente protegidos, tales como los sentimientos religiosos o el orden público. La libertad del humorista no es absoluta, lo que significa que, para eximirle de las exigencias constitucionales, no basta con alegar que se trata de un dibujo, una caricatura o una publicación de contenido humorístico, sino que la ironía y la burla a través de las que se realiza la crítica a una persona, grupo social o acontecimiento, deben contribuir a ese pluralismo político de ideas en el que se basa un Estado democrático.

Teniendo en cuenta estas premisas, si de algo no hay duda, es que el humor satírico se mueve entre los límites de lo "éticamente correcto", rozando, según muchas opiniones, la ilegalidad de sus manifestaciones, especialmente en temas "sensibles" o delicados como la religión o el terrorismo. Todo ello cobra más importancia en un mundo globalizado en el que no existe limitación espacial de noticias e imágenes, y donde el ejercicio responsable de la profesión periodística en clave de humor es esencial, pero no determinante para no abordar ciertos asuntos que pueden ofender a grupos sociales o a parte de la opinión pública.

¿Debe protegerse la libertad de expresión de un humorista que hace sátira de las víctimas de un atentado terrorista? ¿Debe ser delito hacer humor sobre lo éticamente "mal visto"? ¿Deben existir límites a la hora de hacer chistes sobre las víctimas del terremoto de Italia o del huracán Harvey de Texas, dos de las portadas más criticadas de la polémica revista Charlie Hebdo?

153 - El poder del humor y el humor bajo el poder: la viñeta periodística Rosalba Mancinas-Chávez y Ramón Reig - ramonreig@us.es Universidad de Sevilla (España)

Tras una base metodológica descrita ya a través de una viñeta, se muestra un breve planteamiento teórico de la cuestión en el que se divide al mensaje periodístico en coyuntural y estructural. Seguidamente, se ofrecen análisis genéricos de diversas viñetas periodísticas que, a nuestro juicio, pueden ilustrar la citada división mensajística, centrándonos sobre todo en las viñetas articuladas con el mensaje estructural a las que hemos dividido en varias categorías como, por ejemplo: el sistema único de mercado, el desprecio por los derechos 
El fin de un modelo de política

humanos, la ablación de la conciencia, la doble moral, el pensamiento sin pensamiento, funcionalidad del mensaje, desarticulación social, nueva economía y soledad, la ilusión de libertad, consecuencias de las críticas a las creencias (Charlie Hebdo), etc. Todo ello para terminar con una breve conclusión.

154 - Estudio de la comunicación para la promoción turística de la cal artesanal de Morón de la Frontera (Sevilla) - Ana Almansa Martínez-anaalmansa@uma.es y María Rodríguez López Universidad de Málaga - mariarodriguezlopez@uma.es

La cal artesanal de Morón de la Frontera ha sido reconocida internacionalmente por la UNESCO, al incluirla en su Registro de buenas prácticas de salvaguardia. Es interesante conocer si la importancia reconocida por la UNESCO se corresponde con la importancia que se le da a su difusión. Por ello, se estudiarán las estrategias de comunicación que se están utilizando para difundir este bien mediante el análisis de contenido y la entrevista en profundidad. Por un lado, se estudiará la comunicación online que se está haciendo, a través del análisis de las webs de las organizaciones dedicadas y/o relacionadas con la cal de Morón de la Frontera, para ver qué presencia tiene este bien en las webs y para valorar si son buenos canales de comunicación del mismo. Las webs que se analizarán serán la web de Diputación de Sevilla, la web del Ayuntamiento de Morón de la Frontera, el portal de turismo de la provincia de Sevilla, la web del Museo de la Cal de Morón y la web de la última empresa que fabrica la cal de manera artesanal (Gordillos Cal de Morón). Por otro lado, se estudiará la comunicación offline que se está realizando a través de la entrevista en profundidad con el director del Museo de la Cal de Morón, que nos dará información sobre las herramientas que utilizan para su difusión y promoción, así como sobre la gestión de la candidatura a la UNESCO y cómo ha influido su reconocimiento en la difusión de este bien y con ello, en el turismo. Con esta información se conocerán cuáles son los puntos fuertes y débiles de la promoción de este bien patrimonial y cómo podría mejorarse dicha comunicación.

* 155 - Uma cidade com identidade dupla. Lisboa como estudo de casoIvone Ferreira (Graduada e Doutora em Ciências da 
Comunicação pela Universidade da Beira Interior, Professora Auxiliar na Universidade Nova de Lisboa, Portugal. Investigadora no CIC-Digital, membro da SOPCOM.)

Este projeto teve por objetivo conhecer a forma como instituições de grande dimensão planeiam a sua comunicação e, de que forma, o seu planeamento, a existir, tem em conta os seus públicos. Em simultâneo procurou aferir-se como se articulam as marcas "Câmara Municipal de Lisboa"(CML) e "Turismo de Lisboa".

A partir da leitura e análise de alguns jornais nacionais portugueses fezse um mapeamento dos públicos prioritários. Elaborou-se, posteriormente, um questionário, destinado aos nossos públicos: indivíduos naturais e residentes na cidade, turistas nacionais e internacionais, estudantes e trabalhadores que, não residindo em Lisboa, fazem na cidade o seu dia-a-dia e minorias étnicas/religiosas.

O questionário, respondido por 115 indivíduos, permitiu conhecer os problemas que os públicos detetam na comunicação daquela entidade, nomeadamente no que diz respeito à possibilidade de esta os escutar, o desconhecimento do logótipo da CML por parte do spúblicos, bem como dos eventos promovidos ou patrocinados pela entidade.

Posteriormente, foram entrevistados o Diretor de Relações Públicas da CML e a responsável pelo estudo da marca CML. Os entrevistados destacam a descoordenação entre os Departamentos da CML e a inexistência de uma estratégia combinada para media impressos e digitais, e para comunicação interna e externa, dado que o planeamento é feito por profissionais distintos.

No total, a estrutura de comunicação da Câmara Municipal de Lisboa conta com 268 colaboradores. Todavia, o destaque dado à aparição pública dos vereadores faz com que os cinco responsáveis pela produção de vídeos e fotografias não sejam suficientes para estar em todos os momentos que seriam importantes para promover a organização a nível externo. Sobre os recursos financeiros existentes, não dispomos de informações, já que os entrevistados não forneceram estimativas que permitissem perceber qual a parte, dos 776 milhões 
El fin de un modelo de política

referentes ao orçamento da CML para 2017, destinada diretamente à comunicação.

A partir dos dados obtidos, foi elaborada uma proposta de um plano de comunicação externa, para um ano, para a CML, que foi remetido à instituição.

O presente estudo é acompanhado por uma reflexão sobre o estado da arte da comunicação municipal em Portugal, complementado com a explicitação de conceitos como públicos, identidade e cultura corporativa.

156 - Procesos de cambio en la comunicación de la imagen del deportista en la lucha libre mexicana - Mtra. Patricia Celis Banegas -

Universidad Nacional del Arte (Argentina) celisbanegas@gmail.com

La lucha libre mexicana es un deporte espectáculo, considerado una de las expresiones culturales populares más relevantes de los últimos 70 años en México. En la lucha libre mexicana conviven estéticas, representaciones y significados populares que se presentan con una alta raíz performativa, donde luchadores y espectadores son parte del mismo fenómeno.

A lo largo de su historia, desde los primeros eventos donde el público asistía a ver a sus ídolos hasta la actualidad, los soportes comunicacionales fueron evolucionando de modo tal que también modificó la práctica del deporte mismo. La lucha libre se expandió en medios impresos, con crónicas y fotografías, luego con el advenimiento de la televisión sufrió una transformación radical en su retórica. A continuación, el cine de luchadores, aumentó la popularidad y espectacularidad del deporte.

En la actualidad la lucha libre mexicana sigue transformándose con las lógicas de la mass media transnacional. Y un último giro se debió al uso masivo de redes sociales. En este contexto los luchadores comienzan a gestionar su propia imagen. Facebook, twitter e Instagram pasan a ser los grandes espacios donde el luchador ya no necesita intermediarios, 
ni empresas, ni medios especializados, sino que se genera un contacto directo con el público. La presente ponencia problematizará el impacto de los diferentes soportes que mediaron la relación del luchador con su público y como dichos actores vivieron y viven estos cambios, junto a sus estrategias de comunicación en cada soporte.

\section{7 - Usos y gratificaciones de las nuevas tecnologías de la Comunicación} - M.C Romulo Flores de la Rosa - Universidad Autónoma de Nuevo León (México) - floresdelarosa94@gmail.com

Propósito y Método del estudio. El propósito del presente trabajo fue identificar el perfil de los usuarios de las noticias en redes sociales o describir el comportamiento de esta audiencia en la búsqueda de noticias. Con ello se respondió a dos preguntas de investigación que dieron origen al estudio. ¿Quién usa las noticias en redes sociales y por qué? Para obtener los datos se utilizó muestra de 350 estudiantes de la Facultad de Ciencias de la Comunicación, a quienes se aplicó una encuesta. Para responder a la primera pregunta, se compararon las características usuarios y no usuarios las noticias en redes sociales y se utilizó las técnicas de análisis de agrupamiento para identificar a la audiencia activa de las noticias. En cuanto a la segunda pregunta, se hizo la distribución de las respuestas de los participantes y se enlistaron las razones por las cuales se usan las noticias en las redes sociales. Se hizo el análisis factorial para reducir dimensiones de las variables. Después de obtener los factores se hizo análisis, regresión múltiple para definir el grado en que los factores relacionados de los atributos de las noticias en redes sociales influyen el uso de las noticias. Contribuciones y conclusiones. En este estudio se identificó a una audiencia activa de noticias en redes sociales. Fueron 16 las razones por las cuales los usuarios que motivaron esta audiencia se encuentran ubicados en tres categorías. 1.- Situaciones de la exposición. 2.- Atributos de las redes sociales y 3.- Accesibilidad. Las gratificaciones son consideradas comoresultados esperados que motivan el uso de las redes sociales. Los hallazgos de esta investigación constituyen la base para un análisis de mercado de las redes sociales y sugiere las mejoras pertinentes partiendo de una clara apreciación de que la audiencia desea encontrar en esta nueva tecnología. 
El fin de un modelo de política

158 - Respuesta estratégica ante emergencia sanitaria 2016: plan de comunicación estratégica o acción de comunicación en situaciones de riesgo de la salud pública - Cynthya Ayala Aybar -

cynthy_aa7@hotmail.com y César Mariano Beltrán Gutiérrez Universidad Nacional de San Cristóbal de Huamanga comunicador_social@yahoo.es

Introducción. Quienes han desarrollado académicamente la competencia básica en Gestión de la comunicación para programas y proyectos conocen de diseño, implementación y evaluación de planes de comunicación; sin embargo, en el ejercicio profesional se ignora la importancia de un plan de comunicación, y la correspondiente fundamentación científica, tecnológica y humanística. Para fundamentar la carencia de un plan de comunicación estratégica se ha estudiado el caso de la emergencia sanitaria por dengue y otras arbovirosis del Ministerio de Salud. Al respecto, ¿Cuáles son los componentes del plan de comunicaciones de la declaratoria de emergencia sanitaria por dengue y otras arbovirosis, correspondiente al año 2016? El objetivo es describir los componentes del plan de comunicaciones para determinar si la respuesta estratégica ante la declaratoria de emergencia sanitaria 2016 del MINSA contó con un adecuado plan de comunicación estratégica.

Metodología. El tipo de investigación es cualitativo; el alcance, descriptivo; el diseño no experimental; los métodos, análisis-síntesis e hipotético-deductivo. Técnicas e instrumentos: la recopilación documental y el análisis comparativo, ficha resumen y tabla comparativa respectivamente.

Resultados. El plan de comunicaciones del MINSA carece de los componentes básicos de un plan de comunicación estratégica, de la fundamentación científica, tecnológica y humanística.

Conclusiones. La Respuesta estratégica del sector Salud ante una emergencia sanitaria se reduce a un plan de comunicaciones de carácter instrumental y difusionista, autoritaria y vertical. Por lo expuesto, no existe un plan de comunicación estratégica participativa, y una política 
El fin de un modelo de política

de comunicación, con fundamentación científica, tecnológica y humanística.

159 - Periodismo visual y empresa: nuevas narrativas comunicativas, nuevos horizontes laborales - Jordi Català Domínguez - periodista, infografista, historiador, diseñador. Profesor asociado de la Universidad Autónoma de Barcelona (UAB) y de la Universidad de Vic (UVIC), profesor titular de EINA, Centro Universitario de Diseño y Arte de Barcelona y profesor de ELISAVA, Escuela Universitaria de Diseño e Ingeniería de Barcelona jordicatalad@gmail.com, y José Luis Valero Sancho, Universidad Autónoma de Barcelona (UAB). joseluis.valero@uab.cat

Cuando en las redacciones se produce el tránsito de la infografía como servicio o complemento hacia el periodismo visual, como género, informar con imágenes pasa a ser un sujeto periodístico nuevo que puede tener gran calado fuera de las redacciones. Con este importante bagaje y paralelamente a la crisis en el periodismo tradicional a los comunicadores que se atrevan con el relato visual implícito en las nuevas narrativas de la comunicación se les van a abrir puertas en un nuevo campo de trabajo en el infinito mundo de la empresa, el marketing y los negocios.

La eclosión de las nuevas tecnologías, el acceso individual y personal a la información a partir de múltiples dispositivos, el desarrollo de internet y de las redes sociales, cuyo principal vehículo de expansión se encuentra en lo visual, y su penetración en las nuevas economías como herramienta de difusión, publicidad, conocimiento y convencimiento, están generando a toda velocidad nuevos caminos profesionales para periodistas, informadores y comunicadores que acepten el reto de adentrarse en las nuevas formas narrativas implícitas en la información visual. La empresa, el marketing, los negocios, están empezando a asumir en España, en los EEUU ya hace tiempo que es así, las ventajas de comunicar visualmente, -hasta incluso se le aplica un índice de ahorro, RUI- con respecto a todas las tipologías de comunicación previas y las nuevas formas de negocios como el Inbound Marketing no entienden otra manera de trabajar. Las empresas, en una primera 
El fin de un modelo de política

fase, están requiriendo a formadores en infografía para su propio personal, pero esto será insuficiente. Los departamentos de marketing y RRHH no tendrán más remedio de aceptar si quieren ser más competitivos, que es más rentable trabajar con un departamento propio de expertos en comunicación visual, interno o externo. Los periodistas convencionales sin formación estética o creativa, disponen ahora de multitud de herramientas 'democráticas' a las que sumar su inteligencia informativa, eso cuando pretendan actuar como lobos solitarios, que también, porque sin duda la opción ideal es la del equipo multidisciplinar que elabore información visual también multidisciplinar: comunicador, programador, infografista, profesional de los negocios y diseñador.

En cualquier caso, el periodista, el informador, tiene ante sí un nuevo e importante horizonte profesional y laboral

160 - Aproximaciones teóricas de la comunicación y salud en Latinoamérica - María Auxiliadora Gabino Campos Universidad Autónoma de San Luis Potosí (México) mgabino7@hotmail.com

La idea de vida saludable ha evolucionado en el tiempo. Al principio, se asociaba lo saludable a algo mágico o natural. La Edad Media contar con ella se atribuía a Dios, mientras su deficiente se relacionaba con el mal y el demonio. En la actualidad, la salud se encuentra en la esfera de los valores en alza del hedonismo que la caracteriza. La salud no es un objeto de estudio exclusivo de las ciencias médicas, también se circunscribe a las ciencias sociales, entre ellas la comunicación. En esta ponencia, presentamos los referentes teóricos que se han utilizado para trabajar la comunicación y salud en Latinoamérica en los últimos años.

Los principales hallazgos aparecen asociadas a la salud y a las nuevas tecnologías, así como a la cultura de la alimentación y la neurociencia. Señalamos que se emplazan escasos trabajos que se sustenten en teorías de la comunicación organizacional.

161 - Relación entre responsabilidad social empresarial y comunicación organizaciones en empresas mexicanas, ¿son socialmente responsables? - 
Irma Esthela Hernández Ramos y María Gabino CamposUniversidad Autónoma de San Luis Potosí (México) irmaesthela7@hotmail.com

\section{La Responsabilidad Social Empresarial (RSE) ha crecido} exponencialmente en México durante los últimos años y poco a poco el fenómeno se está acoplando a gran número de empresas mexicanas. Debido a la falta de consenso que existe para conceptualizarla, parece ser que cada una de las organizaciones la trabaja desde diferentes aristas y con diferentes objetivos finales.

La presente investigación examinará la realidad de los programas de RSE de cinco empresas mexicanas con alcance internacional. Éstas fueron analizadas para determinar el nivel de compromiso que tienen con la sociedad. Nos enfocamos en los aspectos de planeación estratégica y el seguimiento que se realiza a cada una de las actividades que habían propuesto. El objetivo primordial fue evidenciar el vínculo existente entre la RSE y la comunicación organizacional como una respuesta para identificar y potencializar las interacciones de las empresas con sus stakeholders.

La verdadera RSE tiene como principal propósito generar bienestar social, más de las meras acciones filantrópicas, medioambientales o de imagen. Se puede decir que las empresas con mayor presencia internacional poseen un nivel de empoderamiento en RSE más alto ya que han integrado esta actividad a su planeación estratégica, mientras que las que realizan sus propuestas sólo a nivel nacional se han quedo estancadas en el nivel más básico.

162 - La publicidad en el Prime Time de TV andina - Carlos Ortiz ccortiz@utpl.edu.ec, Ana Muñoz-ammunozx@utpl.edu.ec y Abel Suing - Universidad Técnica Particular de Loja (Ecuador) -arsuing@utpl.edu.ec

La investigación indaga sobre la publicidad en el Prime Time de los países andinos: Perú, Colombia, Ecuador y Bolivia con el propósito de establecer las temáticas de los anuncios, identificar el tipo de anunciante y conocer si se cumplen con las regulaciones aplicadas a esta materia. 
El fin de un modelo de política

Las hipótesis de la investigación son: 1) La mayor proporción de anuncios en el Prime Time de la televisión andina corresponde a la promoción de bienes y servicios de primera necesidad; 2) El espacio de mayor publicidad dentro del Prime Time de la televisión andina se ubica entre las 19:00 y 19:59; y, 3) Todos los países del área andina cuentan con marcos normativos que regulan la publicidad de bienes y servicios en televisión. La metodología empleada es cuantitativa y cualitativa que se ejecutan a través del análisis de contenidos de las legislaciones en materia de comunicación, medios de comunicación y defensa del consumidor de los países andinos disponibles en la plataforma de informática jurídica vLex Latinoamérica. Para determinar los porcentajes de publicidad emitidos durante el Prime Time se estudia una estación pública y una privada de cobertura nacional, la tabulación de información se realizó entre el 28 de enero y el 2 de febrero del 2017; para la selección de la muestra se tomó en consideración el rating de sintonía. Se concluye que de los países de la Comunidad Andina únicamente Ecuador regula la transmisión de la publicidad en radio y televisión a través de una ley orgánica. También se deduce que las empresas privadas escasamente llegan a adquirir el 50\% de los espacios publicitarios en el Prime Time.

163 - Big data: una perspectiva general, riesgos y oportunidades - Javier Bello Hardisson - Universidad de La Laguna alu0101160085@ull.edu.es

Registrar datos y usarlos a través de métodos estadísticos para obtener información no es algo nuevo. Sin embargo, con la llegada de Internet, la obtención y registro de datos crece exponencialmente, debido a la combinación entre los sensores insertados en las nuevas tecnologías (móviles, tablets, pulseras y relojes inteligentes, etc.), el software usado para la extracción de datos personales y la interacción humana con esas tecnologías y aplicaciones (Google, redes sociales, páginas web, blogs, etc.). Si antes de Internet obtener datos era algo costoso y limitado, ahora es barato y ocurre cada minuto en cantidades ingentes. Los datos han pasado de ser un recurso escaso, a uno abundante. De ahí que se hable de datos masivos o big data. Como consecuencia de este aumento exponencial, se han creado nuevas herramientas informáticas para poder almacenar, procesar y usar esos datos, de manera que se obtiene 
nueva información a partir de su análisis. Esta información, fruto de la explotación de datos, es muy valiosa. Con las herramientas adecuadas se puede, por ejemplo, predecir comportamientos humanos o conocer los gustos y preferencias de las personas, entre otras muchas aplicaciones. Como toda nueva tecnología, el big data entraña riesgos. Entre los principales encontramos la pérdida de privacidad e intimidad de las personas, su uso para espionaje masivo, crear campañas de desinformación o manipular procesos electorales (un ejemplo es el presunto intento de Rusia de influir en las elecciones estadounidenses, el Brexit o actualmente en Cataluña). A su vez, los datos masivos generan nuevas oportunidades, como contribuir a analizar mejor el cambio climático, predecir y prevenir pandemias, y todo tipo de avances y mejoras tecnológicos. Si bien los beneficios económicos en el sector privado son una realidad, en el sector público todavía está por ver los beneficios sociales gracias a iniciativas como el open government y el open data, con los que se intenta mejorar la transparencia, la rendición de cuentas, la participación ciudadana y la eficiencia en la gestión. En periodismo, ha surgido el llamado "periodismo de datos", que se basa en obtener información usando big data. El Consorcio Internacional de Periodistas de Investigación ha desvelado gracias a estas nuevas herramientas información relevante como son los Papeles de Panamá o, recientemente, los Papeles del Paraíso.

164 - Estrategias comunicativas y (mala) práxis profesional en la difusión de discursos pseudocientíficos en la radio pública. El programa

Complementarias de Radio Nacional de España - Joan Milián Yeste al341301@uji.es y Francisco José López Cantos - flopez@uji.es - Universitat Jaume I

La denominada medicina complementaria o alternativa integra un conjunto de disciplinas terapéuticas que se presentan a sí mismas como respuesta a las carencias de las instituciones y el sistema de salud convencional sin que exista garantía epistémica alguna acerca de su eficacia. A pesar de ello, no solo continúan siendo introducidas bajo distintas denominaciones en algunos centros médicos, sino que además, y a pesar de su probada ineficacia terapéutica, se siguen promoviendo y apoyando de manera incondicional por parte de 
El fin de un modelo de política

algunos medios de comunicación, incluso aquellos que son financiados con fondos públicos.

En esta investigación vamos a analizar las características comunicativas del programa radiofónico Complementarios que la cadena pública Radio 5 emite una vez por semana y que ha venido ocupándose de aspectos tales el método Ikigai, el coaching nutricional y familiar o el eneagrama. Para ello, utilizaremos metodología de análisis de contenido fundamentada en la Frame Theory con el fin de determinar el marco interpretativo y los dispositivos discursivos con que promueven los contenidos pseudocientíficos en este programa radiofónico.

Tal como muestran los resultados de nuestro análisis, la cadena pública de radio pretende promover un espacio divulgativo y de utilidad social utilizando estrategias comunicativas específicas, pero, en lugar de ello, el dispositivo discursivo y los recursos públicos se ponen al servicio de la pseudociencia y lo único que hace la cadena pública es contribuir, de manera totalmente irresponsable, en la difusión de contenidos pseudocientíficos altamente nocivos.

* 165 - La imagen de la deportista a través de los titulares y pies de fotografía de la prensa deportiva española desde 1893 a 1923 - Itzíar de Ozámiz - Universidad de A Coruña itziardeozamiz@hotmail.com

La presente ponencia forma parte de un estudio centrado en la imagen de las deportistas en la prensa deportiva española desde 1893 a 1923. Se analiza dentro de una triple realidad, la de género como categoría relacional, la espacial por ser en la prensa deportiva española y temporal, abarcando el periodo 1893-1923. Este estudio de la imagen de las deportistas en la presa escrita no se basa exclusivamente en el aspecto cuantitativo del contenido del texto o fotografía, sino también en el tratamiento de esa representación y sus causas. Se optó por una muestra no probabilística, escogiendo todos los números del periodo estudiado, por lo que se analizaron un total de 48.869 páginas de un total de 3.027 ejemplares. Se extrajeron 1193 unidades de análisis en las que se han encontrado 564 titulares y 973 pies de fotografía. Las publicaciones de las que procede la muestra fueron: Crónica del Sport, 
Barcelona Sport, Los Deportes, Gran Vida, Mundo Deportivo, Stadium, Heraldo Deportivo, Madrid-Sport, Aire Libre y Sports. El método de análisis utilizado fue el de análisis de contenido para el que se elaboró un sistema de categorías elaborado ad hoc. El tratamiento de los datos se realizó a través del programa FileMaker Pro Advanced 12, y para el análisis de los datos cuantitativos se utilizó el programa estadístico SPPSS. Los resultados muestran que la mayoría de las expresiones que empleaba la prensa hacia las deportistas eran positivas, haciendo mención a sus cualidades deportivas o resaltando sus éxitos, y aunque también se han producido casos de discursos negativos, su número es menor. En cuanto a las conclusiones, podemos decir que, en sus inicios, la prensa deportiva española mostraba un gran respeto hacia las deportistas, especialmente si las comparamos con el tratamiento que se hace actualmente de las mismas.

\section{6 - Consultoria e Academia juntas no desafio da inovação em} comunicação estratégica e desenvolvimento organizacional na transição para a economia do conbecimento - Ricardo Oliveira Neves e Ivone Ferreira - Universidade da Beira Interior (Portugal)

O mercado de empresas consultivas para administração e gestão de organizações, sejam essas orientadas para o lucro, sem fins lucrativos e governamentais, desenvolveu-se e tornou-se mais e mais sofisticado principalmente após as transformações causadas pelo impacto do desenvolvimento das tecnologias de informação e telecomunicações desde os anos 1980. A híper competitividade e a globalização do mercado desde então estimulou a demanda e ajudou a acelerar o movimento de desenvolvimento da chamada indústria do management consulting. Nesse contexto, hoje existe uma verdadeira e pujante indústria cujo produto é fundamentalmente e tão somente o aconselhamento estratégico em variadas especificidades, desde financeira, contábil, planeamento, marketing, comunicação, RH, tecnologia, etc. Apesar de ser fundamentalmente uma atividade intelectual, que envolve pesquisa aplicada, reflexão e copiosa produção de livros e artigos, o management consulting é muito distinto da atividade acadêmica. Os consultores diferentemente dos acadêmicos não passam pelos filtros da revisão por pares, por exemplo, sendo que a validação dos pressupostos, das descobertas e das análises passa 
El fin de un modelo de política

fundamentalmente pela aprovação dos clientes e com base no sucesso da aplicação desses conceitos e aconselhamento aos negócios. A passagem para o século XXI colocou para os negócios um outro patamar de exigência que foi prenunciado e explicitado de forma exemplar por Peter Drucker, considerado uma espécie de pai fundador da moderna administração e gestão dos negócios, que ficou marcada pelo seu artigo seminal intitulado The Coming of the new organization (Peter Drucker, 1988), que aponta que as inovações trazidas principalmente pelo desenvolvimento científico e tecnológico empurrarão o sistema produtivo da era industrial para um patamar exponencialmente mais produtivo. A esse Drucker deu o nome de "economia do conhecimento". Nesse novo contexto produtivo as organizações deverão se tornar ainda mais sofisticadas buscando novos modelos organizacionais para além do paradigma clássico comando e controle, o qual inibe a inovação e a criatividade. No ano de 2016, o Fórum Mundial de Davos escolheu como sua temática central a chamada $4^{\mathrm{a}}$. Revolução Industrial, etapa essa que teria como ícone chamada Fábrica 4.0, na qual torna-se conspícua a presença da inteligência artificial aplicada à produção. As etapas anteriores seriam 1a. - Fábrica 1.0; produção fabril artesanal (1784-1870); 2a . Fábrica 2.0; produção em massa (1870-1969); Fábrica 3.0; produção automatizada (1969 - 2010). De forma análoga à transformação nas fábricas podemos falar em organizações 4.0 como destino evolutivo organizacional em todos os demais setores produtivos, sejam esses escritórios, fazendas, escolas, hospitais, exércitos, etc. O que faz crer que de fato Drucker estava correto em prenunciar o tempo em que agora entramos como sendo a era da economia do conhecimento, ipso facto, das organizações de conhecimento

167 - El Sello Infoparticipa, instrumento para promover transparencia y buen gobierno en las administraciones públicas locales - Amparo Moreno Sardà -amparo.moreno@uab.cat; Marta Corcoy Rius marta.corcoy@uab.cat y Pedro Molina Rodríguez Navas Universidad Autónoma de Barcelona - pedro.molina@uab.cat

Una de las manifestaciones de que el modelo de política hegemónico se está agotando, es la baja calidad de la información publicada por las administraciones locales utilizando instrumentos tan innovadores 
como las páginas web. Y esto, seguramente porque España no aprobó una Ley de Transparencia, acceso a la información pública y buen gobierno, hasta diciembre de 2013, que no estuvo vigente hasta un año después. En 2012, con el objetivo de promover la mejora de las webs municipales, el equipo del LPCCP de la UAB desarrollamos el proyecto que se ha convertido en el Mapa Infoparticipa (www.mapainfoparticipa.com), para publicar los resultados de evaluar estas páginas. Inicialmente evaluamos los 947 ayuntamientos de Cataluña, y en 2013 adaptamos la plataforma para incorporar los de otras Comunidades Autónomas. Ante los resultados obtenidos, para incentivar a los responsables a mejorar sus páginas, decidimos crear el Sello Infoparticipa.

Con los resultados de 2013, organizamos la $1^{\text {a }}$ edición y entregamos el galardón a 48 ayuntamientos (5\% de los 947 de Cataluña). En la $2^{\mathrm{a}}$ edición, con las evaluaciones de 2014, el número de galardones ascendió a 77 (8\% de los ayuntamientos de Cataluña). En la $3^{\text {a }}$ edición, con las evaluaciones de 2015, el número de galardones bajó a 67 (7\% de los ayuntamientos). Esta disminución se puede relacionar con el hecho de que, al haber entrado en vigor la Ley, habíamos incrementado el número de indicadores de 41 a 52 . En la $4^{\text {a }}$ edición, con las evaluaciones de 2016, el número de galardones ascendió a 93 (cerca del $10 \%)$.

El Sello Infoparticipa se ha entregado también a consejos comarcales y diputaciones de Cataluña, y a ayuntamientos de Aragón y Murcia. Los datos permiten concluir que está colaborando a promover la transparencia y el buen gobierno en las administraciones públicas locales.

168 - Análisis de las campañas de comunicación institucionales orientadas a la prevención del consumo de sustancias adictivas y sus consecuencias en materia de seguridad vial, desde una perspectiva de género (2011-2016) Dra. Dña Pilar Paricio Esteban- Universidad Cardenal Herrera Ceu - pparicio@uchceu.es, Dra. Dña. Sandra Femenía Almerich-sfemenia@uchceu.es y Dña. Rosario García Cubells Universidad Cardenal Herrera Ceu-rgarcia@uchceu.es 
El fin de un modelo de política

El Objeto de la Investigación se centra en el análisis desde una perspectiva de género de las campañas preventivas de consumo de sustancias adictivas relacionadas con la seguridad vial. Podría considerarse prioritaria la presencia del hombre en estas campañas por su mayor siniestralidad (INSIA, 2017). Sin embargo, diversas investigaciones, alertan del aumento de consumo de drogas y alcohol en mujeres (UNAD, 2015; OCDE, 2015; PNsD, 2015) y la agenda mediática en 2017 venía marcada por accidentes protagonizados por conductoras que consumieron alcohol y drogas. La construcción de la identidad de género es una parte esencial en la construcción de la propia identidad y, una parte de ésta se ve afectada por los mensajes de los medios y la publicidad. Existen estudios de estereotipos en la publicidad, encontrado antecedentes en campañas preventivas sobre drogas (Gómez, O. y Martín, J., 2012; Cantos, R., 2016) y sobre seguridad vial (Castelló, 2010) pero no hallamos precedentes que combinen ambos aspectos. Nuestra investigación pretende así analizar si existe un tratamiento diferenciador que contribuya a perpetuar los estereotipos de género en las campañas sobre seguridad vial y drogodependencias (2011-2016). Para ello planteamos una metodología cuantitativa realizando un análisis de contenido categorial (Bardin, 1996). El diseño de la herramienta metodológica parte de la definición de 14 variables y sus correspondientes categorías basadas en estudios previos sobre estereotipos en la publicidad (Uribe, R.; Manzur, E.; Hidalgo, P.y Fernández, R., 2008; Fajula, A.; Castelló, E. 2010; Maroto, G., 2015 y Cantos, R., 2016). El análisis evidencia una presencia prioritaria del varón como sujeto protagonista en las campañas enmarcado en el espacio de lo público, especialmente en campañas sobre alcohol y cocaína, con una presencia secundaria de las mujeres. No se percibe una evolución significativa de 2011 a 2016 en la utilización de la perspectiva de género en las campañas.

169 - Calidad y transparencia en la información y comunicación de las webs municipales en Aragón - Nerea Vadillo Bengoa-Universidad San Jorge-nvadillo@usj.es; Vanesa Rodríguez Breijovrbreijo@ull.edu.es; y Lucas Morales Domínguez- Universidad de La Laguna (Tenerife)-lucasmoralesdominguez@gmail.com 
El objetivo de esta comunicación es presentar un informe que refleje con exactitud de qué manera los ayuntamientos aragoneses cumplen con la legislación vigente en España en materia de transparencia e informan a la ciudadanía de todos aquellos indicadores que se consideran fundamentales para mejorar la calidad democrática y la promoción de un modelo de gobierno abierto, que genere una nueva relación entre las Administraciones Públicas aragonesas y los ciudadanos. Así, en este trabajo mostramos los resultados obtenidos de la tercera ola de evaluaciones de los 731 municipios aragoneses, realizada entre octubre de 2016 y junio de 2017.

La metodología empleada para el desarrollo de esta investigación es la del proyecto Mapa Infoparticipa (http://mapainfoparticipa.com/index/home/). De carácter cuantitativo, se centra en el análisis de 52 indicadores repartidos en 2 grupos y 5 sub-grupos. El primer grupo sobre "Transparencia de la Corporación" está compuesto por tres cuestiones: quiénes son los representantes políticos, cómo gestionan los recursos colectivos y cómo se gestionan los recursos económicos: presupuestos, salarios, contrataciones, subvenciones. El segundo grupo, "Información para la Participación", responde a dos interrogantes: Qué información proporcionan sobre el municipio y la gestión de los recursos colectivos y qué herramientas se ofrecen para la participación ciudadana.

170 - Análisis de las campañas publicitarias de prevención del consumo de drogas y alcohol relacionadas con la conducción: Estrategias, tono y mensajes - Dra. Dña. Isabel de Salas Nestares- Catedrática idesalas@uchceu.es, Dra. Dña. María Puchalt López maria.puchalt@uchceu.es y Dra. Dña. María López Trigo Reig Universidad Cardenal Herrera Ceu - maria.lopez3@uchceu.es

Las comunicaciones publicitarias emitidas por la Dirección General de Tráfico (DGT) tiene como objetivo general la prevención de los accidentes de tráfico, muchos de los cuales están relacionados con el consumo de alcohol y otras drogas. Por ello se plantea desarrollar un trabajo de investigación que analice las estrategias de las diferentes campañas de prevención de consumo de alcohol y drogas, ya emitidas 
El fin de un modelo de política

de la DGT, en relación a los mensajes transmitidos a un target, habitualmente joven.

Se parte de los análisis de autores, como Cuesta, Menéndez, y Ugarte (2011) que señalan la importancia de la comunicación en las acciones de prevención con resultados eficaces en la modificación de conductas aditivas. Tras una revisión de la bibliografía, aparecen investigaciones sobre prevención de consumo de drogas en jóvenes y sobre seguridad vial, así como estudios sobre el consumo y los efectos de las drogas relacionados con conductas de riesgo.

Como método de investigación se utilizó la metodología cualitativa basada en un análisis de contenido de tipo categorial (Bardin, 1996) que permitiera analizar el desglose (mediante la formación de categorías, indicadores e índices) de mensajes emitidos en las campañas de prevención de consumo de alcohol y otras drogas al volante de los últimos años, con el objeto de conocer las estrategias de las campañas de comunicación de entidades públicas y privadas en España. Se han establecido cuatro categorías con dieciocho indicadores para poder completar el análisis.

De forma predominante, en la muestra analizada ha quedado demostrado que la estrategia predominante es la de carácter informativo, frente a otras, como, por ejemplo, las de carácter emocional.

171 - El rol de los periodistas en las relaciones diplomáticas: un acercamiento interdisciplinar - María Ruiz Aranguren. Doctora en Comunicación. Profesora en el Departamento de Periodismo I de la Universidad del País Vasco-Euskal Herriko Unibertsitatea - maria.ruiza@ehu.eus, Montserrat Pintado Lobato. Doctora en Comunicación. Profesora en el Departamento de Periodismo II de la Universidad del País Vasco-Euskal Herriko Unibertsitatea - montserrat.pintado@ehu.eus y Juan José Gutiérrez Cuesta. Investigador Contratado en la Universidad del País VascoEuskal Herriko Unibertsitatea.-juanjose.gutierrez@ehu.eus 
La diplomacia pública tiene una importancia creciente en las relaciones internacionales. La expansión de medios de comunicación globales, la necesidad de conciliar públicos domésticos y extranjeros y el aumento de la transparencia global están influyendo en la configuración de la imagen exterior de los países y los modos diplomáticos. Los profesionales de la comunicación ocupan un papel central como mediadores en las relaciones internacionales, actuando en ocasiones como media-brokers. Con este trabajo realizamos una aproximación al tema desde una perspectiva interdisciplinar.

172 - Transparencia y rendición de cuentas en los ayuntamientos de más de 20.000 habitantes de Canarias, País Vasco y Galicia - Lara Carrascosa Puertas, Universidad de La Laguna, lcarrasc@ull.edu.es; Nuria Simelio Solà, Universidad Autónoma de Barcelona, nuria.simelio.sola@uab.cat; Carme Ferré Pavia, carme.ferre@uab.cat y José María Perceval, Universidad Autónoma de Barcelona, josepmaria.perceval@uab.cat

El equipo de investigación del Mapa Infoparticipa (I+D+I 2016-2018 CSO2015-64568-R (MINECO/FEDER) realizó en 2017 análisis de las páginas webs de los ayuntamientos o de sus portales de transparencia de más de 20.000 habitantes de Canarias, País Vasco y Galicia. El objetivo de esta comunicación es comparar los diferentes resultados e identificar buenas y malas prácticas entre los municipios analizados. Con ello pretendemos hallar conclusiones que sirvan para detectar tendencias dentro de la rendición cuentas y el cumplimiento de la Ley de Transparencia. La metodología responde a la aplicación de los 52 indicadores agrupados en dos grupos: Transparencia de la corporación e información para la participación. El primero, a su vez, se divide en tres subgrupos (¿Quiénes son los representantes políticos?, ¿Cómo gestionan los recursos colectivos? y ¿Cómo gestionan los recursos económicos?). El segundo, en dos (¿Qué información proporcionan sobre el municipio y la gestión de los recursos colectivos? y ¿Qué herramientas ofrecen para la participación ciudadana)? La muestra total son 67 municipios (27 canarios, 22 gallegos y 18 vascos). Se puede concluir de manera general que mientras que Euskadi es un referente de buenas prácticas en transparencia, en Galicia y Canarias los 
El fin de un modelo de política

municipios de más de 20.000 habitantes aún tienen que trabajar para alcanzar unos estándares aceptables de rendición de cuentas.

173 - Imágenes de la ideología: teorías y técnicas de la propaganda en las sociedades americanas - Fidel Arturo López Eguizábal - Docente Investigador Universidad Francisco Gavidia - El Salvador flopez@ufg.edu.sv

Los movimientos libertarios en América Latina han llegado a las masas, no solo por la propaganda del meeting o reuniones, las redes sociales también han contribuido a que las masas sean presa de los community manager. En cada campaña política en América Latina el engaño mediático, el cual hace recordar a Noam Chomsky, hace más fácil que la figura del político sea mesiánica o endiosada. El chavismo en Venezuela, como ejemplo, el cual es seguido por el madurismo es un engaño mediático de algunos medios de comunicación venezolanos, los cuales disfrazan a través de mensajes semióticos y bien preparados la burda mentira hacia el mismo pueblo y a los países que aman la democracia. La fiel copia de Joseph Goebbels y otros métodos de burla, según la cosa política son baluartes para que los ciudadanos sean los engañados. Los medios de comunicación, agencias publicitarias, de relacione públicas y el mismo lobby comunicacional de gobiernos que irrespetan las campañas políticas con acciones sucias, siguen construyendo una falsa democracia en América Latina. Se analiza los mensajes de Nicolás Maduro como fiel copia de su predecesor Hugo Chávez y las campañas antiimperialistas que se observan en las cadenas como Telesur y otras que apoyan al gobierno en turno. Analizar las campañas en los medios tradicionales y en redes sociales, es parte del simposio, en especial en el caso venezolano. En El Salvador, la figura mesiánica de Nayib Bukele ha abierto la Caja de Pandora, ha puesto en jaque a los políticos de derecha e izquierda. Su poder mediático es de análisis exhaustivo.

174 - Aproximación al concepto "city branding" y su reflejo a pie de calle

- Tania Arriaga - Universidad del País Vasco tania.arriaga@ehu.eus 
El próximo año, Bilbao acogerá la gala de los premios MTV EMA 2018. Desde finales de los años 90, esta ciudad está demostrando ser un ejemplo de "city branding". Desde las instituciones se esfuerzan por atraer eventos que refuercen la marca local, tales como la final de la competición de salto, Cliff Diving World Series de Red Bull, o el macro-concierto BBK Live y por participar en premios internacionales como el The urbanism Awards 2018 en el cual, Bilbao, ha resultado ganadora. Si bien, en un principio, fueron acontecimientos anecdóticos, al cabo de los años, la vida social de la ciudad termina girando en torno a ellos. Comercios, guías turísticos, medios de comunicación locales, equipos deportivos, instituciones educativas y expresiones artísticas se impregnan del universo simbólico que, en este caso, el signo Bilbao dispara en la mente de los prosumidores locales y visitantes. Los veinte años transcurridos desde el inicio de la puesta en práctica de un intenso "city branding" por parte de las instituciones locales y provinciales, permite comenzar a estudiar este fenómeno a ras de calle, es decir, más allá de las políticas y objetivos institucionales. En el presente artículo recopilamos la bibliografía necesaria para enfrentarnos al análisis del mensaje que los guías turísticos de Bilbao comparten con sus cada vez más numerosos visitantes.

175 - Hiperinfografia: onde está a visualização sintética no jornalismo de nova era? - William Robson Cordeiro -williamdefato@ gmail.com; Raquel Ritter Longhi - Universidade Federal de Santa Catarina (UFSC), Florianópolis, Brasil; y José Luis Valero Sancho - Universitat Autònoma de Barcelona

Há uma mudança nas formas narrativas jornalísticas, sobretudo no contexto do denominado "jornalismo pós-industrial” (ANDERSON; BELL. SHIRKY, 2013), em que o mercado jornalístico atual exige métodos de trabalho diferenciados e processos baseados em mídias digitais que pressupõem alterações nos formatos e no empacotamento da notícia, com sugestões que passam por novas formas de contar histórias.

Assim, onde se encontra a infografia jornalística no contexto do jornalismo pós-industrial, de nova era? ¿E de que maneira se manifesta e vem sendo desenvolvida pelos periódicos? Os estudos que envolvem 
El fin de un modelo de política

a temática de infografia ou visualização da notícia, formalmente, delimitaram em três os estágios para estruturar esta evolução. Primeiro, os infográficos lineares, de sequência estática, comumente praticados no jornalismo impresso, e executados também em plataforma na internet; Segundo, o ambiente da internet propriamente dito, com recursos ainda primários de multimidialidade dos elementos e característica clicável; e o terceiro, a infografia em base de dados, que abarca temáticas que envolvem o jornalismo de dados.

Esta nova fase em andamento, da qual estamos atento, e com amplas características expressivas, necessita ser amplamente dissecada em suas categorias e estruturas. Como, por exermplo, os modelos denomionados de infografias jogáveis (playable infographics) (BOGOST; FERRARI; SCHWEIZER, 2010), 3D, realidade virtual e visualização.

O contexto caminha para um um provável quarto estágio que possa abarcar estes novos exemplos de caráter imersivo ou mesmo desembocar numa estrutura em comum, que congrega a visualização da notícia (apresentação) e a visualidade da notícia (estética) distinções observadas por Valero Sancho (2012).

Para tanto, estamos denominando esta fase em análise de hiperinfografia. A hiperinfografia consiste nos modelos ou conjunto de modelos de infográficos de alta capacidade expressiva, disponíveis no ambiente hipermidiático. O prefixo "Hiper" pode ser compreendido pela complexidade do formato e, do mesmo modo, pelo ambiente da hipermídia. Um fenômeno novo na transmissão de dados, sobretudo em tecnologia multivariada e de síntese que incorpora diferentes linguagens na mensagem.

* 176 - Métodos cualitativos y cuantitativos en la investigación de Ciencias de la Comunicación - Francisco Gerardo Valdez Rincón pacovaldez68@hotmail.com y Verónica Guajardo del Bosque Universidad Autónoma de Nuevo León (México) vguajardob@hotmail.com 
Este trabajo de investigación de las Ciencias de la Comunicación, se aborda desde la perspectiva del enfoque cualitativo y cuantitativo, pretende constituirse en una guía práctica que facilite el estudio e investigación en este campo. El enfoque cualitativo, también llamado etnográfico, utiliza la recolección de datos sin medición numérica, mientras que el enfoque cuantitativo utiliza la recolección de datos para probar hipótesis, patrones de conducta y comprobación de teorías. Esta investigación conserva un sentido didáctico y multidisciplinario, cercano a la realidad social, personal y profesional de los investigadores.

Se presenta un marco referencial sobre algunas investigaciones con diferente temática, pero contextualizadas en el vasto campo de estudio que nos ofrecen las Ciencias de la Comunicación, son publicaciones realizadas del año 2010 al 2015 y el común denominador es que todas ellas se han desarrollado utilizando el método cualitativo y otras con el método cuantitativo.

La investigación, también ofrece al lector, recomendaciones básicas sobre qué tipo de estudio merece ser abordado bajo cualquiera de estas premisas, de igual forma presenta para su reflexión y análisis, 12 categorías que contribuirán a establecer criterios y pautas de investigación.

177 - El periodismo, frente a las redes sociales en el tratamiento de las pseudociencias y la posverdad. Análisis de casos (homeopatía y vacunas) Carlos Elías - Universidad Carlos III de Madrid

La neutralidad no es una virtud del buen periodismo. Y menos del periodismo científico o médico. En ciencia y en el periodismo no caben varias versiones sino la que está refrendada por los datos y el método científico. En esta comunicación se analizan varios casos de pseudociencias (homeopatía, antivacunas, pseudohistoria...) y su cobertura mediática. En varios de ellos -sobre todo publicados en redes sociales o medios online como Youtube- no es fácil atacar este pensamiento. En otros, han sido los medios influyentes -en inglés quality papers; es decir, aquellos que enfocan la información con seriedad y cuyos editoriales tienen gran influencia en las elites- los que más están luchando contra la pseudociencia. A través de una serie de 
El fin de un modelo de política

estudios de caso observamos que el periodismo serio es más beligerante contra la pseudociencia que la propia universidad u otras instituciones científicas. Entre otros, se aborda como estudio de caso la valiente posición del diario El País contra uno de sus redactores que fue neutral respecto a la homeopatía. Asimismo, se analizan varios reportajes que critican la posición de los antivacunas y los reproches que obtuvieron en redes sociales.

* 178 - Las aplicaciones móviles para el cuidado de la salud: Acercamiento a sus usos y funciones - Dra. Edith Molina Carmona edith.molina@correo.buap.mx, Dra. Paola Eunice Rivera Salas paola.rivera@correo.buap.mx y Mtra. María Guadalupe Curro Lau - Benemérita Universidad Autónoma de Puebla (México) guadalupe.curro@correo.buap.mx

De acuerdo con el Institute for Healthcare Informatics (2017) existen más de 130 mil aplicaciones descargables en las tiendas virtuales para aplicaciones móviles. Asimismo, este tipo de software constituye la tercera categoría con mayor crecimiento a nivel mundial después de los videojuegos y las utilidades. Objetivo: Documentar las funciones y los usos ofrecidos por las aplicaciones para el cuidado de la salud. Metodología: Revisión de literatura en las bases de datos de EbscoHost y Google Academic de un total de 41 artículos y un análisis de contenido de las aplicaciones que se ofertan en los sistemas operativos iOS y Android para Latinoamérica. Resultados: Con la revisión de literatura y el análisis de las apps se notó la tendencia hacia una redefinición del campo de la salud en todas sus dimensiones: atención, investigación, comunicación e información en salud, gestión de los servicios, innovación tecnológica, educación, políticas públicas en salud, normatividad sanitaria, economía sanitaria, entre otros tantos. Respecto a las funciones y usos se determinó que la mayoría están dedicadas al seguimiento de rutinas de ejercicios, fitness, caminatas, ejercicios de relajación, ingesta de agua, control de la presión arterial o ritmo cardiaco, supervisión del período menstrual y embarazo, aplicación de medicamentos, entre otras; es decir, están más enfocadas al cuidado y la prevención. En contraste, se observa que son pocas aplicaciones dedicadas al diagnóstico. No obstante, todas son apps populares y bien valoradas. 
179 - Cómo localizar fuentes especializadas para la divulgación científica: las guías de expertos - Aida María de Vicente Domínguez Universidad de Málaga - aidamaria@uma.es

El objetivo principal es dar a conocer estrategias de búsqueda que permitan localizar fuentes especializadas para elaborar piezas informativas. En concreto, se abordan las guías de expertos: recursos digitales que permiten identificar, localizar y contactar con fuentes relevantes e interesantes para contextualizar los hechos, explicar sus causas y consecuencias, verificar lo acontecido, preguntar por la relevancia de una investigación o realizar un análisis del hecho informativo. Unas estrategias de búsqueda cuyo conocimiento se considera significativo para aumentar la presencia de los expertos en las piezas informativas e incrementar la divulgación de lo que se investiga en la sociedad. 
El fin de un modelo de política

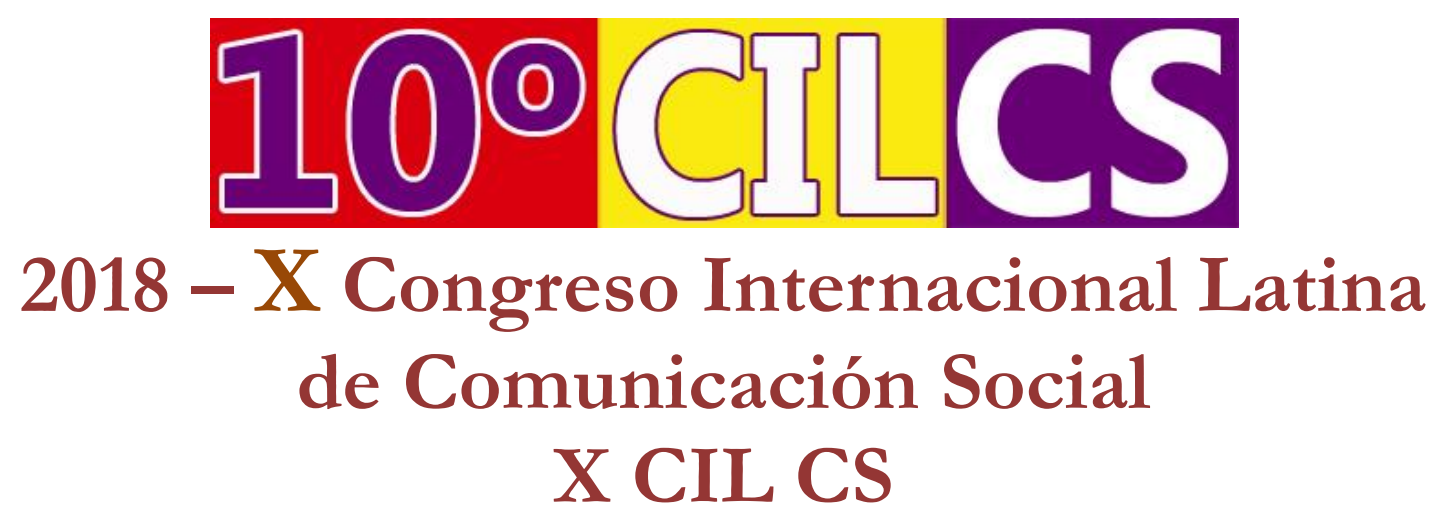

Previsión de fechas:

Mes de diciembre de 2018:

Adelanto de fechas

Lunes, 3 de diciembre

Martes, 4

Miércoles, 5

Viernes, 7 de diciembre

Toda la información estará desde enero de 2018 en esta url: http://www.revistalatinacs.org/17SLCS/2018 convocatoria 10 congreso.html

Nota: este libro recoge todos los resúmenes recibidos hasta el momento de su cierre. Los recibidos después aparecen agregados en la web del congreso

Edita: Sociedad Latina de Comunicación Social - La Laguna, Tenerife.

\section{Editores:}

Francisco Javier Herrero

(Coord.)

Alberto Ardèvol Abreu

Vanessa Rodríguez Breijo

Ciro Hernández

Milena Trenta

Samuel Toledano Buendía 


\section{Libro colectivo del $9^{\circ}$ Congreso Internacional Latina de Comunicación Social}

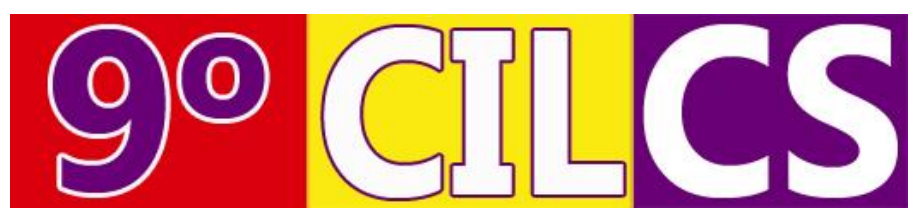

El CD adjunto contiene el libro colectivo originado en el $9^{\circ}$ Congreso Internacional Latina de Comunicación Social, celebrado en la Facultad de Ciencias Políticas, Sociales y de la Comunicación de la Universidad de La Laguna (Tenerife, Canarias; España) en diciembre de 2017.

Todos los trabajos contemplados en ese libro colectivo han sido previamente sometidos a evaluación por los moderadores de las correspondientes mesas de debate donde se presentaron.

Se trata del mismo documento que igualmente aparece en el sitio web: http://www.revistalatinacs.org/17SLCS/cac129.html

El disco está provisto de un pequeño programa de autoarranque: al ser introducido en la disquetera se abre por defecto la página http://www.revistalatinacs.org/17SLCS/libro-colectivo.html

En algunos sistemas puede que no funcione el autoarranque: en esos casos, una vez abierto el disco, hágase doble clic en el fichero http://www.revistalatinacs.org/17SLCS/libro-colectivo.html

Para localizar a un autor, hay que utilizar la herramienta "Buscar en esta página". Ese $\mathrm{CD}$, como obra colectiva, dispone de los siguientes registros, impresos en su carátula:

ISBN: 978-84-16458-83-7 y D.L.: TF- 934-2017

DOI: $10.4185 /$ CAC128 